\title{
A TWO-CONSTITUENT SOLUTE-TRANSPORT MODEL FOR GROUND WATER HAVING VARIABLE DENSITY
}

by Ward E. Sanford and Leonard F. Konikow 


\section{UNITED STATES DEPARTMENT OF THE INTERIOR}

DONALD P. HODEL, Secretary

GEOLOGICAL SURVEY

Dallas L. Peck, Director

For additional information write to:

Project Chief

U.S. Geological Survey MS 431 National Center

Reston, Virginia 22092
Copies of this report can be purchase from:

Open-File Services Section Western Distribution Branch U.S. Geological Survey Box 25425, Federal Center Denver, Colorado 80225 


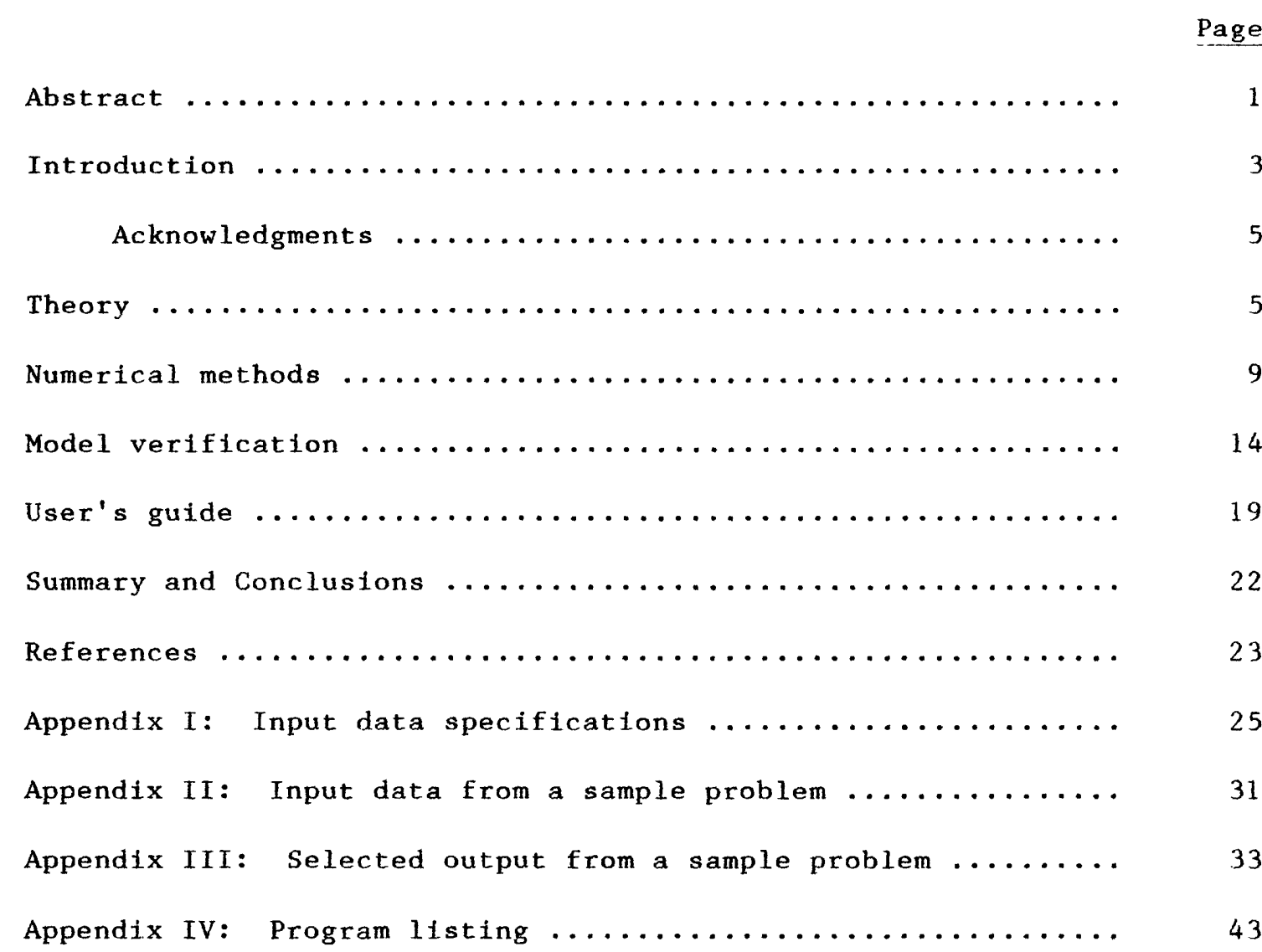

\section{ILLUSTRAT IONS}

Page

Figure 1. - Parameters, boundary conditions, and solution of Henry's problem (Henry, 1964) ..............

2. -- Comparison with finite-element model of Segol and others (1975) for Henry's problem $\left(D_{m}=\right.$ $7.10 \times 10^{-5} \mathrm{ft}^{2} / \mathrm{s}$ in both numerical models) .....

3. - Comparison with the INTERA (1979) finite-difference model for Henry's problem $\left(D_{m}=2.03 \times 10^{-4} \mathrm{ft}^{2} / \mathrm{s}\right.$

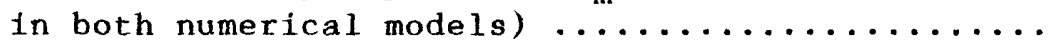

4. -- Initial conditions for a sample problem ........ 


\section{CONVERSION FACTORS}

For use of readers who prefer to use metric units, conversion factors for terms used in this report are listed below:

\begin{tabular}{|c|c|c|}
\hline Multiply & By & To Obtain \\
\hline foot $(f t)$ & 0.3048 & meter $(\mathrm{m})$ \\
\hline square foot $\left(f t^{2}\right)$ & 0.0929 & square meter $\left(\mathrm{m}^{2}\right)$ \\
\hline $\begin{array}{l}\text { square foot per second } \\
\left(f t^{2} / s\right)\end{array}$ & 929.0 & $\begin{array}{l}\text { square centimeter per } \\
\text { second }\left(\mathrm{cm}^{2} / \mathrm{s}\right)\end{array}$ \\
\hline $\begin{array}{l}\text { cubic foot per second } \\
\left(\mathrm{ft}^{3} / \mathrm{s}\right)\end{array}$ & 0.02832 & $\begin{array}{l}\text { cubic meter per second } \\
\left(\mathrm{m}^{3} / \mathrm{s}\right)\end{array}$ \\
\hline pound ( $1 b$ ) & 4.448 & newton (N) \\
\hline $\begin{array}{l}\text { pound per square foot } \\
\left(1 \mathrm{~b} / \mathrm{ft} \mathrm{t}^{2}\right)\end{array}$ & 47.88 & $\begin{array}{l}\text { pascal or newton per meter } \\
\left.\text { squared ( } \mathrm{Pa} \text { or } \mathrm{N} / \mathrm{m}^{2}\right)\end{array}$ \\
\hline $\begin{array}{l}\text { pound per cubic foot } \\
\left(1 \mathrm{~b} / \mathrm{ft} \mathrm{t}^{3}\right)\end{array}$ & 157.1 & $\begin{array}{l}\text { newton per cubic meter } \\
\left(\mathrm{N} / \mathrm{m}^{3}\right)\end{array}$ \\
\hline
\end{tabular}




\section{PRRFACE}

This report presents a digital computer model for calculating changes in the concentration of dissolved chemical species in flowing ground water. The computer program represents a basic and general model that may have to be modified by the user for efficient application to his specific field problem. Although this model will produce reliable calculations for a wide variety of field problems, the user is cautioned that in some cases the accuracy and efflciency of the model can be affected significantly by his discretization and his selection of values for certain other user-specified options.

The user is requested to kindly notify the originating office of any errors found in this report or in the computer program. Updates may occasionally be made to both the report and the computer program. Users who wish to be added to the mailing list to receive updates, if any, may send a request to the originating office at the following address:

\section{U.S. Geological Survey \\ 431 National Center \\ Reston, VA 22092}

Copies of the computer program on tape are available at cost of processing from:

$$
\begin{gathered}
\text { U.S. Geological Survey } \\
\text { WATSTORE Program Office } \\
437 \text { National Center } \\
\text { Reston, VA } 22092 \\
\text { Telephone: } 703 / 860-6871
\end{gathered}
$$




\title{
A TWO-CONSTITUENT SOLUTE-TRANSPORT MODEL FOR GROUND WATER \\ HAVING VARIABLE DENSITY
}

By

Ward E. Sanford and Leonard F. Konikow

\begin{abstract}
A numerical model has been developed to simulate solute transport and dispersion of either one or two constituents in ground water where there is two-dimensional, density-dependent flow. The model is a modified version of the one documented by Konikow and Bredehoeft (1978), which uses finite-difference methods and the method of characteristics to solve the flow and transport equations. The model was tested on an idealized seawater-intrusion problem for which Henry (1964) developed an analytical solution. The results were nearly identical to those of other numerical models tested on the same problem. A description of the formats for the input data, a sample of input and output for a two-constituent example problem, and a listing of the Fortran program are presented.
\end{abstract}




\section{INTRODUCTION}

Various numerical models have recently been ceveloped that simulate ground-water flow and solute transport for a varlety of conditions. Some of the available models are designed to simulate the flow of ground water that has a constant and uniform fluid density, and others can simulate variable density fluids in which the concentration of the solute of interest affects the density of the fluid. The latter models typically have been applied to problems of seawater intrusion in coastal aquifers. However, there are many problems in which contaminants are introduced into an aquifer near the interface or transition zone between freshwater and saltwater. Examples include the injection of waste water into coastal aquifers; Burnham and others (1977), Larson and others (1977), and Rosenshein and Hickey (1977) describe such practices in Hawail and Florida. In such cases the injection will affect the fluid pressure and flow of both the freshwater and saltwater, but the contaminants being injected are generally in such low concentrations that changes in concentration of the contaminants will not affect the fluid density. Simulation of such problems thus requires the ability to simulate the simultaneous flow of variable-density ground water and the transport and dispersion of at least two solutes or soluble constituents. The fluid density needs to be related to the concentration of one of the constituents, which in practice can be either salinity, dissolved-solids concentration, specific conductance, or chloride concentration. The objective of this report is to document a numerical simulation model that is applicable to these types of problems. 
The model described in this report is a modified version of the ground-water flow and solute-transport model of Konikow and Bredehoeft (1978), which was designed to simulate the transport and dispersion of a single solute that does not affect the fluid density. This modified version simulates the flow in a cross-sectional plane rather than in an areal plane. Because the problem of interest involves variable density, the modified model solves for fluid pressure rather than hydraulic head in the flow equation; the solution to the flow equation is still obtained using a finite-difference method. Solute transport is simulated with the method of characteristics as in the original model. Density is considered to be a function of the concentration of one of the constituents. Use of this model depends on assumptions that (1) flow is two-dimensional, with one of the principal axes being parallel to gravity, (2) constituents are conservative (nonreactive), and (3) density and viscosity are a function of concentration and not of other factors such as pressure and temperature. These assumptions are often valid approximations where an aquifer system contains both freshwater and saltwater. This model is applicable in such situations where, in addition to that of the density-controlling species, the movement and concentration of another chemical species, such as a dissolved pollutant, needs to be predicted. The model is also applicable to a two-constituent system with no density-dependence, given that the other assumptions are valid, and to a single-constituent system with variable density. This model documentation needs to be used in conjunction with the original documentation of Konikow and Bredehoeft (1978) because many of the detailed descriptions of theory, numerical methods, and program features and options contained in the original documentation are not repeated in this report. 


\section{Acknowledgments}

This work was prepared in part under a cooperative research grant awarded by the U.S.-Spain Joint Committee for Scientific and Technological Cooperation (Project Number 83-007). The advice and helpful comments of Dave Pollock, Mike Merritt, and Cliff Voss are greatly appreciated.

\section{THEORY}

The model solves an equation which represents the flow of a compressible fluid through a heterogeneous, anisotropic, confined aquifer. By following the developments of Cooper (1966) and of Bredehoeft and Pinder (1973), the general flow equation can be expressed in cartesian tensor notation as:

$$
\frac{\partial}{\partial x_{i}}\left[\frac{\rho g k_{i j}}{\mu}\left(\frac{\partial p}{\partial x_{i}}+\rho g{\frac{\partial z}{\partial x_{j}}}_{j}\right)\right]=s_{s} \frac{\partial p}{\partial t}+w^{*} *_{g} \quad i, j=1,2
$$

where $k_{i j}$ is the intrinsic permeability (a second-order tensor), $L^{2}$;

$\rho$ is the fluid density, $\mathrm{ML}^{-3}$;

$\mu \quad$ is the dynamic viscosity, $\mathrm{ML}^{-1} \mathrm{~T}^{-1}$;

$P \quad$ is the fluid pressure, $\mathrm{ML}^{-1} \mathrm{~T}^{-2}$;

$g$ is the gravitational acceleration constant, $\mathrm{LT}^{-2}$;

$z^{*}$ is the elevation of the reference point above a standard datum, L;

$S_{S}$ is the specific storage of the aquifer, $L^{-1}$; 
$W^{*}=W^{*}(x, y, z, t)$ is a source/sink volume flux per unit volume (positive sign for outflow and negative or inflow), $\mathrm{T}^{-1}$;

$\rho *$ is the density of the source/sink fluid, $\mathrm{ML}^{-3}$;

$x_{i}$ are the cartesian coordinates, $L$; and

$t$ is the time, $T$.

The source/sink term is handled with the method used by Konikow and Bredehoeft (1978) but is written in terms of pressure, as follows:

$$
W^{*}(x, y, z, t)=\frac{Q^{*}(x, y, z, t)}{\Delta x \Delta y \Delta z}-\frac{k z}{\mu m \Delta z}\left(P_{s}-P+\rho g\left(z s^{-z^{*}}\right)\right)
$$

where $Q^{*}(x, y, z, t)$ is the rate of withdrawal (positive sign) or recharge

$$
\text { (negative sign), } T^{-1} \text {; }
$$

$k_{z}$ is the vertical permeability of the confining layer, $\mathrm{L}^{2}$;

$m$ is the thickness of the confining layer, L;

$\Delta y$ is the width of the aquifer cross-section, L;

$\Delta x$ and $\Delta z$ are the grid dimensions in the $x$ and $z$ directions, respectively, L;

$P_{s}$ is the fluid pressure in the source bed, $\mathrm{ML}^{-1} \mathrm{~T}^{-2}$; and

$z_{s}$ is the elevation of the source bed above a standard datum, $L$.

The second term on the right side of equation two can be used to represent steady leakage through a confining bed, which would only be applicable along a boundary node, or to represent a constant-pressure boundary condition, as explained in more detail below.

The equations that represent solute transport and dispersion are also solved in this model. Based on the work of Pinder and Cooper (1970), Bear (1972), Bredehoeft and Pinder (1973), and Konikow and Grove (1977), the equation for transport and dispersion of solutes in flowing 
ground water in cartesian tensor notation can be written:

$$
\frac{\partial C_{n}}{\partial t}=\frac{\partial}{\partial x_{i}}\left(D_{i j} \frac{\partial C_{n}}{\partial x_{i}}\right)-\frac{\partial}{\partial x_{i}}\left(C_{n} V_{i}\right)-\frac{C_{n}^{\prime} W^{*}}{\varepsilon}
$$

where $D_{i j}$ is the coeffictent of hydrodynamic dispersion (a second-order

$$
\text { tensor), } \mathrm{L}^{2} \mathrm{~T}^{-1} \text {; }
$$

$v_{i}$ is the seepage velocity in the direction of $x_{i}, \operatorname{LT}^{-1}$;

$\mathrm{C}_{n}$ is the concentration of the $\mathrm{n}^{\text {th }}$ constituent, $\mathrm{ML}^{-3}$;

$\mathrm{C}_{\mathrm{n}}^{\prime}$ is the concentration of the $\mathrm{n}^{\text {th }}$ constituent in the source or sink fluid, $\mathrm{ML}^{-3}$; and

$\varepsilon \quad$ is the effective porosity (dimensionless).

Two constituents are represented in this model, so $n=1,2$ in equation 3, giving two similar equations, one for each constituent. The density and viscosity are taken to be a linear function of the concentration of the first constituent, $\mathrm{C}_{1}$, as follows:

$$
\begin{aligned}
& p_{(i, j)}=A_{d} C_{1(i, j)}+B_{d} \\
& \mu(i, j)=A_{v} C_{1(i, j)}+B_{v}
\end{aligned}
$$

where $A_{d}$ and $B_{d}$ are the slope and intercept, respectively, for the relationship between density and solute concentration, and $A_{v}$ and $B_{v}$ are the slope and intercept, respectively for the relationship between viscosity and solute concentration. The user has the option of specifying values for these coefficients, or else using default values built into the model for salinity or dissolved-solids concentration. The default values, based on data from Weast (1981, p. D-229) for seawater at different salinities (in parts per million, or $\mathrm{ppm}$ ), are $A_{d}=4.743 \times 10^{-5}$, 
$B_{d}=62.43, A_{v}=3.45 \times 10^{-11}$ and $B_{v}=2.089 \times 10^{-5}$ for $C_{1}<20,000 \mathrm{ppm}$, and $A_{v}=4.733 \times 10^{-11}$ and $B_{v}=2.063 \times 10^{-5}$ for $C_{1}>20,000 \mathrm{ppm}$.

The coefficient of hydrodynamic dispersion represents the sum of the mechanical dispersion, which depends upon both the flow of the fluid and the nature of the pore system, and the molecular and ionic diffusion. These terms can be represented as:

$$
D_{i j}=\alpha_{i j m m} \frac{v_{m} v_{n}}{|V|}+D_{m}
$$

where $D_{m} \quad$ is the coefficient of molecular and ionic diffusion,

$$
\begin{aligned}
& \mathrm{L}^{2} \mathrm{~T}^{-1} \text {; } \\
& \alpha_{i j \mathrm{mn}} \text { is the dispersivity of the aquifer, } \mathrm{L} \text {; } \\
& \mathrm{V}_{\mathrm{m}} \text { and } \mathrm{V}_{\mathrm{n}} \text { are components of velocity in the } \mathrm{m} \text { and } \mathrm{n} \text { directions, } \\
& \text { respectively, } \mathrm{LT}^{-1} \text {; and } \\
& \text { is the magnitude of the velocity, } \mathrm{LT}^{-1} \text {. } \\
& \text { Scheidegger (1961) further shows that for an isotropic aquifer the }
\end{aligned}
$$
dispersivity tensor can be defined in terms of two constants. These are the longitudinal and transverse dispersivities of the aquifer $\left(\alpha_{L}\right.$ and ${ }^{\alpha}$, respectively). These are related to the longitudinal and transverse dispersion coefficients by:

$$
\begin{aligned}
& \mathrm{D}_{\mathrm{L}}=\alpha_{\mathrm{L}}|\mathrm{V}| \\
& \mathrm{D}_{\mathrm{T}}=\alpha_{\mathrm{T}}|\mathrm{V}|
\end{aligned}
$$

Based on the work of Scheidegger (1961) and Bear (1972), we may state explicitly the components of the dispersion coefficlents for two-dimensional flow in an isotropic aquifer as: 


$$
\begin{aligned}
& D_{x x}=D_{L} \frac{\left(V_{x}\right)^{2}}{|V|^{2}}+D_{T} \frac{\left(V_{z}\right)^{2}}{|V|^{2}}+D_{m} \\
& D_{z z}=D_{T} \frac{\left(V_{x}\right)^{2}}{|V|^{2}}+D_{L} \frac{\left(V_{z}\right)^{2}}{|V|^{2}}+D_{m} \\
& D_{x z}=D_{z x}=\left(D_{L}-D_{T}\right) \frac{V_{x} V_{z}}{|V|^{2}}
\end{aligned}
$$

The seepage velocity is calculated from the solution to the flow equation using a form of Darcy's law, as described in Konikow and Grove (1977). The equation can be written in cartesian tensor notation as:

$$
v_{i}=\frac{-k_{i j}}{\varepsilon \mu}\left(\frac{\partial P}{\partial x_{i}}+\rho g \frac{\partial z^{*}}{\partial x_{j}}\right)
$$

NUMERICAL METHODS

The numerical methods used to solve the flow and transport equations in this model are similar to those used In the original model by Konikow and Bredehoeft (1978). An iterative finite-difference scheme that uses a strongly implicit procedure (see Trescott and others, 1976) is used to solve for the flow field (equation 1). The method of characteristics is used to solve for the convective (or advective) part of the transport (equation 3), while an explicit finite-difference scheme is used to solve for dispersion. Some of the additions described below were made to improve the performance and applicability of the orlginal 1978 model. Further additions and modfications were made to provide the capability to simulate two constituents and varlable density. 
The method of characteristics uses particle-tracking to simulate the advection of the solute of interest. In the 1978 version, the user could specify 4, 5, 8, or 9 particles to be generated per node. The first addition made to the original model was to allow 16 particles per node to be specified in order to improve numerical accuracy. As a second addition, molecular diffusion was added to the term describing hydrodynamic dispersion in the solute-transport equation (molecular diffusion had been assumed to be negligible in the original model). This change was necessary to allow a comparison of the model results for a variable-density problem with the analytical solution developed by Henry (1964). Corresponding modifications were then included in the finite-difference scheme that represents dispersion by adding a diffusion constant to the dispersion terms, as shown by equations 9-11. A third minor modification was made that allows the user to specify the maximum number of cells that can be void of tracer particles (NZCRIT). If NZCRIT is exceeded, the particle locations are reinitialized. Fourth, the maximum dimensions of all two-dimensional arrays were increased to (24,20) from the original $(20,20)$. The fifth addition was the introduction of a particle-weighting (or fractional particle) scheme that allows weak sources and sinks to be more accurately represented. In this scheme, particles generated initially at all nodes receive a weight of one. Particles that are later regenerated or removed at sources and sinks are given a weight from zero to one, which represents the fraction of fluid passing through the block that is due to the presence of the source or sink. In effect, particles are weighted in proportion to fluid volumes. This particle-weighting scheme significantly improves the chemical mass 
balance in the model, especlally if the fluid in the source or sink only accounts for a small fraction of the fluid passing through the block. Additional modifications have been made to the model to allow for cross-sectional, density-dependent flow and the transport and dispersion of two constituents. The general flow equation described in equations 1 and 2 can be written together in the following finite-difference form:

$$
\begin{aligned}
& {\left[\frac{\rho g k_{x x}}{\mu}\right]_{\left(i-\frac{1}{2}, j\right)}\left[\frac{P_{i-1, j, k}-P_{i, j, k}}{(\Delta x)^{2}}\right]+\left[\frac{\rho g k x x}{\mu}\right]_{\left(i+\frac{1}{2}, j\right)}\left[\frac{P_{i+1, j, k}-P_{i, j, k}}{(\Delta x)^{2}}\right]} \\
& +\left[\frac{\rho g k z z}{\mu}\right]_{\left(i, j-\frac{1}{2}\right)}\left[\frac{P_{i, j-1, k}-P_{i, j, k}}{(\Delta z)^{2}}+\frac{(\rho g)_{i, j-\frac{1}{2}}}{\Delta z}\right]
\end{aligned}
$$

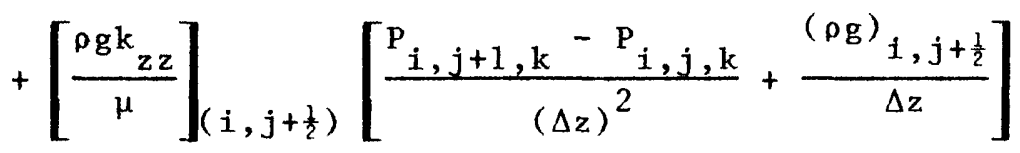

$$
\begin{aligned}
& =s_{s}\left[\frac{P_{i, j, k}-P_{i, j, k-1}}{\Delta t}\right]+\left[\frac{\rho g_{w}}{\Delta x \Delta y \Delta z}\right]_{(i, j)} \\
& +\left[\frac{\rho g k_{z}}{\Delta z \mu m}\right]_{(i, j)}\left[p_{s(i, j)}-P_{i, j}+[\rho g]_{i, j}\left[z s^{\left.-z^{*}\right]}\right]\right.
\end{aligned}
$$

where $i, j, k$ are the indices in the $x, z$, and time dimensions, respectively; and

$q_{w}$ is the volumetric rate of withdrawal or recharge at the $(i, j)$ node, $\mathrm{L}^{3} \mathrm{~T}^{-1}$

The modifications for the solution of the flow equation thus include (1) solving for fluid pressure rather than hydraulic head, (2) using density, viscosity, and intrinsic permeability rather than hydraulic conductivity, (3) using specific storage rather than storage coefficient to represent 
storativity, and (4) using a constant aquifer width rather than a variable thickness to represent the third dimension.

Constant-pressure boundaries are treated in the same basic way as in Konikow and Bredehoeft (1978). This approach is based on the principle that as the leakance coefficient of the confining bed (that is, its conductance, defined as the hydraulic conductivity of the confining layer divided by the thickness of the confining layer) increases to a sufficiently high value, the difference in head across the confining bed will decrease to a negligible value so that the heads will be essentially identical on both sides of the confining bed. Thus, given a sufficiently high value for the leakance coefficient and a constant value of head (or pressure in this case) in the source bed, then the head (or pressure) in the aquifer at that location will always remain essentially the same as the specified constant value of head (or pressure) because the confining bed can readily transmit an adequate flux to compensate for any stresses imposed elsewhere in the aquifer. The constant-pressure term in the equation will then take on virtually the same form as the constant-head term in the original model. However, if the leakance coefficient is specified as too high a value relative to the conductance within the aquifer, then although the computed value of head (or pressure) in the aquifer is the desired constant value, the head difference will be so small that numerical truncation errors may induce significant errors in the subsequent calculation of the flux at that constant-head boundary node. An error in the computed flux can have a serious effect on the accuracy of the computed solute concentrations because that flux represents part of the source term in the solute-transport equation (that is, the third term on the right side of equation 3 ). Therefore, the 
original model, which required the user to specify the head and the leakance coefficient at a constant-head node, was modified to allow the user to specify only the desired constant-pressure value. The model then automatically calculates a value of the leakance coefficient that is ten orders of magnitude greater than the conductance of the aquifer at that location; this ratio of $10^{10}$ was found optimal both in providing the desired constant pressure and in eliminating serious numerical truncation error in the calculation of the flux due to leakage.

Modifications were also made to account for an additional constituent. Only one set of particles is tracked, as in the original method of characteristics, but each particle is assigned two independent concentration values. The finite-difference equations that represent the dispersion, which are presented in detail by Konikow and Bredehoeft (1978), are now solved twice, once for each constituent.

The flow equation and the solute-transport equation are coupled by allowing the density and viscosity to be a function of the concentration of the first constituent. In this model, particles are moved in time steps whose lengths are determined by certain stability criteria (see Konikow and Bredehoeft, 1978). After every movement of all particles is completed, the new model checks to see if a concentration change has occurred that would significantly affect the density. If a significant change in concentration has occurred, the pressures are recalculated using the new densities. In this way, the calculated flow field is periodically updated to account for changes in density due to changes in concentration. The criteria defining the amount of change that is considered significant is specified by the user in the input data. 


\section{MODEL VERIFICATION}

One way to test the accuracy of a numerical model is to compare its results with that of a known analytical solution. Konikow and Bredehoeft (1978) compared the numerical results with analytical solutions for dispersion in one-dimensional steady flow and in plane radial steady flow, in both cases assuming constant fluid density. Their results demonstrated that the model is numerically accurate for these conditions.

For the case of variable-density fluids this model was tested on a problem for which an analytical solution was developed by Henry (1964). The problem was set up with boundary conditions and parameters (as shown in fig. 1) that allowed for the convergence of the infinite series involved in Henry'solution. A constant flux, Q, on the left side of the system balances a tongue of saltwater entering from the right, which gives a steady-state transition zone between freshwater and saltwater. The 0.5 isochlor in figure 1 shows the center of the transition zone.

Pinder and Cooper (1970) were one of the first to use this problem for testing a numerical model. Their parameters of $Q=0.66 \mathrm{~cm}^{2} / \mathrm{s}, \mathrm{K}=$ $1.0 \mathrm{~cm} / \mathrm{s}$, and $D_{m}=0.066 \mathrm{~cm}^{2} / \mathrm{s}\left(7.10 \times 10^{-5} \mathrm{ft}^{2} / \mathrm{s}\right)$ were used in the comparisons between other numerical models and the model being documented in this report. The analyses are further based on $\mathrm{C}_{\mathrm{s}}=35,000 \mathrm{mg} / \mathrm{L}$ and $\rho_{\mathrm{s}}=1.025 \mathrm{~g} / \mathrm{cm}^{3}$, where $\mathrm{C}_{\mathrm{s}}$ is the concentration of salt in seawater and $\rho_{s}$ is the density of seawater.

A direct comparison was not made with Henry's analytical solution, which requires letting the system run to steady state after beginning with some fixed concentration. Also, the right hand boundary condition in 


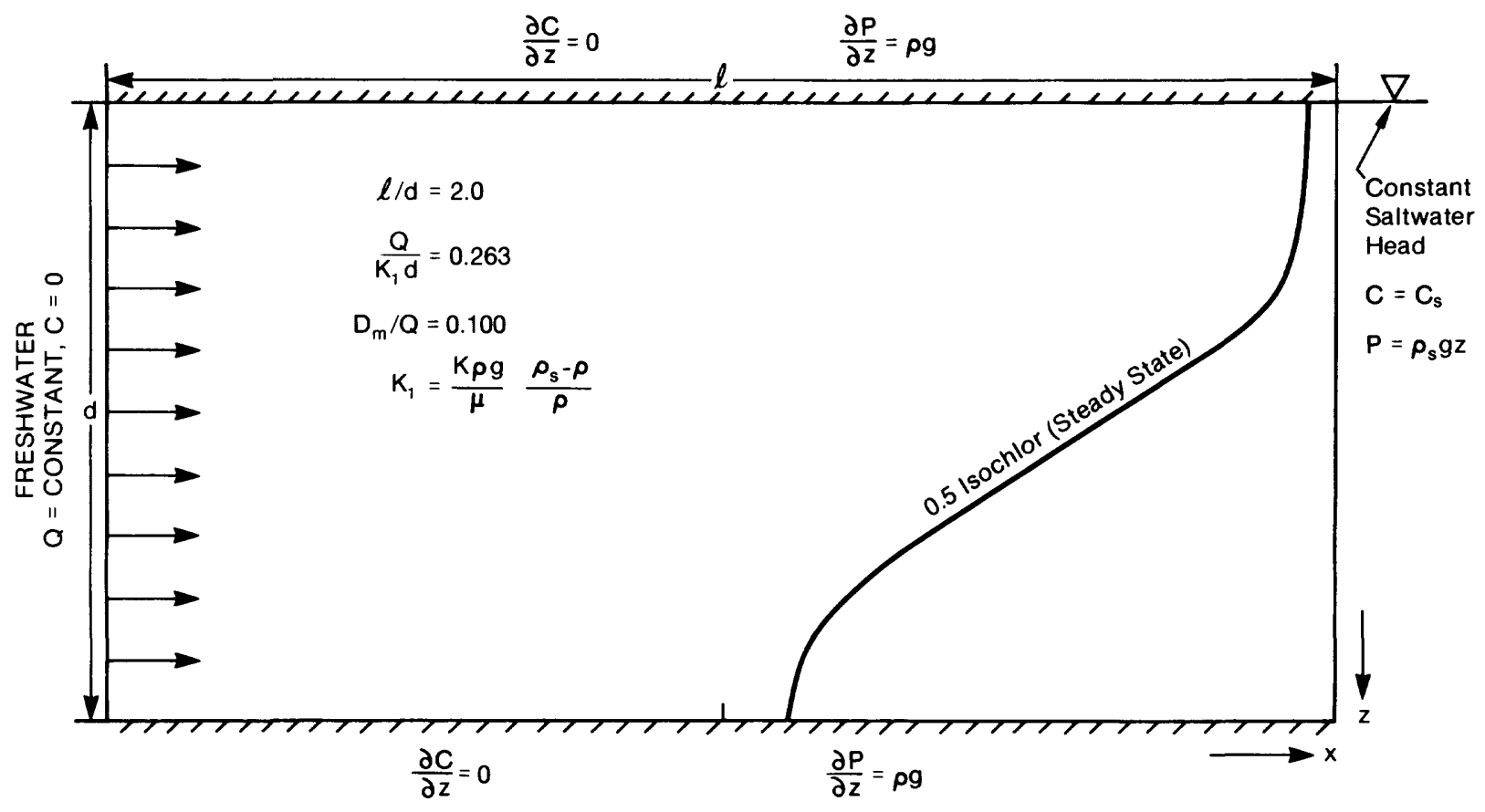

Figure 1. Parameters, Boundary Conditions, and Solution of Henry's Problem (Henry, 1964) 
Henry's problem is unrealistic for a system that a numerical model would be simulating. Fluid is exiting the system at the top right, but Henry's solution allows diffusion to occur back across the boundary. For these reasons, the comparison was made with the results from other numerical models that solved Henry's problem for 100 minutes (simulation time) and allowed no backward diffusion across the boundary. The first comparison was with the results from a finite-element model of Segol and others (1975). As seen in figure 2, the 0.5 isochlors from the two models are at virtually the same location. Note that the 0.5 isochlor is equivalent to $\mathrm{C}=17,500 \mathrm{mg} / \mathrm{L}$.

The finite-difference model by INTERA (1979) was also used to solve Henry's problem. The comparison in figure 3 shows that the isochlors from the two models are very close. The difference between the positions of the isochlors from the solution of Segol and others (1975) (fig. 2) and the positions of those from the INTERA model (fig. 3) is due to a difference in the value of the diffusion constant used. Segol and others (1975) apparently did not divide the diffusion constant used in Pinder and Cooper (1970) by the porosity, as was done for the simulation using the INTERA model. The smaller value of the diffusion coefficient used by Segol and others (1975) caused the front to move further to the left. Both results show that the model being documented in this report gives results comparable to those of other numerical models used on a problem for which an analytical solution is known. The results obtained with this model for the problems shown in figures 2 and 3 are also essentially identical to those obtained by Voss (1984) using a finite-element model for the same two problems. 


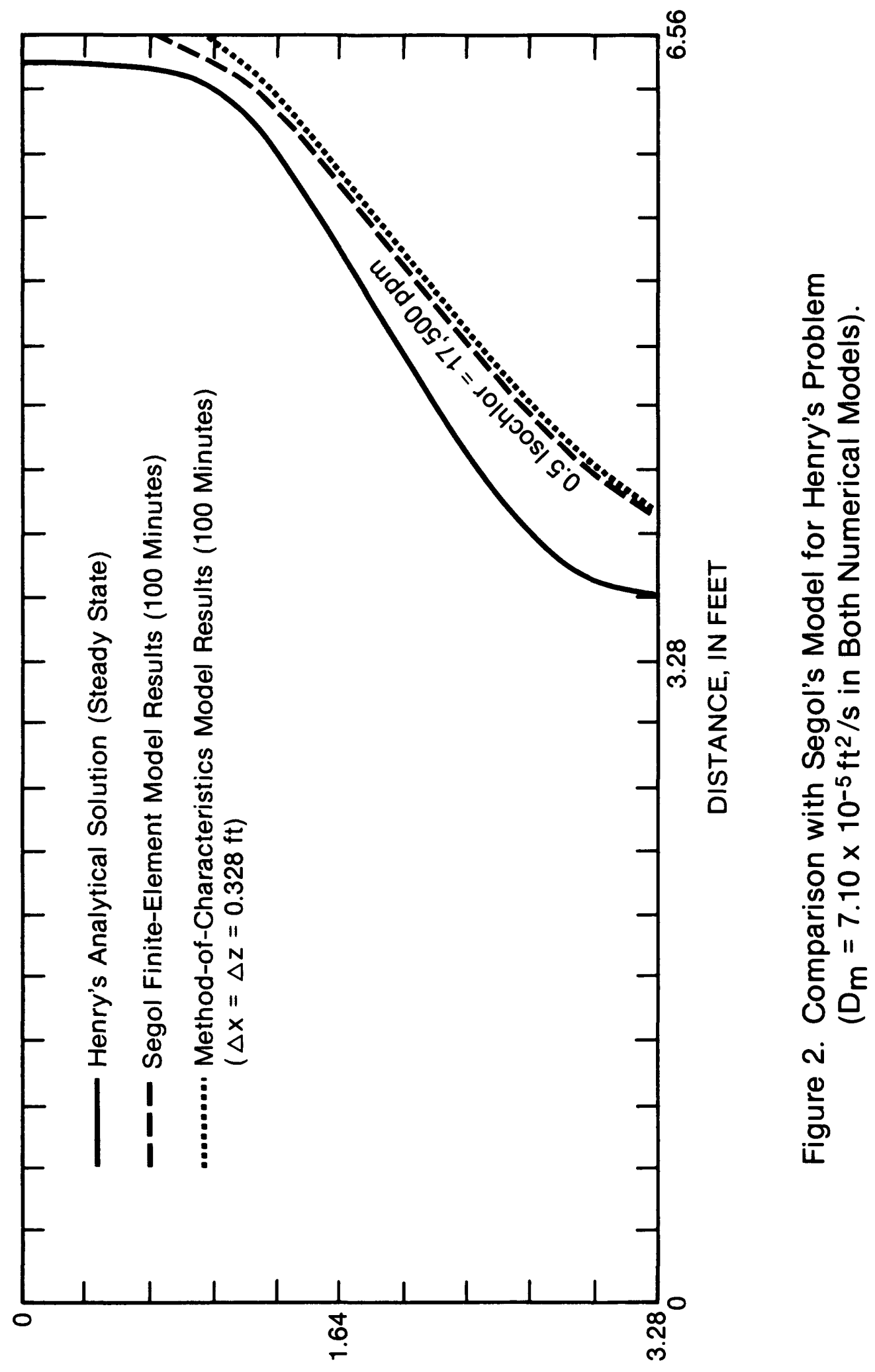

$\perp \exists \exists \exists \mathrm{NI} ' \mathrm{H} \perp d \exists O$ 


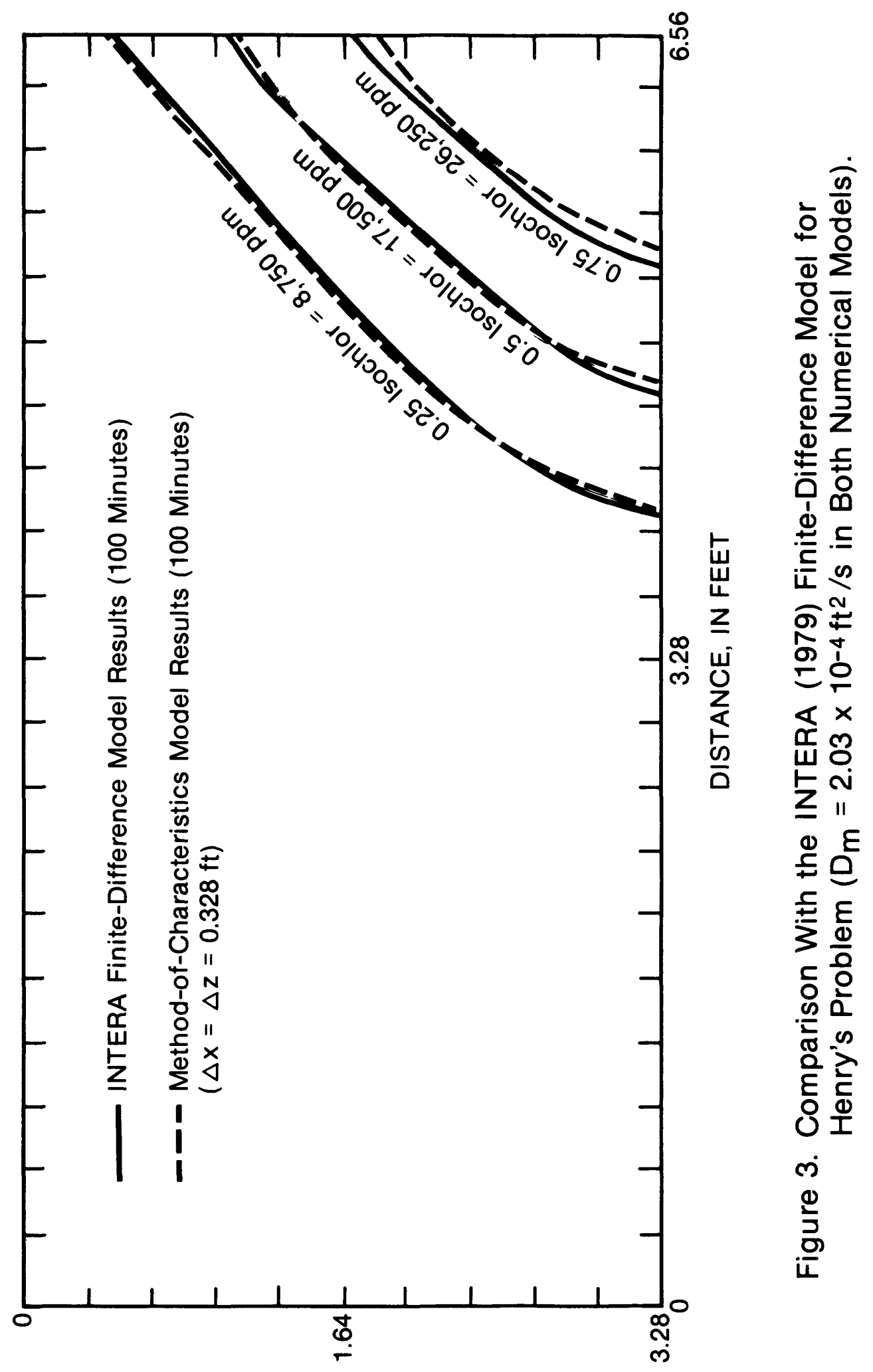

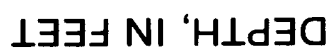


The input and output formats have been designed for flexibility of use and general compatibility with the analysis of typical problems to which the model is applicable. All input data formats are described in Appendix I. Immediately before the program is run, the input data file must be opened as unit 5 of the computer system and the output file must be opened as unit 6 .

The model will allow a unique source/sink rate to be specified at each node, and will allow up to five observation points to be specified for summary printouts of concentration and pressure versus time. The program also includes a node identification array (NODEID), which allows certain nodes or zones to be identified by a unique code number. This feature is used to identify constant-pressure cells. The concentration of the source fluid for each code value is then specified in data set 6 . The values of the constant pressures are taken from the initial pressures specified in data set 7. Additional details and general information are presented by Konikow and Bredehoeft (1978).

Note that $\varepsilon, S$, THICK, WIDTH, $\alpha_{L}, \alpha_{T}, D_{m}$, and ANFCTR are all assumed to be constant and uniform. If it is desired to specify a different value for any of these parameters at different nodes, then these constants must be changed to arrays and the input and output formats and program statements revised accordingly. The user should also change the input/output formats when those specified do not provide enough significant figures. 
A labeled listing of the input data for a sample problem is provided in Appendix II to illustrate the use of the data-input formats for the model. The sample problem is a simple approximation of a cross section through a coastal aquifer in which the freshwater part is subject to contamination (see fig. 4). The right side of the grid is specified as a constant-pressure boundary at hydrostatic saltwater pressures. The freshwater contaminant is introduced in two nodes in the upper left corner of the grid, and uncontaminated freshwater recharges through a constant-pressure boundary over the other top-row cells. This data set also illustrates that only a small data file is required to simulate a relatively simple problem.

Selected output from this sample problem is presented in Appendix III. Not all of the output is reproduced, in order to save space, but a sufficient selection is included to illustrate the type and form of the output provided by the model, as well as to allow the user to compare his output with the documented version for verification of the code.

The initial and boundary conditions for the sample problem result in the freshwater contaminant spreading through the aquifer from the upper left and saltwater moving part way into the aquifer from the right-hand boundary, especially in the deeper part of the aquifer. After the first few time steps, the mass-balance errors for both constituents are consistently less than 5 percent, which is generally acceptable. As a general guideline, execution of this sample problem used less than 1.5 minutes of CPU time on a PRIME 850 computer. 


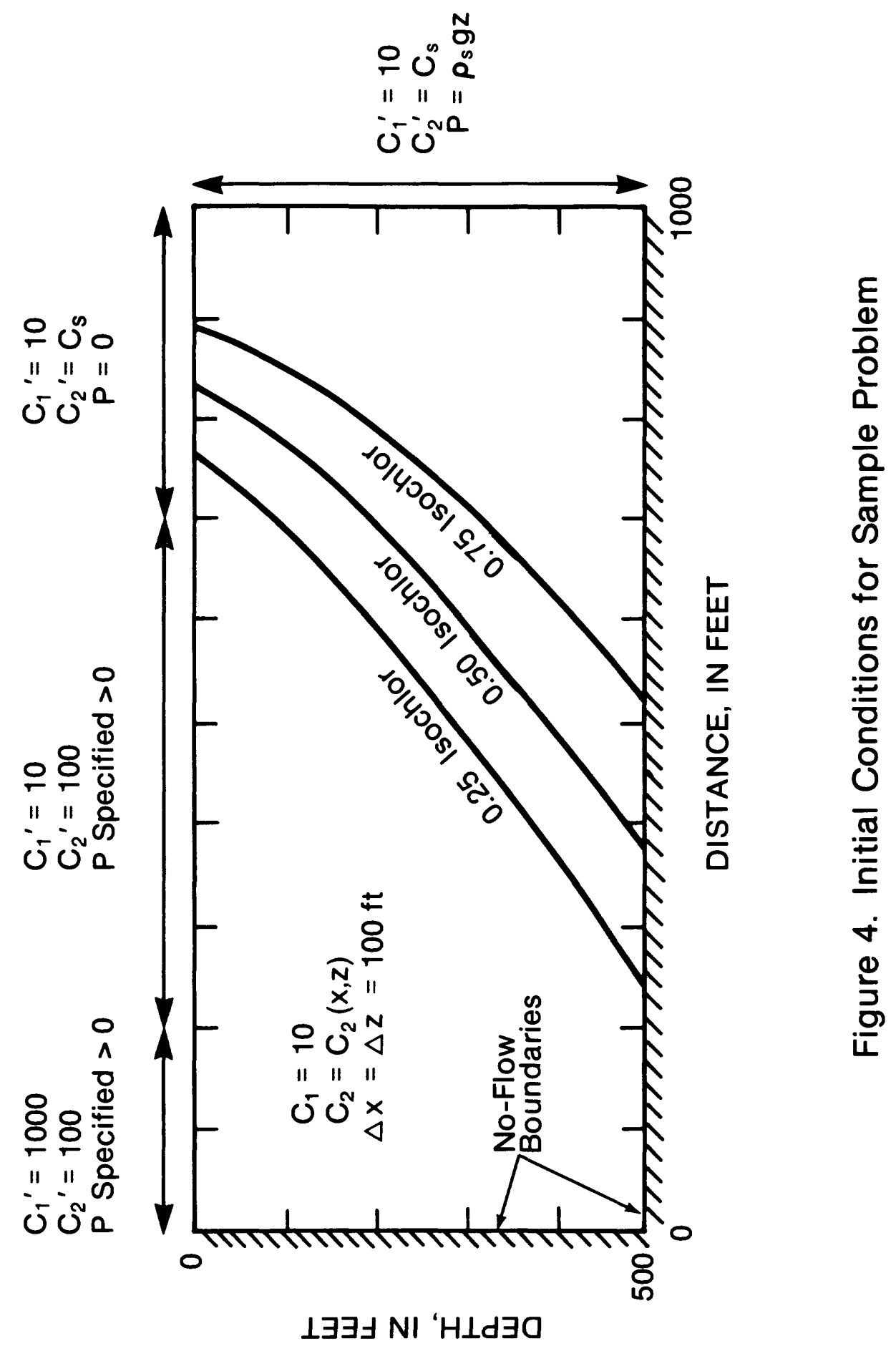


The source code developed for this model was written in Fortran 77. The program is listed in Appendix IV and includes more than 2500 lines. For reference purposes, columns 73-80 of each line contain a label that is numbered sequentially within each subroutine.

\section{SUMMARY AND CONCLUSIONS}

For a numerical model to simulate accurately an aquifer system where both freshwater and saltwater exist, the fluid density must be considered as a variable. The introduction of contaminants into such systems requires that the concentrations of at least two dissolved species be represented in a numerical transport simulation model -- one concentration affecting the fluid density and the other representing a contaminant. The model described here will perform such numerical simulations. The model is a modification of the one documented by konikow and Bredehoeft (1978) in which the equations and numerical methods were modified to represent density-dependent flow and transport of two dissolved constituents in a cross-sectional plane. Other modifications made to the original model include adding a 16-particle-per-cell option, a molecular diffusion option, and the introduction of a particle-weighting scheme.

The variable-density aspects of the model were tested on a problem for which an analytical solution was developed by Henry (1964). The results closely matched the documented results from other numerical models. Therefore, these results, in combination with the previous documentation by Konikow and Bredehoeft (1978) of their model's 
applicability to constant-density problems, indicate that this new

model can be applied to problems involving density-dependent flow and transport of two solutes in a ground-water system.

\section{REFERENCES}

Bear, Jacob, 1972, Dynamics of fluids in porous media: New York, Am. Elsevier Publishing Co., 764 p.

Bredehoeft, J. D., and Pinder, G. F., 1973, Mass transport in flowing groundwater: Water Resources Research, v. 9, no. 1, p. 194-210.

Burnham, W. L., Larson, S. P., and Cooper, H. H., Jr., 1977, Distribution of injected wastewater in the saline lava aquifer, Wailuku-Kahului wastewater treatment facility, Kahului, Maui, Hawaii: U.S. Geological Survey Open-File Report 77-469, 58 p.

Cooper, H. H., Jr., 1966, The equation of groundwater flow in fixed and deforming coordinates: Journal of Geophysical Research, v. 71, no. 20 , p. 4785-4790.

Henry, H. R., 1964, Effects of dispersion on salt encroachment in coastal aquifers: In Seawater in coastal aquifers, U.S. Geological Survey Water-Supply Paper 1613-C, p. C70-C84.

Intera Environmental Consultants, Inc., 1979, Revision of the documentation for a model for calculating effects of liquid waste disposal in deep saline aquifers: U.S. Geological Survey Water-Resources Investigations $79-96,72 \mathrm{p}$.

Konikow, L. F., and Bredehoeft, J. D., 1978, Computer model of twodimensional solute transport and dispersion in ground water: U.S. Geological Survey Techniques of Water-Resources Investigations, Book 7, Chapter C2, $90 \mathrm{p}$.

Konikow, L. F., and Grove, D. B., 1977, Derivation of equations describing solute transport in ground water: U.S. Geological Survey Water-Resources Investigations $77-19,30 \mathrm{p}$.

Larson, S. P., Papadopulos, S. S., Cooper H. H., Jr., and Burnham, W. L., 1977, Simulation of wastewater injection into a coastal aquifer system near Kahului, Maui, Hawaii: Proceedings of Hydraulics in the Coastal Zone, American Society of Civil Engineers, College Station, Texas, p. $107-116$. 
Pinder, G. F., and Cooper, H. H., Jr., 1970, A numerical technique for calculating the transient position of the saltwater front: Water Resources Research, v. 6, no. 3, p. 875-882.

Rosenshein, J. S., and Hickey, J. J., 1977, Storage of treated sewage effluent and storm water in a saline aquifer, Plnellas Peninsula, Florida: Ground Water, v. 15, no. 4, p. 285-293.

Scheidegger, A. E., 1961, General theory of dispersion in porous media: Journal of Geophysical Research, v. 66, no. 10, p. 3273-3278.

Segol, G., Pinder, G. F., and Gray, W. G., 1975, A galerkin finite-element technique for calculating the transient position of the saltwater front: Water Resources Research, v. 11, no. 2, p. 343-347.

Trescott, P. C., Pinder, G. F., and Larson, S. P., 1976, Finite-difference model for aquifer simulation in two dimensions with results of numerical experiments: U.S. Geological Survey Techniques of Water-Resources Investigations, Book 7, Chapter C1, $116 \mathrm{p}$.

Voss, C. I., 1984, A finite-element simulation model for saturated-unsaturated, fluid-density-dependent ground-water flow with energy transport or chemically-reactive single-species solute transport: U.S. Geological Survey Water-Resources Investigations Report 84-4369, 409 p.

Weast, R. C. (ed.), 1981, CRC handbook of chemistry and physics: CRC Press, Inc., Boca Raton, Florida. 


\begin{tabular}{|c|c|c|c|c|}
\hline Line & Column & Format & Variable & Definition \\
\hline 1 & $1-80$ & $10 A 8$ & TITLE & Description of problem. \\
\hline \multirow[t]{12}{*}{2} & $1-4$ & I4 & NTIM & $\begin{array}{l}\text { Maximum number of time steps in a } \\
\text { pumping period (limit }=100) * \text {. }\end{array}$ \\
\hline & $5-8$ & I4 & NPMP & $\begin{array}{l}\text { Number of pumping periods. Note } \\
\text { that if } N P M P>1 \text {, then data set } \\
11 \text { must be completed. }\end{array}$ \\
\hline & $9-12$ & 14 & NX & $\begin{array}{l}\text { Number of nodes in } x \text { direction } \\
(\operatorname{limit}=24) * .\end{array}$ \\
\hline & $13-16$ & 14 & $\mathrm{NZ}$ & $\begin{array}{l}\text { Number of nodes in } z \text { direction } \\
(1 \text { imit }=20) * \text {. }\end{array}$ \\
\hline & $17-20$ & 14 & NPMAX & $\begin{array}{l}\text { Maximum number of particles } \\
(\lim 1 t=6400) * .\end{array}$ \\
\hline & $21-24$ & 14 & NPNT & $\begin{array}{l}\text { Time-step intervai for printing } \\
\text { hydraulic and chemical output data. }\end{array}$ \\
\hline & $25-28$ & I4 & NUMOBS & $\begin{array}{l}\text { Number of observation points to be } \\
\text { specified in a following data set } \\
(\text { limit }=5)^{*} \text {. }\end{array}$ \\
\hline & $29-32$ & I4 & ITMAX & $\begin{array}{l}\text { Maximum allowable number of } \\
\text { iterations in SIP (usually } \\
100 \leq \text { ITMAX } 200 \text { ). }\end{array}$ \\
\hline & $33-36$ & 14 & NREC & $\begin{array}{l}\text { Number of pumping or injection } \\
\text { wells to be specified in a } \\
\text { following data set. }\end{array}$ \\
\hline & $37-40$ & 14 & NPTPND & $\begin{array}{l}\text { Initial number of particles per } \\
\text { node (options }=4,5,8,9,16) \text {. }\end{array}$ \\
\hline & $41-44$ & 14 & NCODES & $\begin{array}{l}\text { Number of node identification codes } \\
\text { to be specified in a following } \\
\text { data set }(1 \text { mit }=10) * \text {. }\end{array}$ \\
\hline & $45-48$ & 14 & NZCRIT & $\begin{array}{l}\text { Maximum number of cells that can be } \\
\text { void of particles before particles } \\
\text { are redistributed (generally equal }\end{array}$ \\
\hline
\end{tabular}

See footnotes at end of table. 


Line Column Format Variable Definition

49-52

$53-56$

$57-60$

$61-64$

$65-68$

$69-72$
I4

I4

I4

I4

I4
NPNTMV

NPNTD

NPDELC

NCONST

NPNTVL

NPNCHV to 1 to 10 percent of the number of active cells in the grid).

Number of constituents present (1 or 2).

Particle movement interval (IMOV) for printing chemical output data. (Specify 0 to print only at end of time steps.)

Options for printing computed velocities ( $0=$ do not print; $1=$ print for first time step; $2=$ print for all time steps).

Option for printing computed dispersion equation coefficients (option definition same as for NPN'TVL) .

Option for printing computed changes in concentration $(0=$ do not print; $1=$ print).

Option to write velocity data in separate file (option definition same as for NPNTVL). When specified, program will write the velocities at nodes on unit 7 .

$\begin{array}{lll}1-10 & \text { G10.0 } & \text { PINT } \\ 11-20 & \text { G10.0 } & \text { TOL } \\ 21-30 & \text { G10.0 } & \text { POROS } \\ 31-40 & \text { G10.0 } & \text { BETA } \\ 41-50 & \text { G10.0 } & \text { S } \\ 51-60 & \text { G10.0 } & \text { TIMX }\end{array}$

Pumping period in years.

Convergence criteria in SIP (usually TOL $\leq 0.01$ ).

Effective porosity.

Longitudinal dispersivity, in feet.

Storage coefficient (set $S=0$ for steady-flow problems).

Time increment multiplier for transient flow problems. TIMX is disregarded if $S=0$. 


\begin{tabular}{|c|c|c|c|c|}
\hline Line & Column & Format & Variable & Definition \\
\hline & $61-70$ & G10.0 & TINIT & $\begin{array}{l}\text { Size of initial time step in } \\
\text { seconds. TINIT is disregarded if } \\
S=0 \text {. }\end{array}$ \\
\hline \multirow[t]{8}{*}{4} & $1-10$ & G10.0 & XDEL & $\begin{array}{l}\text { Width of finite-difference cell in } \\
x \text { direction, in feet. }\end{array}$ \\
\hline & $1-20$ & G10.0 & ZDEL & $\begin{array}{l}\text { Width in finite-difference cell in } \\
\mathrm{z} \text { direction, in feet. }\end{array}$ \\
\hline & $21-30$ & G10.0 & DLTRAT & $\begin{array}{l}\text { Ratio of transverse to longitudinal } \\
\text { dispersivity. }\end{array}$ \\
\hline & $31-40$ & G10.0 & CELDIS & $\begin{array}{l}\text { Maximum cell distance per particle } \\
\text { move (value between } 0 \text { and } 1.0 \text { ). }\end{array}$ \\
\hline & $41-50$ & G10.0 & ANFCTR & Ratio of $\mathrm{K}_{\mathrm{zz}}$ to $\mathrm{K}_{\mathrm{xx}}$ \\
\hline & $51-60$ & G10.0 & WIDTH & $\begin{array}{l}\text { Width (third dimension) of the } \\
\text { aquifer cross-section, in feet. }\end{array}$ \\
\hline & $61-70$ & G10.0 & CTOL & $\begin{array}{l}\text { Concentration change increment for } \\
\text { density-dependent constituent to } \\
\text { determine whether pressures are } \\
\text { recalculated. }\end{array}$ \\
\hline & $71-80$ & G10.0 & DMOLEC & $\begin{array}{l}\text { Molecular diffusion coefficient, in } \\
\mathrm{ft}^{2} / \mathrm{s} \text {. }\end{array}$ \\
\hline
\end{tabular}

\begin{tabular}{|c|c|c|c|c|}
\hline $\begin{array}{l}\text { Data } \\
\text { Set }\end{array}$ & $\begin{array}{l}\text { Number } \\
\text { of Lines }\end{array}$ & Format & Variable & Definition \\
\hline 1 & $\begin{array}{l}\text { Value of } \\
\text { NUMOBS }\end{array}$ & 212 & $\begin{array}{l}\text { IXOBS, } \\
\text { IZOBS }\end{array}$ & $\begin{array}{l}x \text { and } z \text { coordinates of observation } \\
\text { points. This data set is elimi- } \\
\text { nated if NUMOBS is specified as } \\
=0 .\end{array}$ \\
\hline 2 & $\begin{array}{l}\text { Value of } \\
\text { NREC }\end{array}$ & $\begin{array}{l}2 \mathrm{I} 2, \\
3 \mathrm{G} 10.2\end{array}$ & $\begin{array}{l}\text { IX, IZ, } \\
\text { REC } \\
\text { CNREC, } \\
\text { TDSREC }\end{array}$ & $\begin{array}{l}x \text { and } z \text { coordinates of pumping }(+) \\
\text { or injection ( }- \text { ) wells, rate in } \\
\mathrm{ft} 3 / \mathrm{s} \text {, and if an injection well, } \\
\text { the concentration in the injected } \\
\text { water of the trace constituent, } \\
\text { which does not affect density }\end{array}$ \\
\hline
\end{tabular}




\begin{tabular}{|c|c|c|}
\hline $\begin{array}{l}\text { Data } \\
\text { Set }\end{array}$ & $\begin{array}{l}\text { Number } \\
\text { of Line. }\end{array}$ & Format \\
\hline
\end{tabular}

3 a. 1

b. Value of NZ

4 a. 1

b. Value of NZ

c. Value of NZ

5

a. 1

b. Value of NZ

6 Value of NCODES

7

a. 1

I1, $\mathrm{G} 10.0$

INPUT, FCTR

b. Value of $\mathrm{NZ} 12 \mathrm{G} 6.0$ (double if $\mathrm{NX}>12$ ).

8 a. 1

I1, $\mathrm{G} 10.0$

INPUT FCTR

CONC
(CNREC), and of the densitycontrolling constituent (TDSREC). This data set is eliminated if NREC $=0$.

Parameter line ${ }^{\dagger}$ for PERM.

The intrinsic permeability of the aquifer, in $\mathrm{ft}^{2}$.

Parameter linet for VPRM.

Leakance coefficient, in $\mathrm{ft}^{-1} \mathrm{~s}^{-1}$.

Elevation difference between the source bed and the aquifer node (negative if confining bed is below aquifer), in feet.

Parameter linet for NODEID.

Node Identification matrix (use a nonzero value to define constantpressure nodes).

Boundary codes and concentrations of constituents 1 and 2 , respectively, in the source fluid where NODEID=ICODE.

Parameter linet for PI.

Initial fluid pressures in the aquifer, in $1 \mathrm{~b} / \mathrm{ft}^{2}$.

Parameter card ${ }^{\dagger}$ for CONC.

Initial concentration of the trace constitutent in the aquifer. This data set is eliminated if NCONST<2. 
9 a. 1

b. Value of NZ $12 \mathrm{G} 6.0$ (double if NX $>12$ ) .
I1, G10.0 a. 1

b. 1
I1

$4 G 10.3$

11 a. 1

I 1

b. 1
$914,3 G 5.0$
DEN 1, DEN2, VIS1, VIS 2

INPUT, FCTR

TDS

INPUT

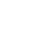




\begin{tabular}{|c|c|c|c|c|}
\hline $\begin{array}{l}\text { Data } \\
\text { Set }\end{array}$ & $\begin{array}{l}\text { Number } \\
\text { of Lines }\end{array}$ & Format & Variable & Definition \\
\hline & $\begin{array}{l}\text { C. Value of } \\
\text { NREC }\end{array}$ & $2 \mathrm{I} 2,3 \mathrm{G} 10.2$ & $\begin{array}{l}\text { IX, IZ, REC, } \\
\text { CNREC, } \\
\text { TDSREC }\end{array}$ & $\begin{array}{l}\text { Revision of previously defined } \\
\text { data set } 2 \text {. Include part } c \text { only } \\
\text { if } I C H K=1 \text { in previous part a and } \\
\text { if NREC }>0 \text { in previous part } b \text {. }\end{array}$ \\
\hline
\end{tabular}

* These limits can be modified if necessary by changing the corresponding array dimensions in the COMMON statements of the program.

t The parameter line must be the first line of the indicated data sets. It is used to specify whether the parameter is constant and uniform, and can be defined by one value, or whether it varies in space and must be defined at each node. If INPUT $=0$, the data set has a constant value, which is defined by FCTR. If INPUT=1, the data set is read as described by part b (and part $c$, if applicable) immediately following the parameter line. Then FCTR is a multiplication factor for the values read in part $b$ of the data set. 


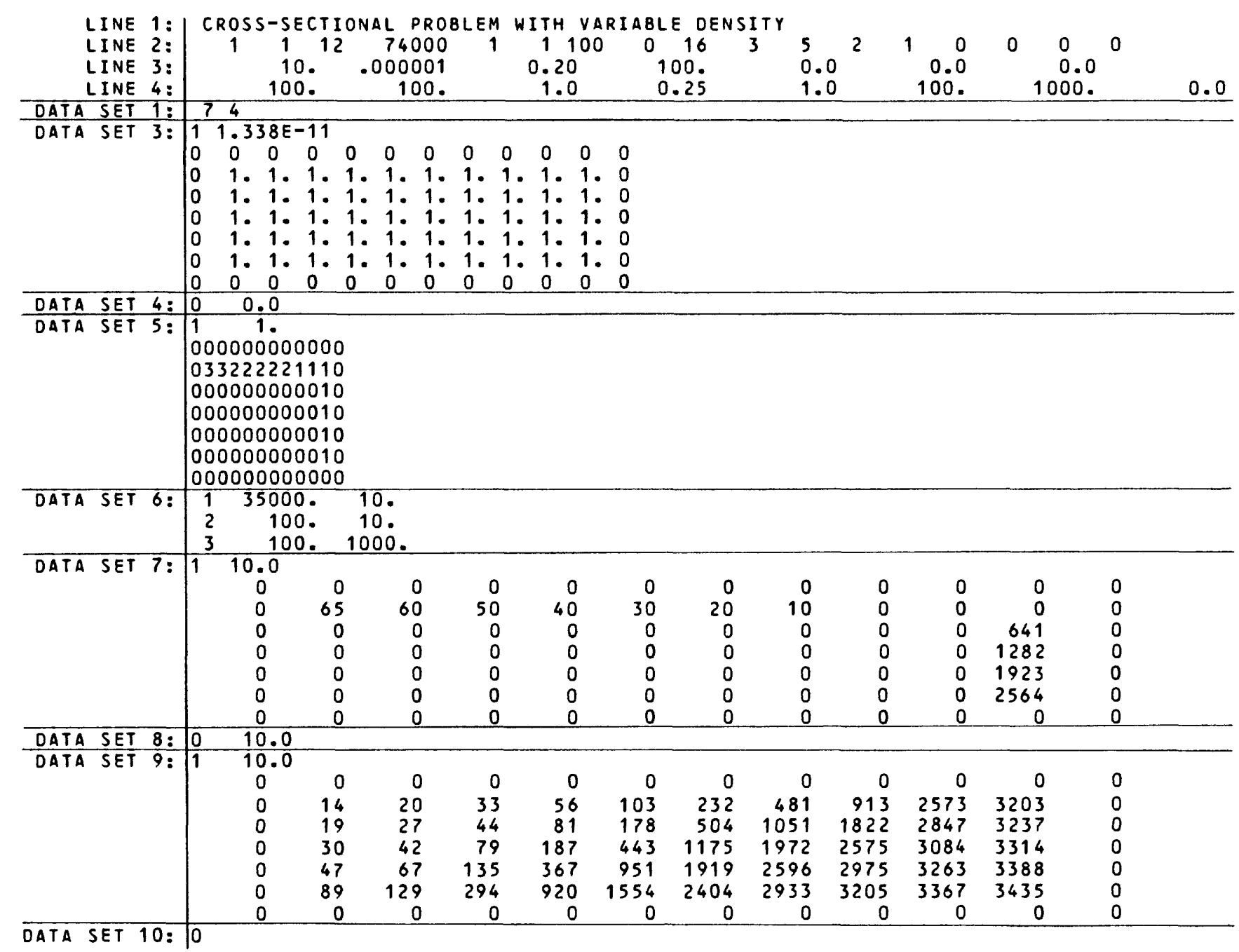



Appendix III:

\section{Selected Output from a Sample Problem}

U.S.G.S. METHOD-OF-CHARACTERISTICS MODEL FOR SOLUTE TRANSPORT IN GROUNO WATER CROSS-SECTIONAL PROBLEM WITH VARIABLE DENSITY

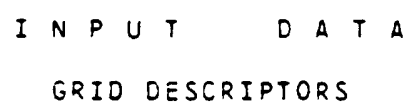


STEADY-STATE FLOW

TIME INTERVAL (IN SEC) FOR SOLUTE-TRANSPORT SIMULATION $=0.31558 E+09$

LOCATION OF OBSERVATION WELLS

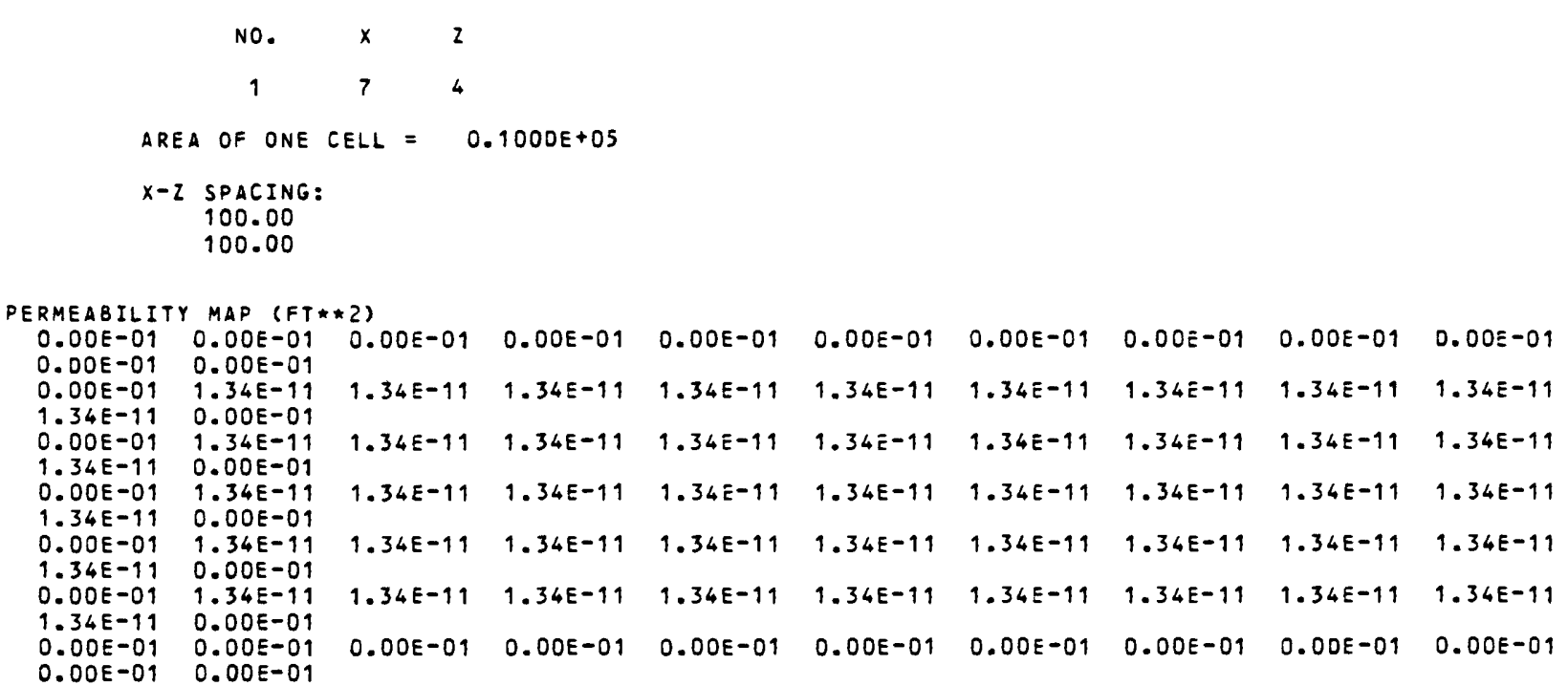

NO. OF FINITE-DIFFERENCE CELLS IN AQUIFER $=50$

AREA OF AQUIFER IN MODEL $=0.50000 E+06$ SQ. FT.

NICRIT CMAX. NO. OF CELLS THAT CAN BE VOID OF

PARTICLES; IF EXCEEDED, PARTICLES ARE REGENERATED) = 5

NODE IDENTIFICATION MAP

$\begin{array}{llllllllllll}0 & 0 & 0 & 0 & 0 & 0 & 0 & 0 & 0 & 0 & 0 & 0 \\ 0 & 3 & 3 & 2 & 2 & 2 & 2 & 2 & 1 & 1 & 1 & 0 \\ 0 & 0 & 0 & 0 & 0 & 0 & 0 & 0 & 0 & 0 & 1 & 0 \\ 0 & 0 & 0 & 0 & 0 & 0 & 0 & 0 & 0 & 0 & 1 & 0 \\ 0 & 0 & 0 & 0 & 0 & 0 & 0 & 0 & 0 & 0 & 1 & 0 \\ 0 & 0 & 0 & 0 & 0 & 0 & 0 & 0 & 0 & 0 & 1 & 0 \\ 0 & 0 & 0 & 0 & 0 & 0 & 0 & 0 & 0 & 0 & 0 & 0\end{array}$

NO. OF NODE IDENT. CODES SPECIFIED $=3$

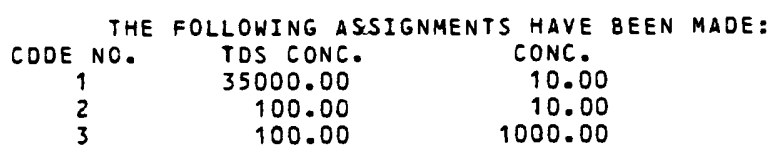

\begin{tabular}{|c|c|c|c|c|c|c|c|c|c|}
\hline $\begin{array}{l}\text { ERTICAL PE } \\
0.00 E-01 \\
0.00 E-01 \\
0.00 E-01 \\
1.34 E-03 \\
0.00 E-01 \\
1.34 E-03 \\
0.00 E-01 \\
1.34 E-03 \\
0.00 E-01 \\
1.34 E-03 \\
0.00 E-01 \\
1.34 E-03 \\
0.00 E-01 \\
0.0 O E-01\end{array}$ & $\begin{array}{l}\text { RMEABILITY } \\
0.00 E-01 \\
0.00 E-01 \\
1.34 E-03 \\
0.00 E-01 \\
0.00 E-01 \\
0.00 E-01 \\
0.00 E-01 \\
0.00 E-01 \\
0.00 E-01 \\
0.00 E-01 \\
0.00 E-01 \\
0.00 E-01 \\
0.00 E-01 \\
0.00 E-01\end{array}$ & $\begin{array}{l}0.00 E-01 \\
0.00 E-01 \\
0.00 E-01 \\
0.00 E-01\end{array}$ & $\begin{array}{l}0.00 E-01 \\
1.34 E-03 \\
0.00 E-01 \\
0.00 E-01 \\
0.00 E-01 \\
0.00 E-01\end{array}$ & $\begin{array}{l}0.00 E-01 \\
1.34 E-03 \\
0.00 E-01 \\
0.00 E-01 \\
0.00 E-01 \\
0.00 E-01 \\
0.00 E-01\end{array}$ & $\begin{array}{l}0.00 E-01 \\
1.34 E-03 \\
0.00 E-01 \\
0.00 E-01\end{array}$ & $\begin{array}{l}0.00 E-01 \\
1.34 E-03 \\
0.00 E-01 \\
0.00 E-01 \\
0.00 E-01 \\
0.00 E-09\end{array}$ & $\begin{array}{l}0.00 E-01 \\
1.34 E-03 \\
0.00 E-01 \\
0.00 E-01 \\
0.00 E-01 \\
0.00 E-01 \\
0.00 E-01\end{array}$ & $\begin{array}{l}0.00 E-01 \\
1.34 E-03 \\
0.00 E-01 \\
0.00 E-01 \\
0.00 E-01 \\
0.00 E-01\end{array}$ & $\begin{array}{l}0.00 E-01 \\
1.34 E-03 \\
0.00 E-01 \\
0.00 E-01 \\
0.00 E-01 \\
0.00 E-01 \\
0.00 E-01\end{array}$ \\
\hline
\end{tabular}




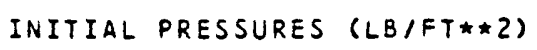

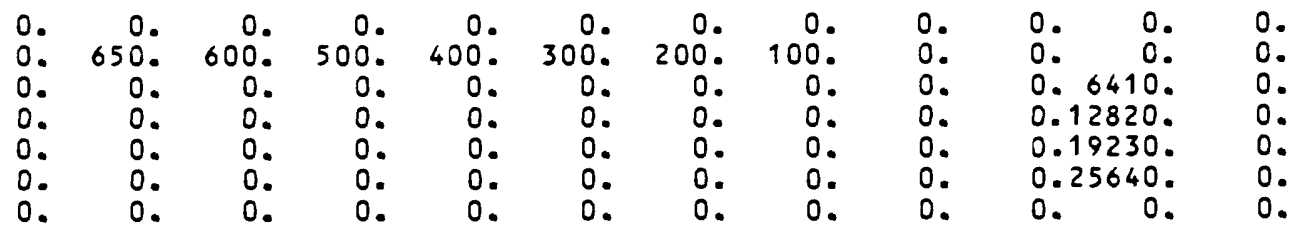

\begin{tabular}{|c|c|c|c|c|c|c|c|c|c|c|}
\hline \multicolumn{2}{|c|}{$\begin{aligned} & \text { PRESSURE DISTRIBUTION } \\
& \text { NUMBER OF TIME STEPS }= \\
& \text { TIME(SECONDS) }= \\
& \text { TIME (DAYS) }= \\
& \text { TIME(YEARS) }=\end{aligned}$} & \multicolumn{2}{|c|}{$\begin{array}{l}-R O W \\
=\quad 0 \\
=0.00000 \\
=0.00000 \mathrm{E}-01 \\
=0.00000 \mathrm{E}-01\end{array}$} & \multirow[b]{2}{*}{0.0000} & \multirow[b]{2}{*}{0.0000} & \multirow[b]{2}{*}{0.0000} & \multirow[b]{2}{*}{0.0000} & \multirow[b]{2}{*}{0.0000} & \multirow[b]{2}{*}{0.0000} & \multirow[b]{2}{*}{0.0000} \\
\hline 0.0000 & 0. & 0000 & 0.0000 & & & & & & & \\
\hline 0.0000 & & 0000 & & & & & & & & \\
\hline 0.0000 & 650. & 0000 & 600.0000 & 500.0000 & 400.0000 & 300.0000 & 200.0000 & 100.0000 & 0.0000 & 0.0000 \\
\hline 0.0000 & & 0000 & & & & & & & & \\
\hline 0.0000 & & 0000 & 0.0000 & 0.0000 & 0.0000 & 0.0000 & 0.0000 & 0.0000 & 0.0000 & 0.0000 \\
\hline 6410.0000 & & 0000 & & & & & & & & \\
\hline 0.0000 & & 0000 & 0.0000 & 0.0000 & 0.0000 & 0.0000 & 0.0000 & 0.0000 & 0.0000 & 0.0000 \\
\hline 12820.0000 & & 0000 & & & & & & & & \\
\hline 0.0000 & & 0000 & 0.0000 & 0.0000 & 0.0000 & 0.0000 & 0.0000 & 0.0000 & 0.0000 & 0.0000 \\
\hline 19230.0000 & & 0000 & & & & & & & & \\
\hline 0.0000 & & 0000 & 0.0000 & 0.0000 & 0.0000 & 0.0000 & 0.0000 & 0.0000 & 0.0000 & 0.0000 \\
\hline 25640.0000 & & 0000 & & & & & & & & \\
\hline 0.0000 & & 0000 & 0.0000 & 0.0000 & 0.0000 & 0.0000 & 0.0000 & 0.0000 & 0.0000 & 0.0000 \\
\hline 0.0000 & & 0000 & & & & & & & & \\
\hline
\end{tabular}

INITIAL CONCENTRATION MAP - TRACE SOLUTE

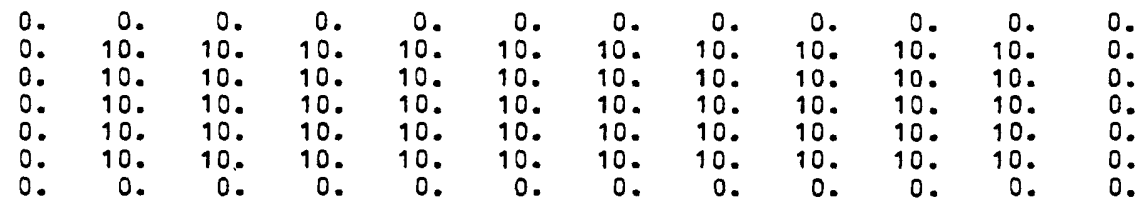

INITIAL TDS MAP - DENSITY-CONTROLLING SOLUTE

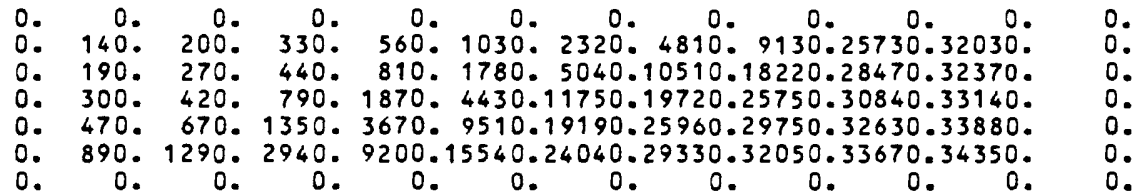


INITIAL DENSITIES (LB/FT**3)

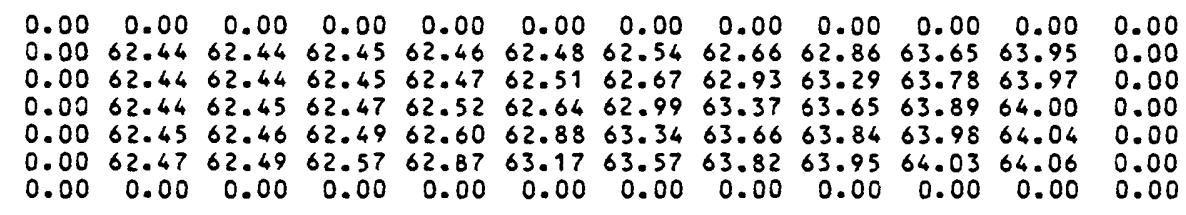

INITIAL VISCOSITIES (LB*SEC/FT**Z)

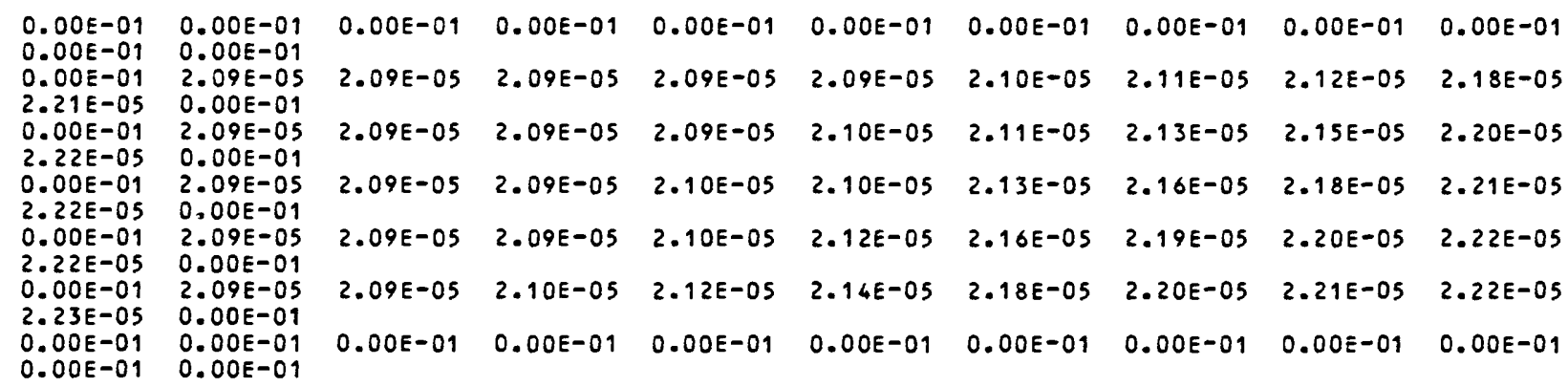

\section{CONCENTRATION}

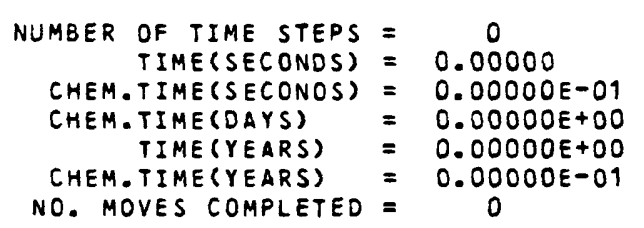

TRACE SOLUTE

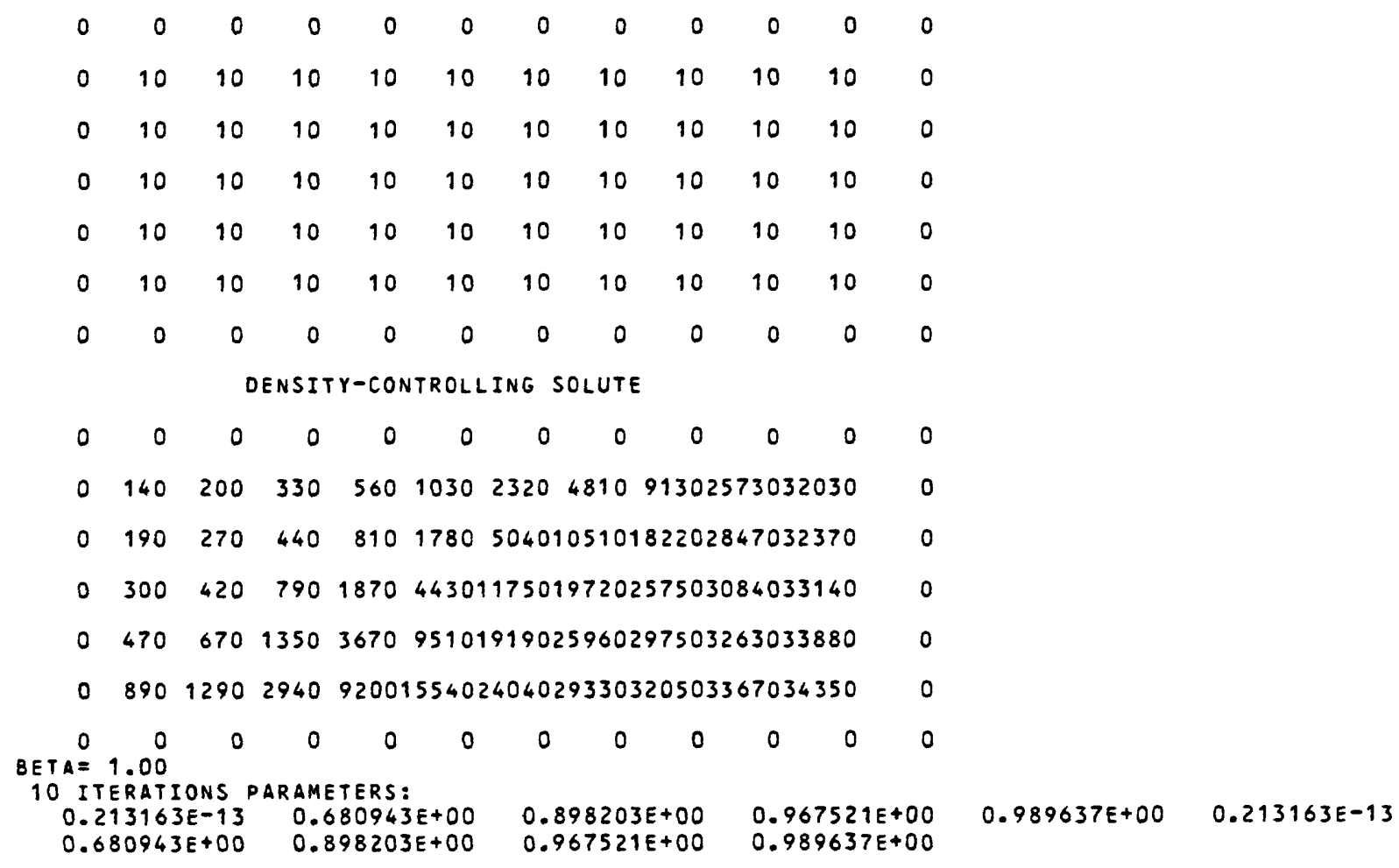

$N=1$

NUMBER OF ITERATIONS $=22$ 


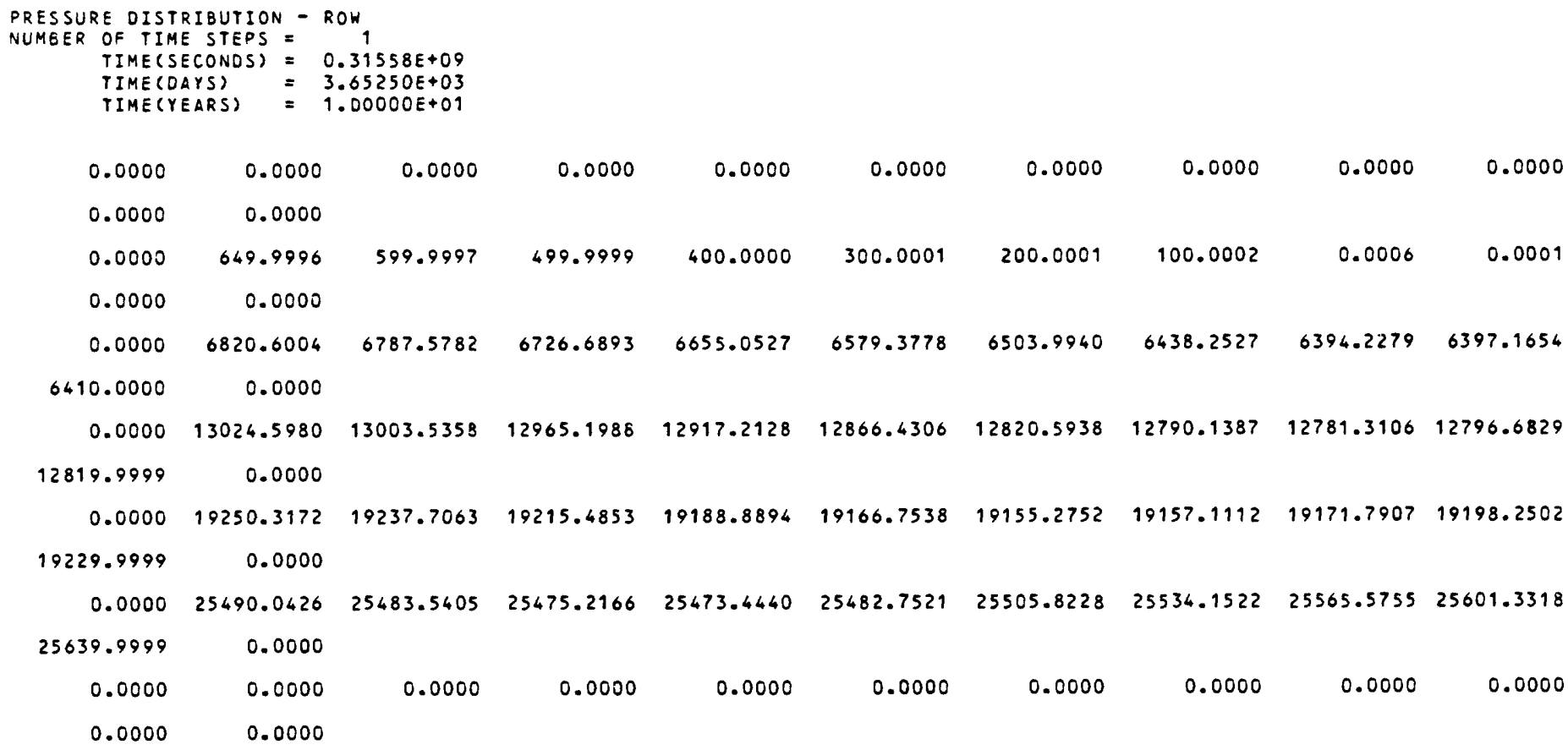

PRESSURE MAP

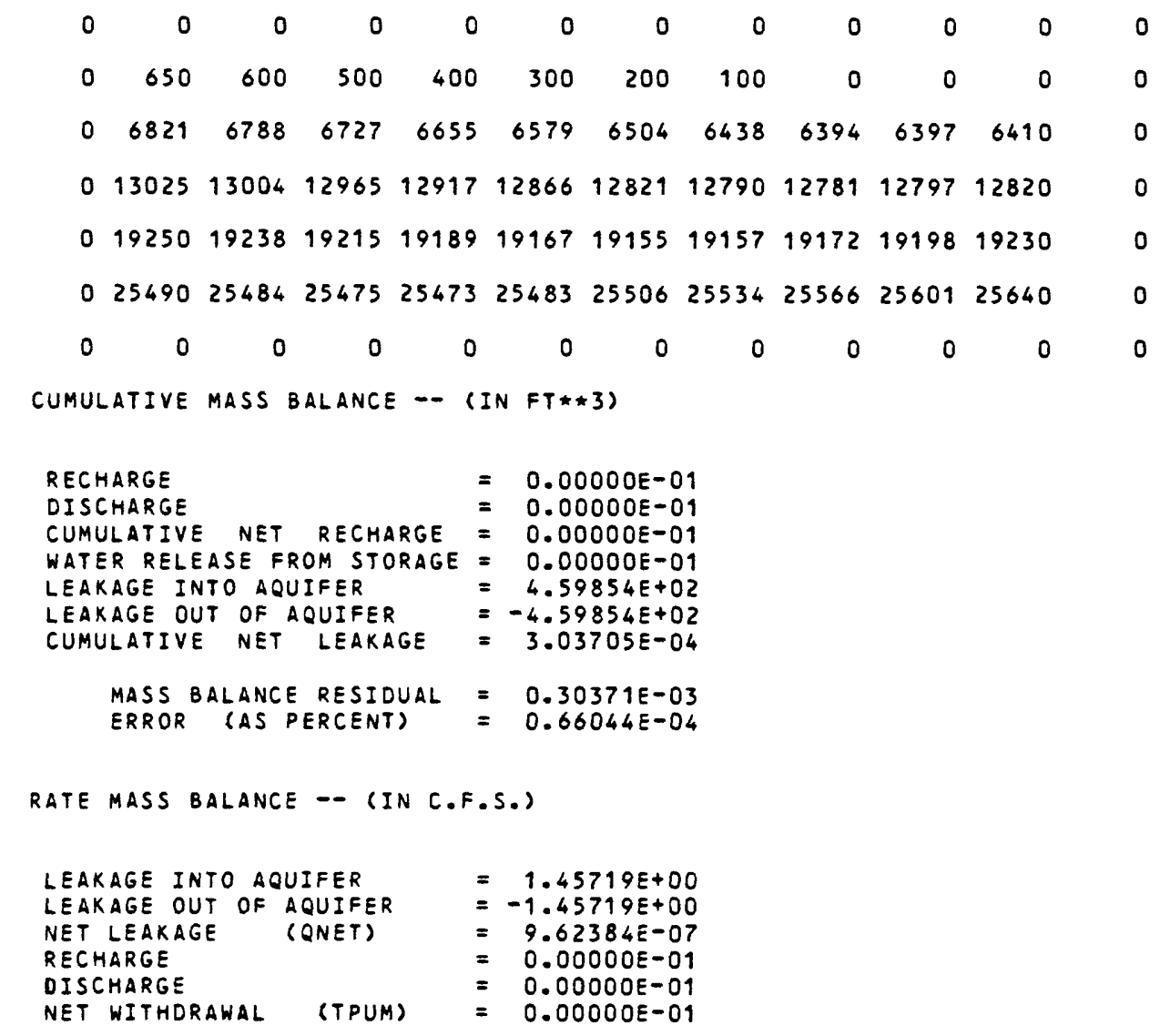




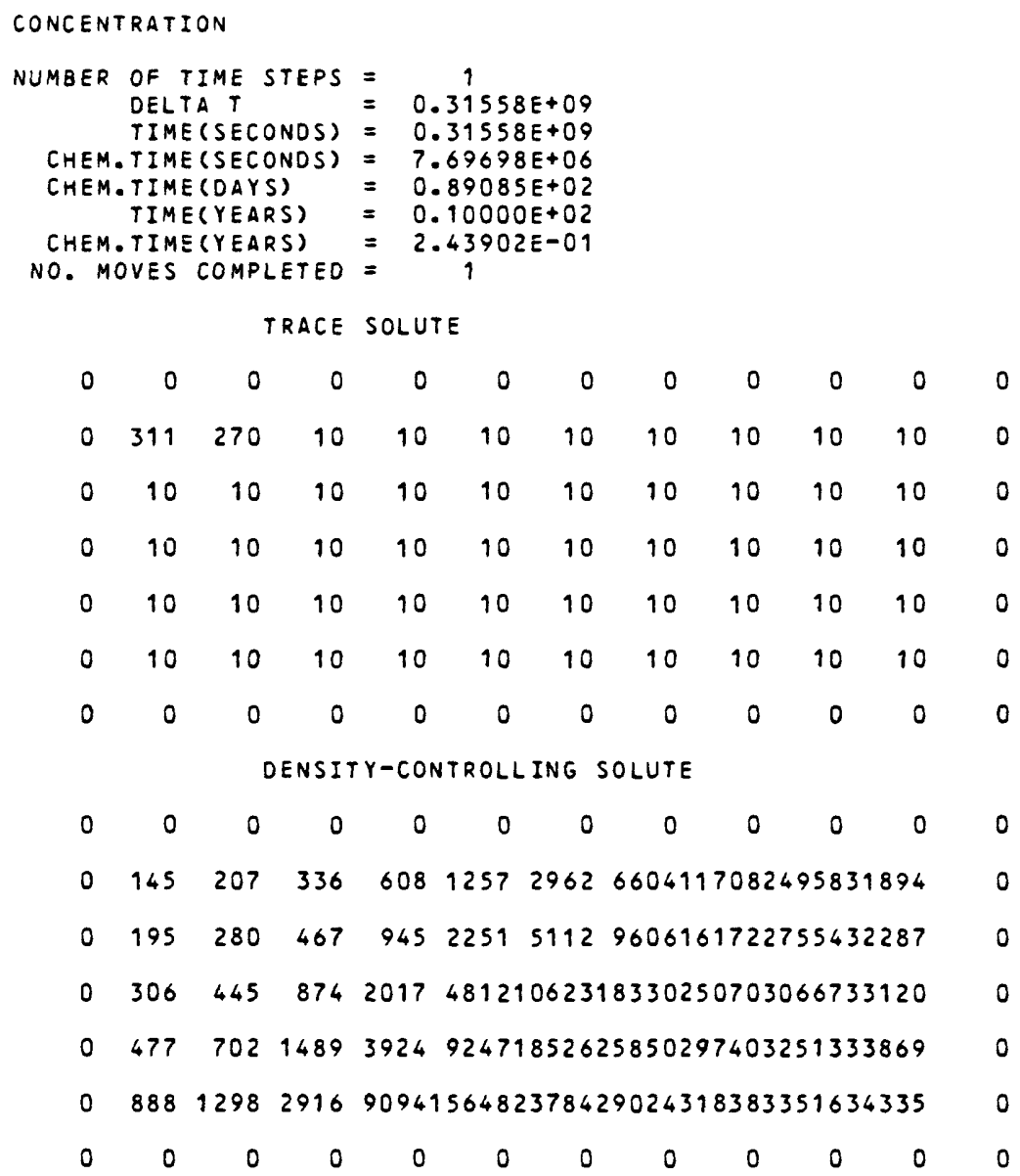

CHEMICAL MASS BALANCE

TRACE SOLUTE

$\begin{array}{ll}\text { MASS IN BOUNDARIES } & =1.13861 E+08 \\ \text { MASS OUT BOUNDARIES } & =-1.78475 E+06 \\ \text { MASS PUMPED IN } & =0.00000-01 \\ \text { MASS PUMPED OUT } & =0.00000 E-01 \\ \text { INFLOW MINUS OUTFLOW } & =1.12076 E+08 \\ \text { INITIAL MASS STORED } & =1.00000 E+08 \\ \text { PRESENT MASS STORED } & =2.12079 E+08 \\ \text { CHANGE MASS STORED } & =1.12079 E+08\end{array}$

COMPARE RESIDUAL WITH NET FLUX AND MASS ACCUMULATION: MASS BALANCE RESIDUAL $=-2.70385 E+03$

ERROR (AS PERCENT) $=-2.37469 E-03$

COMPARE INITIAL MASS STORED WITH CHANGE IN MASS STORED: ERROR (AS PERCENT) $=-2.23896 \Xi-02$

CHEMICAL MASS BALANCE

DENSITY-CONTROLLING SOLUTE

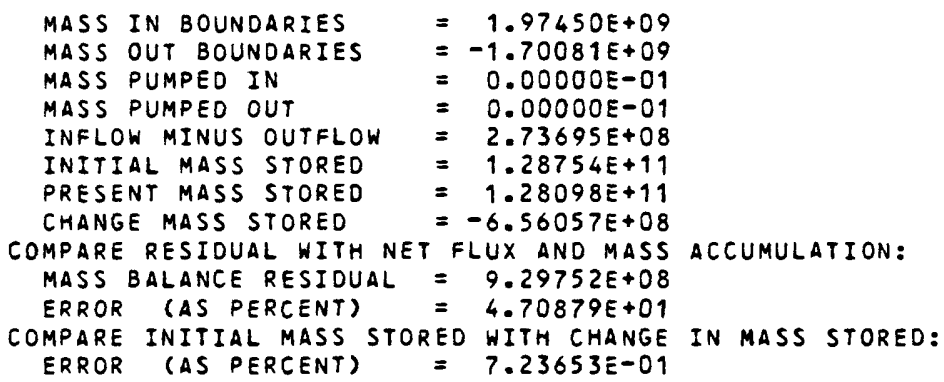




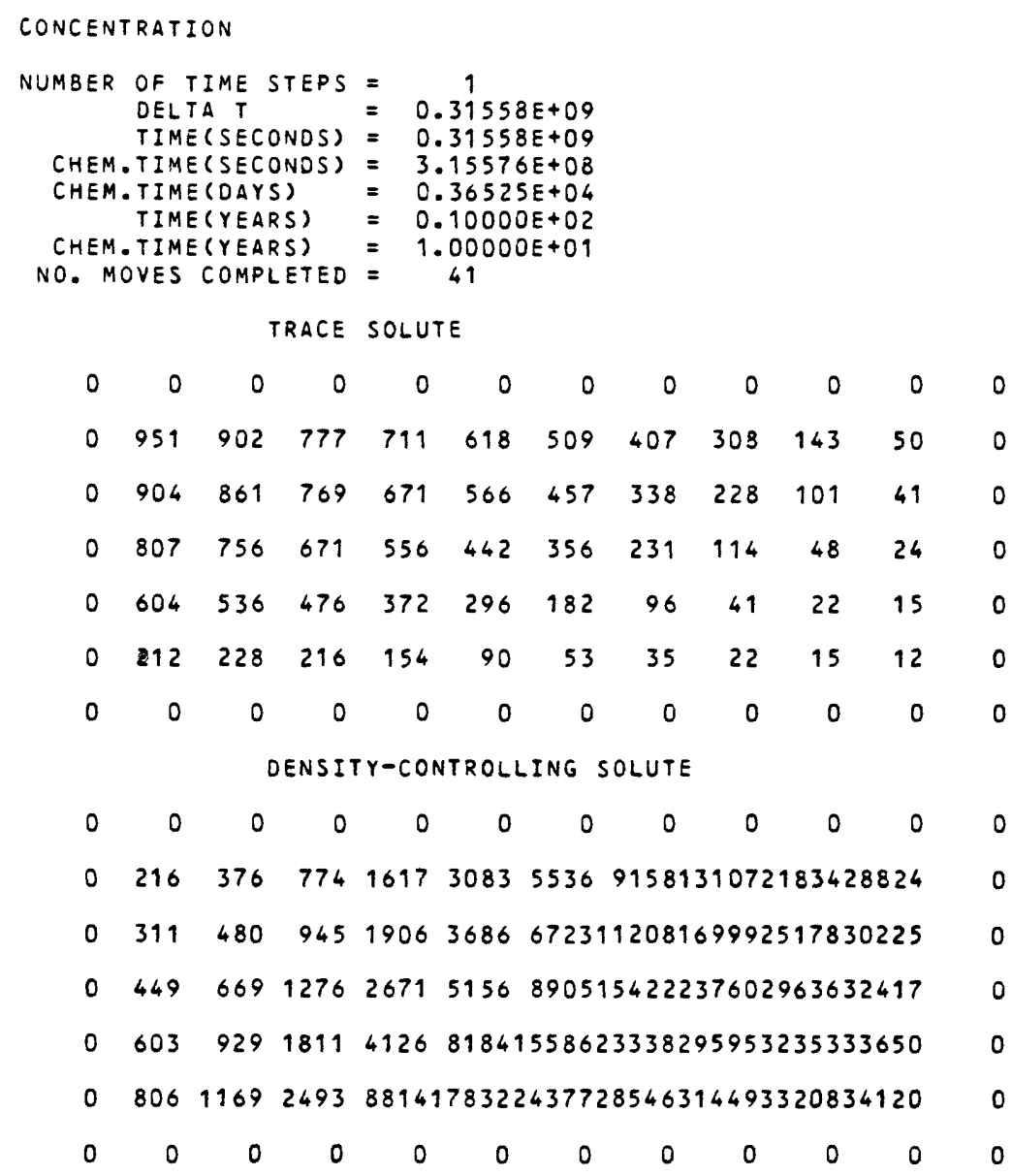

CHEMICAL MASS BALANCE

TRACE SOLUTE

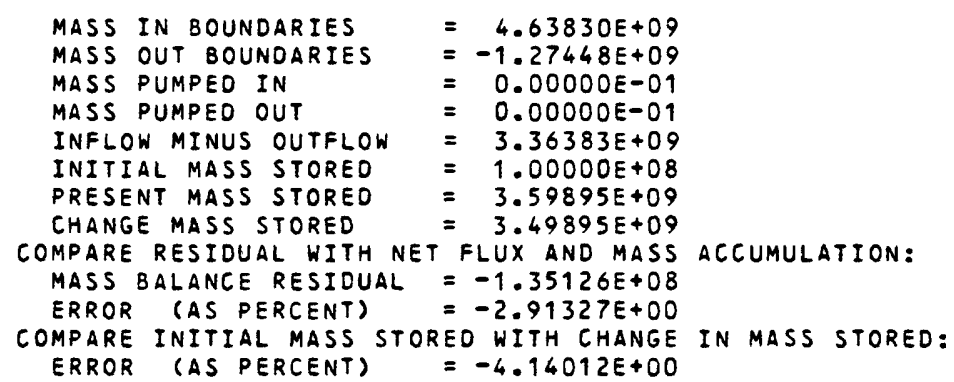

CHEMICAL MASS BALANCE

DENSITY-CONTROLLING SOLUTE

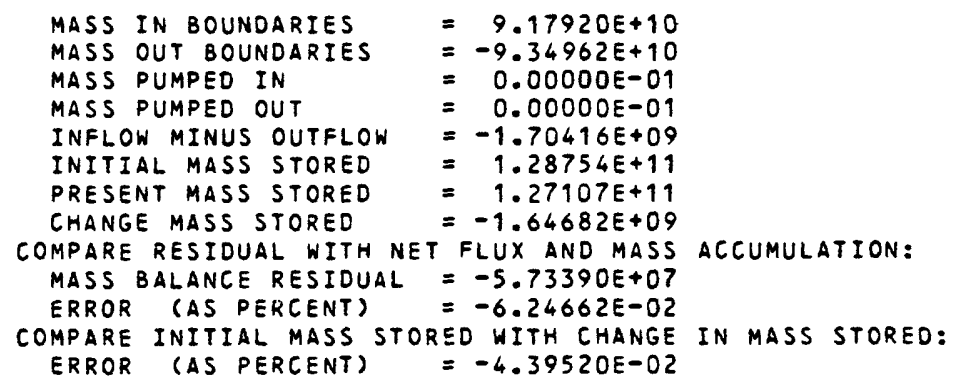


CROSS-SECTIONAL PROBLEM HITH VARIABLE DENSITY

TIME VERSUS HEAD AND CONCENTRATION AT SELECTED OBSERVATION POINTS

PUMPING PERIOD ND. 1

i

STEADY-STATE SOLUTION

OBS.WELL NO. $X \quad 2$

N PRESSURE (LB/FT*\#2) CONC. (MG/L) TDS (MG/L)

TIME (YEARS)

1

74

\begin{tabular}{|c|c|c|c|c|}
\hline $\begin{array}{l}0 \\
1 \\
2 \\
3 \\
4 \\
5 \\
6 \\
7 \\
8 \\
9 \\
10 \\
11 \\
12 \\
13 \\
14 \\
15 \\
16 \\
17 \\
18 \\
19 \\
20 \\
21 \\
22 \\
23 \\
24 \\
25 \\
26 \\
27 \\
28 \\
29 \\
30 \\
31 \\
32 \\
33 \\
34 \\
35 \\
36 \\
37 \\
38 \\
39 \\
40 \\
41\end{array}$ & $\begin{array}{r}0.0 \\
12821.0 \\
12825.2 \\
12825.7 \\
12826.3 \\
12827.8 \\
12827.8 \\
12827.9 \\
12827.9 \\
12827.9 \\
12827.9 \\
12828.1 \\
12827.7 \\
12829.3 \\
12829.3 \\
12827.4 \\
12827.4 \\
12827.2 \\
12828.5 \\
12829.0 \\
12829.0 \\
12829.5 \\
12829.5 \\
12827.4 \\
12827.4 \\
12827.4 \\
12827.2 \\
12827.2 \\
12827.2 \\
12827.9 \\
12827.9 \\
12828.2 \\
12828.2 \\
12828.2 \\
12826.8 \\
12826.8 \\
12826.8 \\
12828.0 \\
12828.0 \\
12828.0 \\
12828.0 \\
12829.1\end{array}$ & $\begin{array}{l}10.0 \\
10.0 \\
10.0 \\
10.0 \\
10.0 \\
10.3 \\
11.4 \\
13.6 \\
17.4 \\
21.8 \\
28.5 \\
37.0 \\
46.4 \\
57.2 \\
66.2 \\
74.7 \\
80.5 \\
97.5 \\
108.5 \\
115.5 \\
133.6 \\
139.4 \\
155.9 \\
147.9 \\
152.1 \\
180.7 \\
200.0 \\
201.1 \\
213.8 \\
231.9 \\
248.0 \\
238.9 \\
256.3 \\
275.1 \\
280.2 \\
278.2 \\
274.1 \\
297.8 \\
310.2 \\
309.0 \\
339.2 \\
356.0\end{array}$ & $\begin{array}{r}11750.0 \\
10623.1 \\
9589.7 \\
10883.2 \\
9930.0 \\
9590.4 \\
10155.3 \\
9756.9 \\
9240.1 \\
10335.0 \\
10244.6 \\
9789.1 \\
9839.2 \\
9446.7 \\
10047.3 \\
9241.7 \\
9904.2 \\
9458.6 \\
9306.3 \\
9185.0 \\
9080.0 \\
9111.4 \\
8903.1 \\
9098.9 \\
9566.0 \\
9222.6 \\
9218.4 \\
9149.8 \\
8792.0 \\
8636.0 \\
8616.8 \\
9132.1 \\
8849.4 \\
8618.6 \\
8831.9 \\
9347.3 \\
9406.1 \\
9426.6 \\
9497.1 \\
9902.6 \\
9392.2 \\
8905.4\end{array}$ & $\begin{array}{l}0.000 \\
0.244 \\
0.488 \\
0.732 \\
0.976 \\
1.220 \\
1.463 \\
1.707 \\
1.951 \\
2.195 \\
2.439 \\
2.683 \\
2.927 \\
3.171 \\
3.415 \\
3.659 \\
3.902 \\
4.146 \\
4.390 \\
4.634 \\
4.878 \\
5.122 \\
5.366 \\
5.610 \\
5.854 \\
6.098 \\
6.341 \\
6.585 \\
6.829 \\
7.073 \\
7.317 \\
7.561 \\
7.805 \\
8.049 \\
8.293 \\
8.537 \\
8.780 \\
9.024 \\
9.268 \\
9.512 \\
9.756 \\
10.000\end{array}$ \\
\hline
\end{tabular}




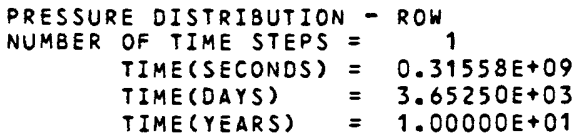

\begin{tabular}{|c|c|c|c|c|c|c|c|c|c|}
\hline 0.0000 & 0.0000 & 0.0000 & 0.0000 & 0.0000 & 0.0000 & 0.0000 & 0.0000 & 0.0000 & 0.0000 \\
\hline 0.0000 & 0.0000 & & & & & & & & \\
\hline 0.0000 & 649.9996 & 599.9997 & 499.9999 & 400.0000 & 300.0001 & 200.0001 & 100.0002 & 0.0006 & 0.0001 \\
\hline 0.0001 & 0.0000 & & & & & 1 & & & \\
\hline 0.0000 & 6821.9500 & 6789.1432 & 6728.8278 & 6658.4667 & 6585.2778 & 6513.8730 & 6448.9856 & 6400.5963 & 6396.5393 \\
\hline 6409.9999 & 0.0000 & & & & & & & & \\
\hline 0.0000 & 13027.2510 & 13006.4717 & 12968.8480 & 12922.1782 & 12873.5568 & 12829.0524 & 12796.2058 & 12782.2901 & 12794.2695 \\
\hline 2819.9999 & 0.0000 & & & & & & & & \\
\hline 0.0000 & 19254.0165 & 19241.6942 & 19219.9270 & 19193.0369 & 19168.3022 & 19153.5298 & 19153.2745 & 19168.1763 & 19195.4638 \\
\hline 9229.9999 & 0.0000 & & & & & & & & \\
\hline 0.0000 & 25493.9469 & 25487.5349 & 25478.9805 & 25476.2633 & 25483.1227 & 25500.2442 & 25526.4975 & 25560.1024 & 25597.9893 \\
\hline 5639.9999 & 0.0000 & & & & & & & & \\
\hline 0.0000 & 0.0000 & 0.0000 & 0.0000 & 0.0000 & 0.0000 & 0.0000 & 0.0000 & 0.0000 & 0.0000 \\
\hline 0.0000 & 0.0000 & & & & & & & & \\
\hline
\end{tabular}

PRESSURE MAP

$\begin{array}{rrrrrrrrrrrrr}0 & 0 & 0 & 0 & 0 & 0 & 0 & 0 & 0 & 0 & 0 & 0 \\ 0 & 650 & 600 & 500 & 400 & 300 & 200 & 100 & 0 & 0 & 0 & 0 \\ 0 & 6822 & 6789 & 6729 & 6658 & 6585 & 6514 & 6449 & 6401 & 6397 & 6410 & 0 \\ 0 & 13027 & 13006 & 12969 & 12922 & 12874 & 12829 & 12796 & 12782 & 12794 & 12820 & 0 \\ 0 & 19254 & 19242 & 19220 & 19193 & 19168 & 19154 & 19153 & 19168 & 19195 & 19230 & 0 \\ 0 & 25494 & 25488 & 25479 & 25476 & 25483 & 25500 & 25526 & 25560 & 25598 & 25640 & 0\end{array}$

CUMUlative MASS BALANCE -- (INFT**3)

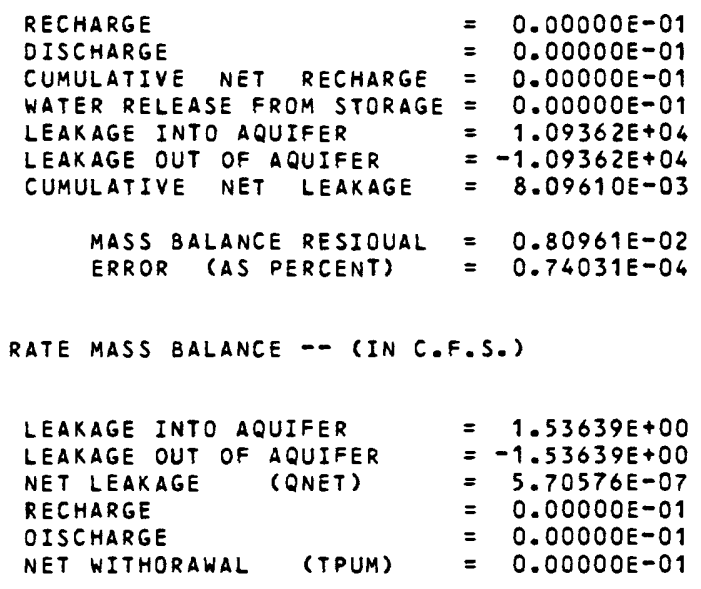


Appendix IV:

Program Listing

IMPLICIT DOUBLE PRECISION $(A-H, O-Z)$

COMMON /PRMJ/ NTIM,NPMP,NPNT,NITP,N,NX,NZ,NP,NREC,INT,NNX,NNZ,NUMO $1 B S, N M O V, I M O V, N P M A X, I T M A X, N Z C R I T, I P R N T, N P T F N D, N P N T M V, N P N T V L, N P N T D, N$ 2PNCHV,NPDELC, ICHK, NCONST

COMMON IPRMCI NODEID $(24,20), N P C E L L(24,20), N P O L D(24,20), L I M B O(500)$, 1 IXOBS (5),IZOBS (5)

COMMON /PRESS/ PERM $(24,20), P M R X(24,20,4), P I(24,20), P R(24,20), P C(24$ $1,20), P K(24,20), \operatorname{REC}(24,20), D E N S(24,20), G T E R M(24,20), V I S C(24,20), V P R$ $2 M(24,20), T M W L(5,50), T M O B S(50), T I M(100), A O P T(20), T I T L E(10), A N F C T R, X$ 3DEL, ZDEL , WIDTH, S, AREA, SUMT, RHO, PARAM, TEST,TOL, PINT,HMIN,PYR, VOL

COMMON ICHMAI PART $(4,6400), C O N C(24,20), T O S(24,20), V X(24,20), V Z(24$, $120)$, CONINT $(24,20)$, TDSINT $(24,20), C N R E C(24,20), T D S R E C(24,20), T M C N(5$, 250), TMTDS $(5,50)$, POROS, SUMTCH,BETA,TIMV,STORM, STORT, STORMI, STORTI,C 3MSIN, TDSIN, CMSOUT, TDSOUT,FLMIN,FLTIN,FLMOT,FLTOT, SUMIO,TDSIO, CELDI 4S,DLTRAT, CSTORM,CSTORT, DMOLEC

COMMON /CHMC/ SUMC $(24,20), V X B D Y(24,20), V Z B O Y(24,20), S U M T D S(24,20)$, 1 WTFCTR $(24,20)$, SUMWT $(24,20), P T Q(24,20)$, PTWT $(6400)$, ELEV $(24,20)$

TMSUM $=0.0$

CALL PARLOD

CALL GENPT

A 10

A 20

A 30

A 40

A 50

A 60

A 70

A 80

A 90

A 100

A 110

A 120

A 130

A 140

A 150

A 160

A 170

A 180

A 190

A 200

A 210

A 220

A 230

A 240

A 250

A 260

A 270

A 280

A 290

A 300

A 310

A 320

A 330

A 340

A 350

A 360

A 370

A 380

A 390

A 400

A 410

A 420

A 430

A 440

A 450

A 460

A 470

A 480

A 490

A 500

A 510

A 520

A 530 
IF (S.EQ.0.0.AND.ICHK.EQ.O.AND.(N.GT.1.OR.INT.GT.1)) GO TO 110

CALL ITERAT

IF (REMN.EQ.0.0.OR.N.EQ.NTIM.OR.IPCK.EQ.1) CALL OUTPT

CALL VELO

c

110 CALL MVPT

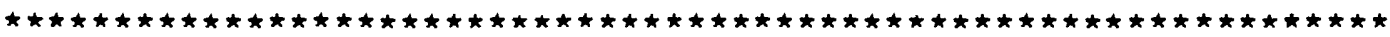

C

---STORE OBS. WELL DATA FOR TRANSIENT FLOW PROBLEMS---

IF $(S . E Q .0 .0)$ GO TO 130

IF (NUMOBS.LE.O) GO TO 130

$J=M O D(N, 5 O)$

IF $(J . E Q .0) \quad J=50$

TMOBS $(J)=S U M T$

DO $120 \quad I=1$, NUMOBS

$\operatorname{TMWL}(I, J)=\operatorname{PK}(I \times O B S(I), I Z O B S(I))$

$\operatorname{TMCN}(I, J)=\operatorname{CONC}(I X O B S(I), I Z O B S(I))$

c

120 CONTINUE

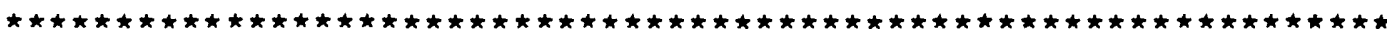

--OOUTPUT ROUTINES---

130 IF (REMN.EQ.0.0.OR.N.EQ.NTIM.OR.MOD(N,50).EQ.0.OR.IPCK.EQ.1) CALL 1CHMOT

IF (SUMT.GE.(PYR+TMSUM)) GO TO 150

140 CONTINUE

c

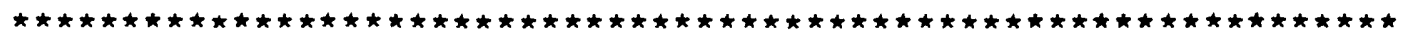

C --- SUMMARY OUTPUT---

150 CONTINUE

I PRNT $=1$

CALL CHMOT

160 CONTINUE

CALL OUTPT

C

ENDFILE(6)

IF (NPNCHV.EQ.O) GO TO 170

ENDFILE ( 7 )

170 CONTINUE

STOP

c

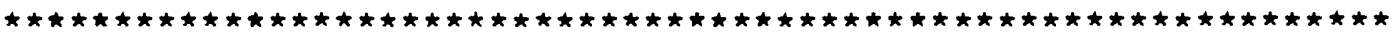

END

SUBROUTINE PARLOD

IMPLICIT DOUBLE PRECISION (A-H,O-Z)

INTEGER OVERRD

COMMON /PRMJ/ NTIM,NPMP,NPNT,NITP,N,NX,NZ,NP,NREC,INT,NNX,NNZ,NUMO

$1 B S, N M O V, I M O V, N P M A X, I T M A X, N Z C R I T, I P R N T, N P T P N D, N P N T M V, N P N T V L, N P N T D, N$

2PNCHV, NPDELC, ICHK, NCONST

COMMON /PRMC/ NODEID $(24,20), N P C E L L(24,20), N P O L D(24,20), L I M B O(500)$,

1 IXOBS (5), IZOBS (5)

COMMON IPRESS/ PERM $(24,20), P M R X(24,20,4), P I(24,20), P R(24,20), P C(24$

$1,20), P K(24,20), \operatorname{REC}(24,20), \operatorname{DENS}(24,20), G T E R M(24,20), V I S C(24,20), V P R$

$2 M(24,20), T M W L(5,50), T M O B S(50), T I M(100), A O P T(20), T I T L E(10), A N F C T R, X$

3DEL, ZDEL,WIDTH, S, AREA, SUMT, RHO,PARAM, TEST,TOL,PINT,HMIN,PYR, VOL

COMMON /OENVIS/ DEN1,DEN2,VIS1,VIS2

COMMON /CHMAI PART $(4,6400), C O N C(24,20), T D S(24,20), V \times(24,20), V 2(24$, 120), CONINT $(24,20), T D S I N T(24,20), C N R E C(24,20), T D S R E C(24,20), T M C N(5$, 250),TMTOS $(5,50)$, POROS, SUMTCH,BETA,TIMV,STORM, STORT,STORMI,STORTI,C $3 M S I N, T D S I N, C M S O U T, T D S O U T, F L M I N, F L T I N, F L M O T, F L T O T, S U M I O, T D S I O, C E L D I$ 4S,DLTRAT, CSTORM,CSTORT, DMOLEC

COMMON /BALM/ TOTLQ,TOTLQI,TPIN,TPOUT

COMMON /XINV/ DXINV,DIINV,ARINV,PORINV

A 540

A 550

A 560

A 570

A 580

A 590

A 600

A 610

A 620

A 630

A 640

A 650

A 660

A 670

A 680

A 690

A 700

A 710

A 720

A 730

A 740

A 750

A 760

A 770

A 780

A 790

A 800

A 810

A 820

A 830

A 840

A 850

A 860

A 870

A 880

A 890

A $900-$

B 10

B 20

B 30

B 40

$B 50$

B 60

B 70

B 80

B 90

B 100

B 110

B 120

B 130

B 140

B 150

B 160

B 170

B 180

S 190

B 200 
COMMON /CHMC/ SUMC $(24,20), V X B D Y(24,20), V Z B D Y(24,20)$, SUMTDS $(24,20)$, 1WTFCTR $(24,20)$, SUMWT $(24,20), P T Q(24,20), P T W T(6400), E L E V(24,20)$ COMMON /CNCHNG/ CNCHCK $(24,20), C T O L$ 


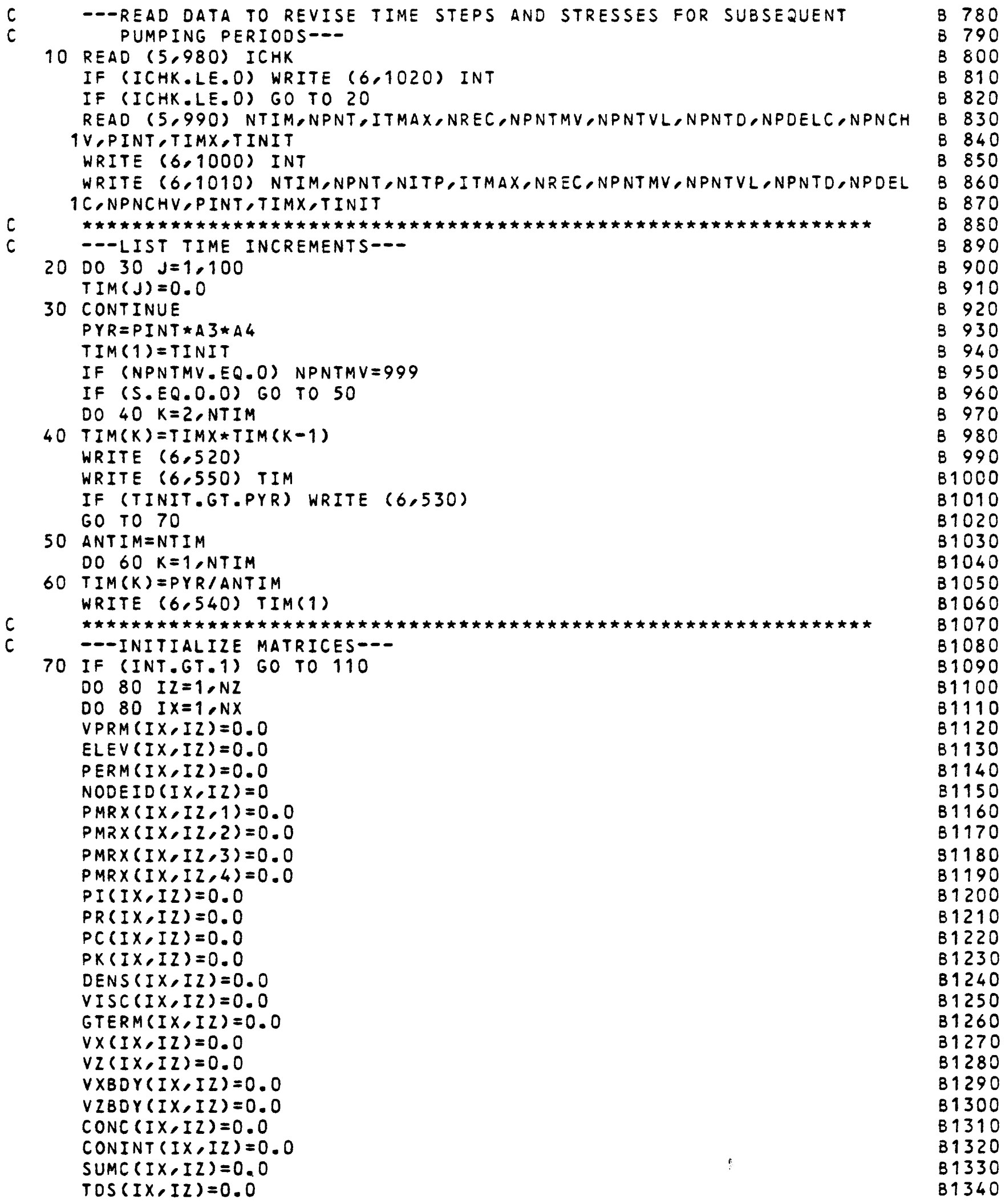




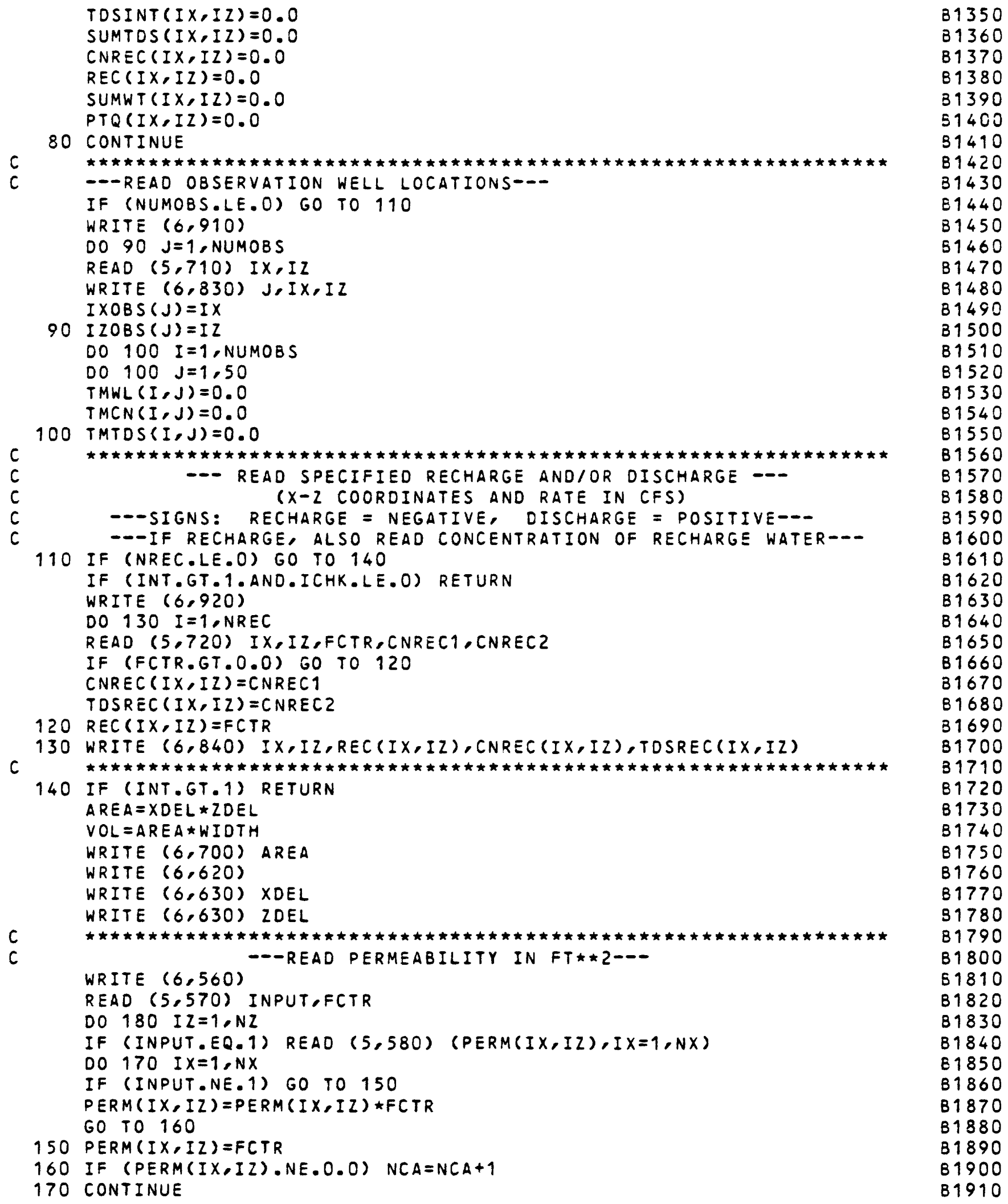


180 WRITE $(6,850)$ (PERM(IX,IZ),IX $=1, N X$ )

81920 


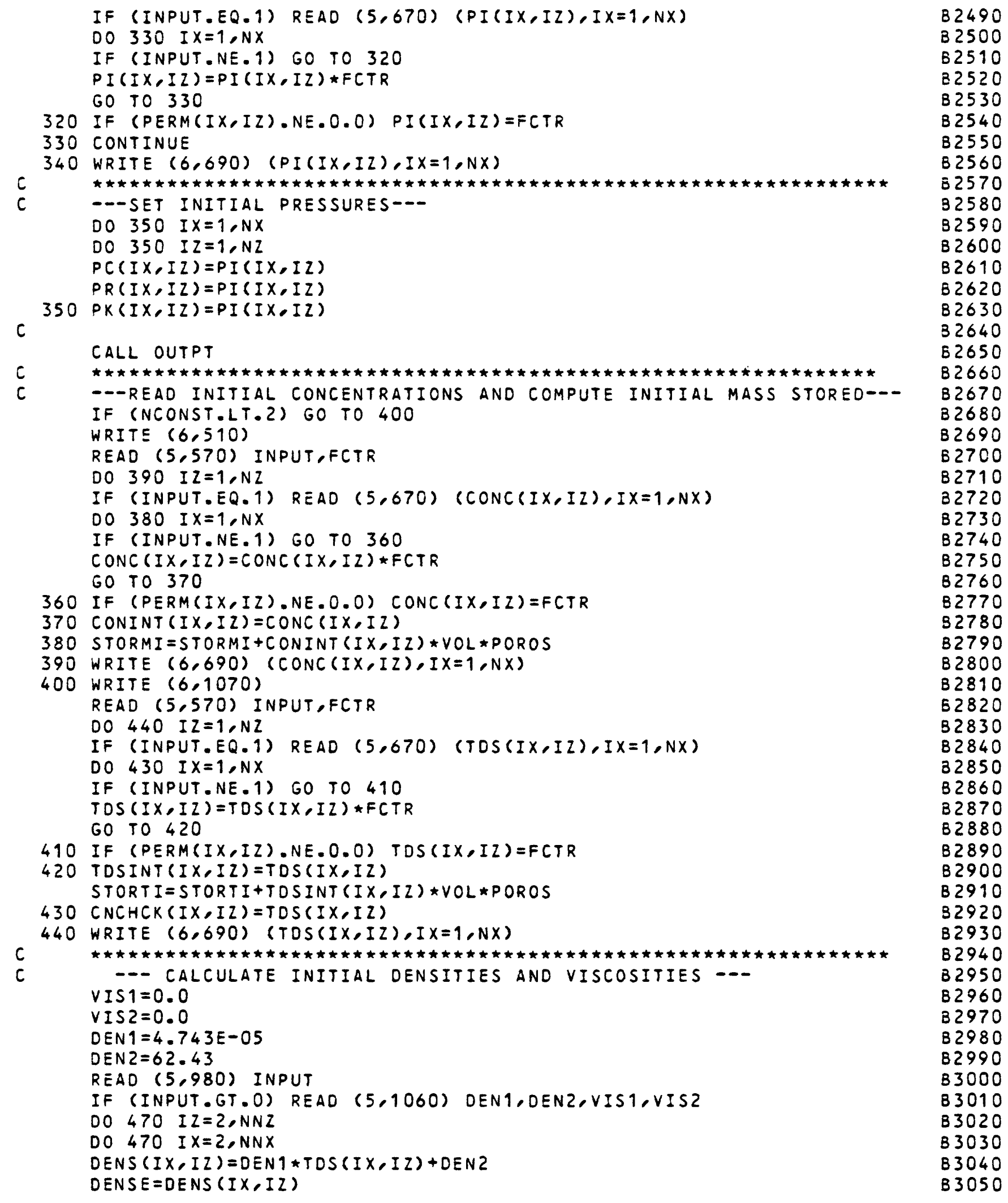


IF $(R E C(I X, I Z) \cdot L T, 0.0)$ DENSE = DEN 1*TDSREC (IX,IZ)+DEN 2

$R E C(I X, I Z)=(R E C(I X, I Z) \star D E N S E) / V O L$

IF (INPUT.GT.O) GO TO 460

IF (TOS (IX,IZ).GT.20000.) GO TO 450

$V I S C(I X, I Z)=3.45 E-11 * T D S(I X, I Z)+2.089 E-05$

GO TO 470

$450 V I S C(I X, I Z)=4.733 E-11 * \operatorname{TDS}(I X, I Z)+2.063 E-05$

GO TO 470

460 VISC $(I X, I Z)=V I S 1 * \operatorname{TOS}(I X, I Z)+V I S 2$

470 CONTINUE

WRITE $(6,1030)$

DO 480 IZ $=1, N Z$

480 WRITE $(6,1040)$ (DENS $(I X, I Z), I X=1, N X)$

WRITE $(6,1050)$

DO 490 IZ $=1, N Z$

WRITE $(6,850)$ (VISC (IX,IZ), IX $=1, N X)$

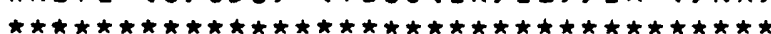

$B 3060$

$B 3070$

83080

$B 3090$

83100

83110

83120

83130

83140

B3150

83160

B 3170

B 3180

83190

B3200

B3210

B 3220

83230

B3240

B3250

B 3260

B 3270

B3280

B 3290

B 3300

B3310

B 3320

63330

83340

B 3350

83360

B 3370

B3380

B 3390

83400

63410

83420

B3430

83440

83450

B3460

B 3470

83480

B3490

B 3500

B 3510

83520

B3530

B3540

B3550

83560

B3570

B 3580

B3590

$B 3600$

83610

B3620 
720 FORMAT $(2 I 2,3610.2)$
730 FORMAT $(10 A 8)$
740 FORMAT $(1$ HO, $10 A 8)$
750 FORMAT $(20 I 4)$
760 FORMAT (1H1,77HU.S.G.S. METHOD-OF-CHARACTERISTICS MODEL FOR SOLUTE
1 TRANSPORT IN GROUND WATER)

770 FORMAT (1HO,21X,21HIN P U T

780 FORMAT (1HO,23X,16HGRID DESCRIPTORS/113X,3OHNX (NUMBER OF COLUM $1 \mathrm{NS})=, I 4 / 13 \mathrm{X}, 28 \mathrm{HNZ}$ (NUMBER OF ROWS) =,IS/13X,29HXOEL (XX 2-DISTANCE IN FEET) $=$,F9.3/13X,29HZDEL (Z-DISTANCE IN FEET) =,F9 3.3/13X, 29HWIDTH (Y-DISTANCE IN FEET) $=$,F9.3)

790 FORMAT (1H0,23X,16HTIME PARAMETERS/113X,4OHNTIM (MAX. NO. OF TI 1 ME STEPS) $\quad=. I 6 / 13 X, 40 H N P M P$ (NO. OF PUMPING PERIODS)

$2=, I 6 / 13 X, 39 H P I N T$ (PUMPING PERIOD IN YEARS) $=, F 11.3 / 13 X, 39$ 3 HTIMX (TIME INCREMENT MULTIPLIER) =,F10.2/13X,39HTINIT (INIT 4 IAL TIME STEP IN SEC.) =,F8.0)

800 FORMAT (1HO,14X,34HHYDROLOGIC AND CHEMICAL PARAMETERS//13X,1HS,7X, $129 H$ (SPECIFIC STORAGE) $=, 5 X, F 9.6 / 13 X, 28 H P O R O S$ (EFFECTIVE 2 POROSITY) $, 8 X, 3 H=$,F $8.2 / 13 X, 39 H B E T A$ (LONGITUDINAL DISPERSIVITY $3)=$,F $7.1 / 13 X, 31 H D L T R A T$ (RATIO OF TRANSVERSE TO/21X,3OH LONGITUD 4INAL OISPERSIVITY) $=$,F9.2/13X.39HANFCTR (RATIO OF $K-Z Z$ TO K-XX)

$5=$,F12.6/13X,28HDMOLEC (COEF. OF DIFFUSION),8X,3H=,1PE9.21 $613 X, 39 H N C O N S T$ (NUMBER OF CONSTITUENTS) = ,I2)

810 FORMAT $(7610.0)$

820 FORMAT $(8610.0)$

830 FORMAT $(1 \mathrm{H}, 16 X, I 2,5 X, I 2,4 X, I 2)$

840 FORMAT $(1 H, 7 X, 2 I 4,3 X, E 12,5,2(3 X, F 8.2))$

850 FORMAT (1H,1P10E10.2)

860 FORMAT $(I 2,2610.2)$

870 FORMAT (1H, 7X,I2,2(7X,F9.2))

880 FORMAT ( 1 HO,21X,20HEXECUTION PARAMETERS//13X,39HTOL (CONVERGENC $1 E$ CRITERIA - SIP) =,F9.7/13X.39HITMAX (MAX.NO.OF ITERATIONS - S $2 I P)=, I 4 / 13 X, 34 H C E L D I S$ (MAX.CELL DISTANCE PER MOVE/24X,28HOF PAR $3 T I C L E S-M .0 . C$. ) = IF8.3/13X.3OHNPMAX (MAX. NO. OF PARTICLES), $47 X, 2 H=, I 4 / 12 X, 32 H$ NPTPND (NO. PARTICLES PER NODE),6X,3H= ,I4/13X $5,33 H C T O L$ (MINIMUM CONC. CHANGE /21X,31HFOR PRESSURE RECALCUL GATION) $=, F 5.0)$

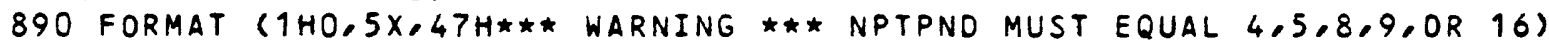
900 FORMAT (1HO,23X,15HPROGRAM OPTIONS/113X,3OHNPNT (TIME STEP INTER $1 \mathrm{VAL} F O R / 21 \mathrm{X}, 18 \mathrm{HCOMPLETE} \mathrm{PRINTOUT),7X,3H=,I4/13X,31 \textrm {HNPNTMV } \text { (MOVE }}$ 2INTERVAL FOR CHEM./21X,28HCONCENTRATION PRINTOUT) = ,I4/13X,29HN 3PNTVL (PRINT OPTION-VELOCITY $/ 21 X, 24 H O=N O: 1=F I R S T$ TIME STEP:/21X,1 $47 H 2=A L L$ TIME STEPS),8X,3H= I4/13X,31HNPNTD (PRINT OPTION-DISP.C 5OEF. $/ 21 \mathrm{X}, 24 H 0=N O ; 1=F I R S T$ TIME STEP:/21X,17H2=ALL TIME STEPS),8X,3 $6 H=$, I $4 / 13 X, 32 H N U M O B S$ (NO. OF OBSERVATION WELLS/21X,28HFOR HYDROGR $7 A P H$ PRINTOUT) $=, I 4 / 13 X, 35 H N R E C$ (NO. OF RECHARGE CELLS) =, I5 $8 / 13 X, 24 H N C O D E S$ (FOR NODE IDENT.) ,9X,2H=, I5/13X,32HNPNCHV (WRITE V 9ELOCITIES-UNIT 7), $1 \mathrm{X}, 2 \mathrm{H}=$, I5/13X,36HNPDELC (PRINT OPT.-CONC. CHANG $S E)=(I 4)$

910 FORMAT (1HO,10X,29HLOCATION OF OBSERVATION WELLS//17X,3HNO.,5X,1HX $1,5 X, 1 \mathrm{HZ} /)$

920 FORMAT (1H0,10X,28HLOCATION OF RECHARGE CELLS//11X,37HX Z RA 1TE(IN (FS) CONC. TOS CONC.)

930 FORMAT (1HO,5X,37HNO. OF NODE IDENT. CODES SPECIFIED =,I2)

940 FORMAT (1HO,10X,41HTHE FOLLOWING ASSIGNMENTS HAVE BEEN MADE:/5X,40 1 HCODE NO. TOS CONC. CONC. 950 FORMAT (1H,5X,61H*** WARNING $\star \star \star$ PERM.EQ.0.O AND NODEID.GT.O.O

33630

33640

$B 3650$

B3660

E 3670

B3680

B 3690

B3700

B3710

83720

B3730

B3740

63750

83760

B3770

53780

53790

B3800

B3810

B 3820

53830

B3840

83850

B3860

83870

83880

B 3890

B 3900

B3910

83920

83930

B3940

B3950

B3960

83970

B3980

$B 3990$

$B 4000$

B4010

B4020

B4030

84040

$B 4050$

B4060

34070

$B 4080$

34090

B4100

B 4110

B4120

84130

34140

34150

B4160

B 4170

B4180

B 4190 
1 AT NODE IX $=, I 4,6 \mathrm{H}, I Z=, I 4)$

84200

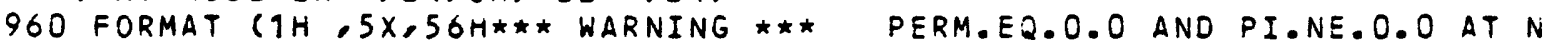
1OOE IX $=, I 4,6 \mathrm{H}, I Z=, I 4)$

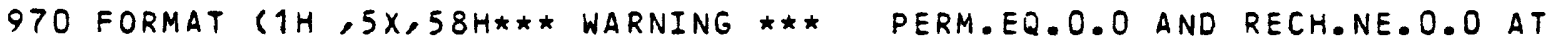

$B 4210$

$B 4220$

1 NODE IX $=, I 4,6 \mathrm{H}, I Z=, I 4)$

980 FORMAT (II)

990 FORMAT $(9 I 4,365.0)$

1000 FORMAT ( 1 H1,5X,25HSTART PUMPING PERIOD NO, I $2 / / 2 X, 75 H T H E$ FOLLOWIN $1 G$ TIME STEP, PUMPAGE, AND PRINT PARAMETERS HAVE BEEN REDEFINED: /)

1010 FORMAT (1H0,14X,9HNTIM =,I4/15X,9HNPNT =,I4/15X,9HNITP =, 1I4/15X,9HITMAX $=, I 4 / 15 X, 9 H N R E C=, I 4 / 15 X, 9 H N P N T M V=, I 4 / 15 X, 9 H$ 2NPNTVL $=.14 / 15 \mathrm{X}, 9 \mathrm{HNPNTO}=.14 / 15 \mathrm{X}, 9 \mathrm{HNPDELC}=, I 4 / 15 \mathrm{X}, 9 \mathrm{HNPNCHV}=$

$3, I 4 / 15 X, 9 H P I N T=, F 10.3 / 15 X, 9 H T I M X=, F 10.3 / 15 X, 9 H T I N I T=, F 1$ $40.3 / 1$

1020 FORMAT (1H1,5X,25HSTART PUMPING PERIOD NO. II2//2X,23HNO PARAMETER IS REDEFINED/)

1030 FORMAT ( 1 HO, 28HINITIAL DENSITIES (LB/FT**3) 1 )

1040 FORMAT (2OF6.2)

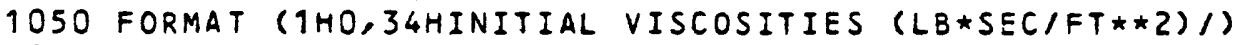

1060 FORMAT $(4610.3)$

1070 FORMAT ( 1 HO, 44HINITIAL TOS MAP - DENSITY-CONTROLLING SOLUTE/)

END

SUBROUTINE ITERAT

IMPLICIT DOUBLE PRECISION $(A-H, O-Z)$

COMMON /PRMJ/ NTIM,NPMP, NPNT, NITP, N, NX,NZ,NP,NREC,INT, NNX, NNZ, NUMO

1BS, NMOV, IMOV, NPMAX, ITMAX, NZCRIT, IPRNT, NPTPND, NPNTMV , NPNTVL , NPNTD,N

2PNCHV, NPDELC, ICHK, NCONST

COMMON /PRMC/ NODEID $(24,20)$,NPCELL $(24,20), N P O L D(24,20), L I M B O(500)$, 1 IXOBS (5), IZOBS (5)

COMMON /PRESSI PERM $(24,20)$, PMRX $(24,20,4), P I(24,20), P R(24,20), P C(24$ $1,20), P K(24,20), \operatorname{REC}(24,20)$, DENS $(24,20)$, GTERM $(24,20), V I S C(24,20), V P R$ $2 M(24,20)$, TMWL $(5,50)$, TMOBS $(50), T I M(100), A O P T(20), T I T L E(10)$, ANFCTR, X 3DEL, ZDEL, WIOTH, S, AREA, SUMT, RHO,PARAM, TEST, TOL, PINT, HMIN, PYR , VOL

COMMON /CHMA/ PART $(4,6400), C O N C(24,20), T D S(24,20), V \times(24,20), V 2(24$, 120), CONINT $(24,20), \operatorname{TDSINT}(24,20), C N R E C(24,20), \operatorname{TDSREC}(24,20), \operatorname{TMCN}(5$, 250), TMTDS (5, 50), POROS, SUMTCH, BETA, TIMV, STORM, STORT, STORMI, STORTI, C 3MSIN, TDSIN, CMSOUT, TOSOUT, FLMIN, FLTIN, FLMOT, FLTOT, SUMIO, TDSIO, CELDI 4S,DLTRAT, CSTORM, CSTORT, DMOLEC

COMMON /CHMC/ SUMC $(24,20), V X B D Y(24,20), \operatorname{VYBOY}(24,20)$, SUMTOS $(24,20)$,

IWTFCTR $(24,20)$, SUMWT $(24,20)$, PTQ $(24,20)$, PTWT $(6400)$, ELEV $(24,20)$

COMMON /BALM/ TOTLQ,TOTLQI,TPIN,TPOUT

COMMON /XINV/ DXINV, DZINV,ARINV,PORINV

COMMON IDENVIS/ DEN1,DEN2,VIS1,VIS2

COMMON /CNCHNG/ CNCHCK $(24,20)$, CTOL

DIMENSION DEL $(24,20)$, ETA $(24,20), V(24,20), X I(24,20)$, IORDER(21),

1 RHOP(20), TEMP(20), TEST3(201)

DATA IORDER/1,2,3,4,5,1,2,3,4,5,11*1/

HMAX $=1.0$

DO $30 \quad I X=1, N X$

DO $30 \quad I Z=1, N Z$

IF $(P E R M(I X, I Z) . E Q .0 .0)$ GO TO 30

CNCHCK $(I X, I Z)=T D S(I X, I Z)$

--- REASSIGN DENSITIES AND VISCOSITIES ---

DTEMP $=$ DENS $(I X, I Z)$

DENS $(I X, I Z)=D E N I * T D S(I X, I Z)+D E N Z$

IF (REC (IX,IZ).GT.0.0) REC (IX,IZ) $=R E C(I X, I Z) \star D E N S(I X, I Z) /$ OTEMP

IF (VIS1.NE.0.0) GO TO 20

34230

64240

34250

$B 4260$

84270

84280

84290

B4300

84310

84320

84330

34340

84350

34360

34370

B4380

64390

64400

B4410-

C 10

c 20

c 30

C 40

C 50

C 60

c 70

c 80

c 90

C 100

C 110

C 120

c 130

C 140

c 150

C 160

c 170

C 180

c 190

c 200

C 210

c 220

C 230

C 240

C 250

C 260

c 270

C 280

c 290

c 300

c 310

c 320

c 330

c 340

C 350 
IF (TOS (IX,IZ).GT.20000) GO TO 10

$\operatorname{VISC}(I X, I Z)=3.45 E-11 * \operatorname{TOS}(I X, I Z)+2.089 E-05$

c 370

GO TO 30

$10 V I S C(I X, I Z)=4.733 E-11 * \operatorname{TDS}(I X, I I)+2.063 E-05$

c 380 GO TO 30

$20 V I S C(I X, I Z)=V I S 1 * \operatorname{TOS}(I X, I I)+V I S 2$

30 CONTINUE

0080 I $Z=2, N N Z$

DO 80 IX $=2, \mathrm{NNX}$

IF (PERM (IX,IZ).EQ.0.0) GO TO 80

$F F 1=P E R M(I X, I Z) / V I S C(I X, I Z)$

$F Y=F F I * D E N S(I X, I Z)$

IF $(P E R M(I X+1, I Z), E Q .0 .0)$ GO TO 40

$F F 2=P E R M(I X+1, I Z) / V I S C(I X+1, I Z)$

c 390

$F Z=F F 2 \star D E N S(I X+1, I Z)$

C 400

C 410

C 420

C 430

c 440

C 450

C 460

C 470

C 480

C 490

GO TO 50

C 500

C 510

$40 \quad F F 2=0.0$

$F 2=0.0$

50 IF (PERM $(I X, I Z+1), E Q .0 .0)$ GO TO 60

c 520

C 530

$F F 3=P E R M(I X, I Z+1) / V I S C(I X, I Z+1)$

c 540

$F 3=F F 3 \star D E N S(I X, I Z+1)$

GO TO 70

C 550

c 560

C 570

C 580

60 FF $3=0.0$

$F 3=0.0$

$70 \operatorname{PMRX}(I X, I Z, 1)=2.0 * F 1 * F 2 /((F 1+F 2) * X D E L)$

C 590

$P M R X(I X, I Z, 2)=2.0 * F 9 * F 3 /((F 1+F 3) * Z D E L)$

c 600

$P M R X(I X, I Z, 2)=P M R X(I X, I Z, 2) \star A N F C T R$

$P M R X(I X, I 2,3)=2.0 * F F 1 \star F F 2 /(F F 1+F F 2)$

$P M R X(I X, I I, 4)=2.0 \star F F 1 \star F F 3 /(F F 1+F F 3)$

c 610

C 620

C 630

PMRX $(I X, I Z, 4)=P M R X(I X, I Z, 4) \star A N F C T R$

DENS $1=(D E N S(I X, I Z+1)+D E N S(I X, I Z)) \star 0.500$

C 640

c 650

C 660

DENS $Z=(D E N S(I X, I Z)+D E N S(I X, I Z-1)) \star 0.500$

GTERM $(I X, I Z)=P M R X(I X, I Z, 2) \star D E N S 1-P M R X(I X, I Z-1,2) \star D E N S Z$

C 670

c 680

C

80 CONTINUE

C 690

c 700

COMPUTE AND PRINT ITERATION PARAMETERS

c 710

c 720

$P Q I N=0.0$

c 730

PQOUT $=0.0$

c 740

KOUNT $=-1$

DO $90 \quad I=1, N X$

c 750

$D O 90 \mathrm{~J}=1, N Z$

c 760

$P R(I, J)=P K(I, J)$

c 770

C 780

90 CONTINUE

IF (INT.NE.1) GO TO 120

c 790

C 800

C 810

---INITIALIZE ORDER OF ITERATION PARAMETERS

C 820

C 830

INO1 $=\mathrm{NX}-1$

C 840

JNOI $=N Z-1$

C 850

$I 2=I N 01-1$

C 860

$\mathrm{J} Z=\mathrm{JN} 01-1$

C 870

$L 2=N I T P / 2$

C 880

$P L 2=L 2-1$

C 890

COMPUTE MAXIMUM PARAMETER FOR PROBLEM

c 900

c 910

C 920 


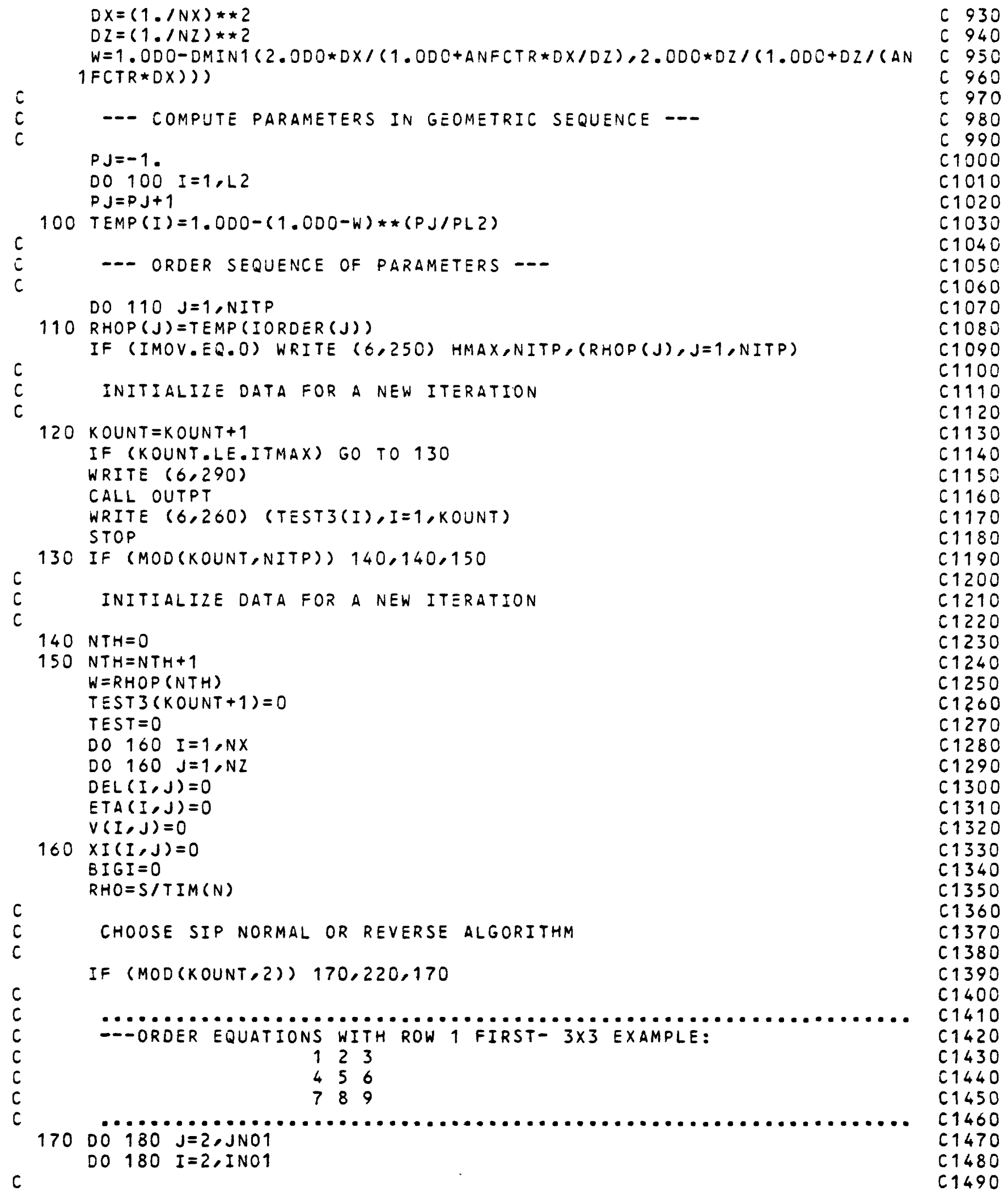


c

$c$

c

$c$

$c$

c

c

c
--- SKIP COMPUTATIONS IF NODE IS OUTSIDE AQUIFER BOUNDRY--IF (PERM (I,J).EQ.O.) GO TO 180

--- COMPUTE COEFFICIENTS---

$D=P M R \times(I-1, J, 1) / X D E L$

$F=P M R X(I, J, 1) / X D E L$

$B=P M R X(I, J-1,2) / Z D E L$

$H=P M R X(I, J, 2) / Z D E L$

$C H=D E L(I, J-1) * B /(1 .+W * D E L(I, J-1))$

$G H=E T A(I-1, J) * D /(1,+W * E T A(I-1, J))$

--SIP 'NORMAL・ ALGORITHM ---

---FOWARD SUBSTITUTE, COMPUTING INTERMEDIATE VECTOR V---

$E=-B-D-F-H-R H O-V P R M(I, J)$

$B H=B-W \star C H$

$D H=D-W \star G H$

$E H=E+W *(C H+G H)$

$\mathrm{FH}=\mathrm{F}-W \star \mathrm{CH}$

$H H=H-W * G H$

$A L F A=B H$

$B E D A=D H$

GAMA $=E H-A L F A \star E T A(I, J-1)-B E D A \star D E L(I-1, J)$

$D E L(I, J)=F H / G A M A$

$E T A(I, J)=H H / G A M A$

$Q L=-V P R M(I, J) \star(P I(I, J)+D E N S(I, J) * E L E V(I, J))$

$R E S=-O \star P K(I-1, J)-F \star P K(I+1, J)-H \star P K(I, J+1)-B \star P K(I, J-1)-E \star P K(I, J)-R H O$

$1 * P R(I, J)+Q L+R E C(I, J)+G T E R M(I, J)$

$V(I, J)=(H M A X \star R E S-A L F A \star V(I, J-1)-B E D A \star V(I-1, J)) / G A M A$

c

C

c

C

190 CONTINUE

- BACK SUBSTITUTE FOR VECTOR XI ---

DO $190 \mathrm{~J}=1, \mathrm{~J} 2$

$\mathrm{J} Z=\mathrm{NZ}-\mathrm{J}$

DO $190 \quad I=1, I 2$

I $3=N X-I$

IF $(P E R M(I 3, J 3), E Q .0$.$) GO TO 190$

$X I(I 3, J 3)=V(I 3, J 3)-D E L(I 3, J 3) * X I(I 3+1, J 3)-E T A(I 3, J 3) * X I(I 3, J 3+1)$

--- COMPARE MAGNITUDE OF CHANGE WITH CLOSURE CRITERION---

$T C H K=D A B S(X I(I 3, J 3))$

IF (TCHK.GT.BIGI) BIGI $=$ TCHK

$P K(I 3, J 3)=P K(I 3, J 3)+X I(I 3, J 3)$

200 IF (BIGI.GT.TOL) TEST $=1$

TEST $3($ KOUNT +1) $=B I G I$

IF (TEST.EQ.1.) GO TO 120

DO 210 IZ $=1, N Z$

DO 210 IX $=1, N X$

IF (PERM $(I X, I Z), E Q .0 .0)$ GO TO 210

$P T Q(I X, I Z)=R E C(I X, I Z)$

IF (REC (IX,IZ).LT.0.O) $P Q I N=P Q I N+R E C(I X, I Z) * V O L$

IF (REC $(I X, I Z) . G T .0 .0)$ PQOUT $=P Q O U T+R E C(I X, I Z) \star V O L$

C
C1500

C1510

C 1520

C1530

C1540

C1550

C1560

C1570

C1580

C1590

C1600

C1610

C1620

C1630

C1640

C1650

C1660

C1670

C1680

C1690

C1700

C1710

C1720

C1730

C1740

C1750

C1760

C1770

C1780

C 1790

C1800

C1810

C1820

C1830

C 1840

C1850

C1860

C1870

C1880

C 1890

C1900

C 1910

C1920

C1930

C1940

C1950

C1960

C 1970

C1980

C1990

C 2000

C 2010

C 2020

C2030

C 2040

C 2050

C2060 
IF (VPRM(IX,IZ).EQ.0.0) GO TO 210

C2070

DELQ $=V P R M(I X, I Z) \star(P I(I X, I Z)-P K(I X, I Z)+D E N S(I X, I Z) \star E L E V(I X, I Z))$

C2080

$P T Q(I X, I Z)=P T Q(I X, I Z)-D E L Q$

IF (DELQ.GT.0.0) TOTLQI=TOTLQI+DELQ*TIM(N)

C2090

IF (DELQ.LT.0.O) TOTLQ $=$ TOTLQ+DELQ*TIM(N)

C2100

C2110

210 CONTINUE

$T P I N=P Q I N \star T I M(N)+T P I N$

C2120

TPOUT $=$ PQOUT $* T I M(N)+T P O U T$

C2130

C2140

C2150

WRITE $(6,270) \mathrm{N}$

C2160

WRITE $(6,280)$ KOUNT

C2170

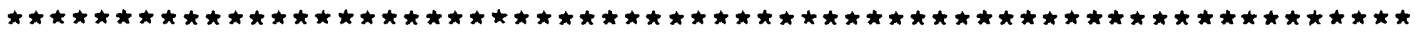

C2180

RETURN

C2190

$C 2200$

C2210

C2220

..........................................

---ORDER EQUATIONS WITH THE LAST ROW FIRST- $3 \times 3$ EXAMPLE:

C2230

789

C2240

C2250

456

C2260

123

C2270

C2280

C2290

C2300

$\mathrm{J}=\mathrm{NZ}-\mathrm{J} \mathrm{J}$

DO $230 \quad I=2$, INO1

C2310

C2320

-- SKIP COMPUTATIONS IF NODE IS OUTSIDE OF AQUIFER BOUNDRY--IF (PERM $(I, J) . E Q .0$.$) GO TO 230$

C2330

C2340

C2350

C2360

C2370

$D=P M R \times(I-1, J, 1) / X D E L$

C 2380

$F=P M R X(I, J, 1) / X D E L$

$8=P M R X(I, J-1,2) / Z D E L$

C2390

$H=P M R X(I, J, 2) / Z O E L$

C2400

C2410

C2420

--- SIP "REVERSE" ALGORITHM---

- FOWARD SUBSTITUTE, COMPUTING INTERMEDIATE VECTOR V-.-

C2430

C2440

$E=-B-D-F-H-R H O-V P R M(I, J)$

$C H=D E L(I, J+1) \star H /(1,+W \star D E L(I, J+1))$

C2450

C2460

$G H=E T A(I-1, J) * D /(1 .+W * E T A(I-1, J))$

C2470

$B H=H-W \star C H$

$C 2480$

$D H=D-W \star G H$

C2490

$E H=E+W \star(C H+G H)$

$C 2500$

$F H=F-W * C H$

C2510

$H H=B-W \star G H$

C2520

$A L F A=B H$

C2530

$B E D A=D H$

C2540

GAMA $=E H-A L F A \star E T A(I, J+1)-B E D A \star D E L(I-1, J)$

C2550

$D E L(I, J)=F H / G A M A$

C2560

$E T A(I, J)=H H / G A M A$

C2570

$Q L=-V P R M(I, J) *(P I(I, J)+D E N S(I, J) \star E L E V(I, J))$

C2580

$R E S=-D \star P K(I-1, J)-F \star P K(I+1, J)-H \star P K(I, J+1)-B \star P K(I, J-1)-E \star P K(I, J)-R H O$

C2590

$1 \star P R(I, J)+Q L+R E C(I, J)+G T E R M(I, J)$

$V(I, J)=(H M A X \star R E S-A L F A * V(I, J+1)-B E D A \star V(I-1, J)) / G A M A$

C2600

C2610

c

230 CONTINUE

C2620

C2630 
C2670

$X I(I, J)=V(I, J)-D E L(I, J) \star X I(I+1, J)-E T A(I, J) \star X I(I, J-1)$

C2680

$c$

\section{--- COMPARE MAGNITUDE OF CHANGE WITH CLOSURE CRITERION ---}

c

$$
240 \text { CONTINUE }
$$$$
T C H K=D A B S(X I(I, J))
$$$$
\text { IF (TCHK.GT.BIGI) BIGI }=T C H K
$$$$
P K(I, J)=P K(I, J)+X I(I, J)
$$

C

250 FORMAT $(1 X, 6$ HBETA $=, F 4.2,1,1 \mathrm{X}, I 3,23 \mathrm{H}$ ITERATIONS PARAMETERS:,66/1X, 16E15.6))

260 FORMAT (1X,39HMAXIMUM HEAD CHANGE FOR EACH ITERATION:, $20(1,1 \mathrm{X}, 106 \mathrm{~F}$ $112.5))$ )

270 FORMAT (1HO//3X,4HN $=, 1$ I 4 )

280 FORMAT ( $1 \mathrm{X}, 22$ HNUMBER OF ITERATIONS $=$, I3)

290 FORMAT (1HO,5X,53H* E* EXECUTION TERMINATED -- MAX \# ITERATIONS EXC 1EEDED/26X, 21HFINAL OUTPUT FOLLOWS: )

END

SUBROUTINE GENPT

IMPLICIT DOUBLE PRECISION $(A-H, O-Z)$

INTEGER $\star 2 P T I D$

COMMON /PRMJ/ NTIM,NPMP, NPNT,NITP,N,NX,NZ,NP,NREC,INT,NNX,NNZ,NUMO $18 S, N M O V, I M O V, N P M A X, I T M A X, N Z C R I T, I P R N T, N P T P N D, N P N T M V, N P N T V L, N P N T D, N$ 2PNCHV, NPDELC, ICHK, NCONST

COMMON /PRMC/ NODEID $(24,20)$, NPCELL $(24,20)$, NPOLD $(24,20)$, LIMBO(500), 1 IXOBS (5), IZOBS (5)

COMMON /PRESS/ PERM $(24,20)$, PMRX $(24,20,4), P I(24,20), P R(24,20), P C(24$ $1,20), P K(24,20), \operatorname{REC}(24,20), D E N S(24,20), \operatorname{GTERM}(24,20), \operatorname{VISC}(24,20), V P R$ $2 M(24,20)$, TMWL $(5,50), T M O B S(50)$, TIM $(100), A O P T(20), T I T L E(10), A N F C T R, X$ 3 DEL, ZDEL, WIDTH, S, AREA, SUMT, RHO, PARAM, TEST, TOL, PINT, HMIN, PYR , VOL

COMMON /CHMA/ PART $(4,6400), C O N C(24,20), T D S(24,20), V X(24,20), V Z(24$, 120), CONINT $(24,20)$, TDSINT $(24,20), C N R E C(24,20), \operatorname{TOSREC}(24,20), \operatorname{TMCN}(5$, 250), TMTDS $(5,50)$, POROS, SUMTCH,BETA, TIMV, STORM, STORT, STORMI, STORTI, C 3MSIN, TOSIN, CMSOUT, TDSOUT, FLMIN, FLTIN, FLMOT, FLTOT, SUMIO, TDSIO, CELDI 4 S,DLTRAT, CSTORM, CSTORT, DMOLEC

COMMON /CHMC/ SUMC $(24,20), V X B D Y(24,20), \operatorname{VYBOY}(24,20), \operatorname{SUMTOS}(24,20)$, IWTFCTR $(24,20)$, SUMWT $(24,20)$, PTQ $(24,20)$, PTWT $(6400), E L E V(24,20)$ COMMON /CHMP/ PTID (6400) DIMENSION RPT (16), RNT(16), RP(16), RN(16), IPT (16), RPT2(16), RNT $12(16), \operatorname{RP2}(16), \operatorname{RN} 2(16)$
C2690

$C 2700$

C2710

C2720

C2730

C 2740

C 2750

C 2760

C 2770

C2780

C 2790

$C 2800$

C2810

C2820

C 2830

C 2840

C2850

C2860

C2870-

D 10

D 20

D 30

D 40

D 50

D 60

D 70

D 80

D 90

D 100

D 110

D 120

D 130

D 140

D 150

D 160

D 170

D 180

D 190

D 200

D 210

D 220

D 230

D 240

D 250

D 260

D 270

D 280

D 290

D 300

D 310

D 320

D 330 


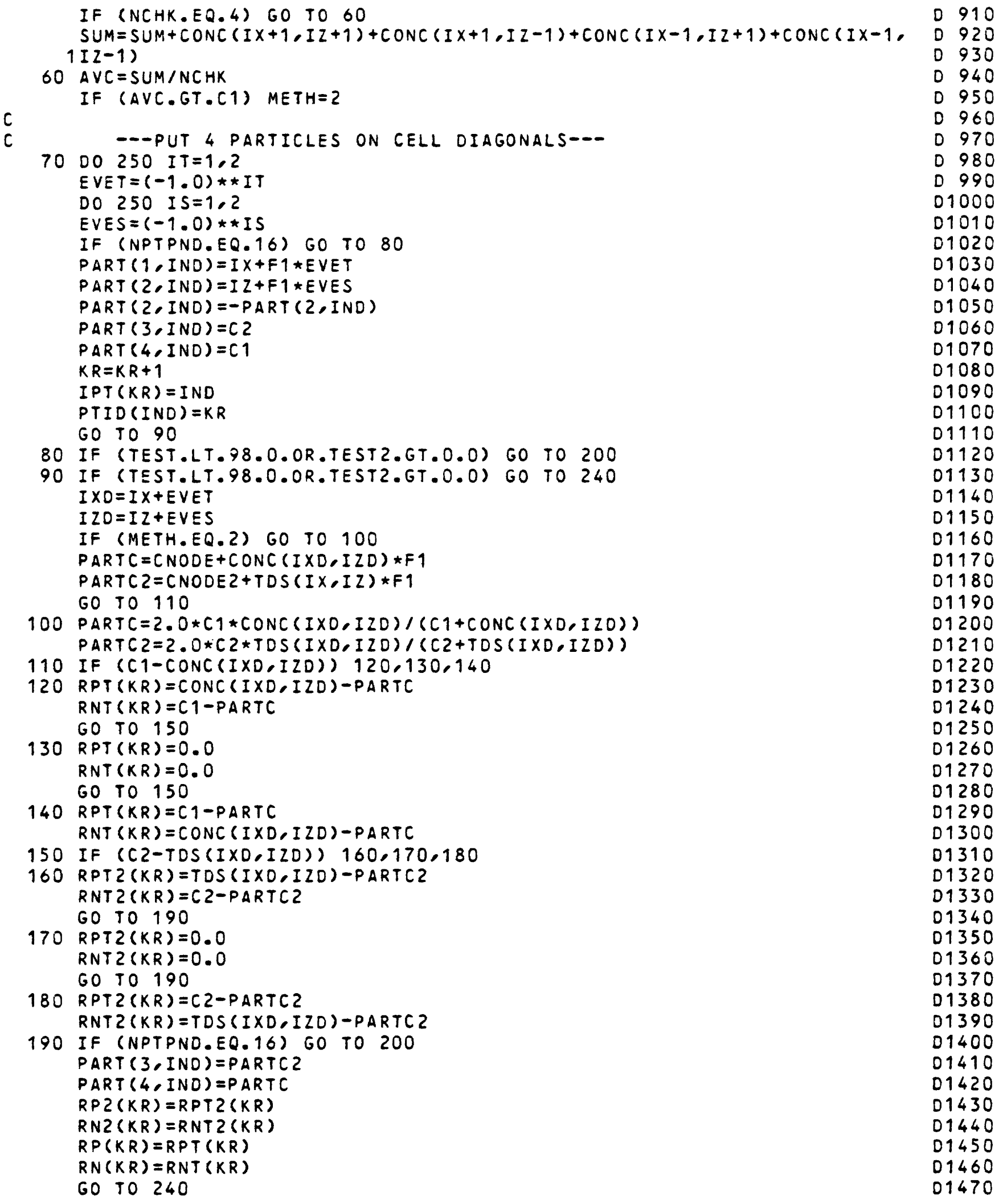


200 DO 230 ITT $=1,2$

EVET $2=(-1.0) * \star I T T$

01480

DO 230 ISS $=1,2$

EVES $2=(-1.0) * \star I S S$

$P A R T(1, I N D)=(I X+F 1 \star E V E T)+F 2 \star E V E T 2$

01490

01500

01510

01520

$P A R T(2, I N D)=(I Z+F 1$ *EVES $)+F 2$ *EVESZ

01530

PART $(2, I N D)=-P A R T(2, I N D)$

01540

$K R 2=K R 2+1$

IF (TEST.LT.98.0.OR.TEST2.GT.0.0) GO TO 210

01550

PART $(3, I N D)=P A R T C 2$

01560

PART $(4, I N D)=$ PARTC

01570

$R P(K R 2)=R P T(K R)$

01580

$R N(K R 2)=R N T(K R)$

01590

$R P 2(K R 2)=R P T 2(K R)$

01600

$R N 2(K R 2)=R N T 2(K R)$

$I P T(K R 2)=I N D$

GO TO 220

01610

01620

01630

D1640

210 PART $(3$, IND $)=C 2$

PART $(4, I N D)=C 1$

01650

01660

$220 P T I D(I N D)=K R 2$

IND $=$ IND+1

230 CONTINUE

GO TO 250

240 IND $=$ IND+1

250 CONTINUE

IF (NPTPND.EO.16) GO TO 480

IF (NPTPND.EQ.5.OR.NPTPND.EQ.9) GO TO 260

GO TO 270

c ---PUT ONE PARTICLE AT CENTER OF CELL---

$260 \operatorname{PART}(1, I N D)=I X$

PART $(2, I N D)=-I 2$

01670

01680

01690

01700

01710

01720

01730

01740

01750

01760

01770

01780

$\operatorname{PART}(3, I N D)=C 2$

01790

PART $(4, I N D)=C 1$

PTID (IND) $=5$

$I N D=I N D+1$

c - - PLACE NORTH, SOUTH, EAST, AND WEST PARTICLES---

270 IF (NPTPND.LT.8) GO TO 480

CNOOE $=C 1 *(1.0-F 2)$

CNODE $2=C 2 *(1.0-F 2)$

DO $470 \quad I T=1,2$

EVET $=(-1,0) * \star I T$

PART $(1, I N D)=I X+F 2 \star E V E T$

01800

01810

01820

01830

D1840

01850

01860

01870

01880

01890

$\operatorname{PART}(2, I N D)=-I Z$

$\operatorname{PART}(3, I N D)=C 2$

PART $(4, I N O)=C 1$

IF (EVET.LT.O) PTID (IND) $=6$

IF (EVET.ET.O) PTID (IND) $=8$

IF (TEST.LT.98.0.OR.TEST2.GT.0.0) GO TO 370

01900

01910

01920

01930

01940

$I X D=I X+E V E T$

$K R=K R+1$

01950

01960

01970

IPT $(K R)=I N D$

IF (METH.EQ.2) GO TO 280

PART $(4, I N D)=C N O D E+C O N C(I X D, I Z) \star F 2$

01980

01990

$P A R T(3, I N D)=C N O D E Z+T D S(I X D, I Z) \star F Z$

02000

02010

GO TO 290

02020

02030

280 PART $(4, I N D)=2.0 * C 1 * \operatorname{CONC}(I \times D, I Z) /(C 1+\operatorname{CONC}(I \times D, I Z))$

02040 
290 IF $(C 1-C O N C(I X D, I 2)) 300,310,320$

02050

$300 R P(K R)=C O N C(I X D, I Z)-P A R T(4, I N D)$

02060

$R N(K R)=C 1-P A R T(4, I N D)$

GO TO 330

02070

02080

$310 R P(K R)=0.0$

02090

$R N(K R)=0.0$

GO TO 330

$320 R P(K R)=C 1-P A R T(4, I N D)$

$R N(K R)=C O N C(I X D, I Z)-P A R T(4, I N D)$

02100

02110

02120

02130

330 IF $(C 2-T D S(I X D, I Z)) 340,350,360$

$340 R P 2(K R)=T D S(I X D, I Z)-P A R T(3, I N D)$

02140

$R N 2(K R)=C 2-P A R T(3, I N D)$

02150

GO TO 370

$350 R P Z(K R)=0.0$

$R N 2(K R)=0.0$

02160

02170

$D 2180$

02190 GO TO 370

$360 R P 2(K R)=C 2-P A R T(3, I N D)$

$R N 2(K R)=T D S(I X D, I Z)-P A R T(3, I N D)$

02200

02210

02220

02230

02240

PART $(1, I N D)=I X$

PART $(2$,IND) $=I Z+F 2$ *EVET

PART $(2, I N D)=-P A R T(2, I N D)$

02250

02260

$P A R T(3, I N D)=C 2$

02270

PART $(4, I N D)=C 1$

IF (EVET.LT.O) PTIDSIND) =?

02280

IF (EVET.GT.O) PTID (IND) $=9$

02290

02300

IF (TEST.LT.98.0.0R.TEST2.GT.0.0) GO TO 470

02310

$I Z D=I Z+E V E T$

$K R=K R+1$

IPT $(K R)=I N D$

IF (METH.EQ.2) GO TO 380

PART $(4, I N D)=C N O D E+C O N C(I X, I Z D) * F 2$

PART $(3, I N D)=C N O D E 2+T O S(I X, I Z D) * F 2$

GO TO 390

D2320

02330

02340

02350

02360

02370

02380

02390

02400

PART $(3, I N D)=2.0 \star C 2 \star T D S(I X, I Z O) /(C 2+T D S(I X, I Z D))$

02410

390 IF $(C 1-C O N C(I X, I Z D)) \quad 400,410,420$

$400 R P(K R)=C O N C(I X, I Z D)-P A R T(4, I N D)$

02420

02430

$R N(K R)=C 1-P A R T(4, I N D)$

02440

GO TO 430

02450

$410 R P(K R)=0.0$

02460

$R N(K R)=0.0$

02470

GO TO 430

02480

$420 R P(K R)=C 1-P A R T(4, I N D)$

$R N(K R)=\operatorname{CONC}(I X, I Z D)-P A R T(4, I N D)$

02490

02500

02510

02520

02530

02540

D2550

02560

02570

02580

02590

C

470 IND $=$ IND +1

02600

480 IF (TEST.LT.98.0.OR.TEST2.GT.0.0) GO TO 720

D2610 


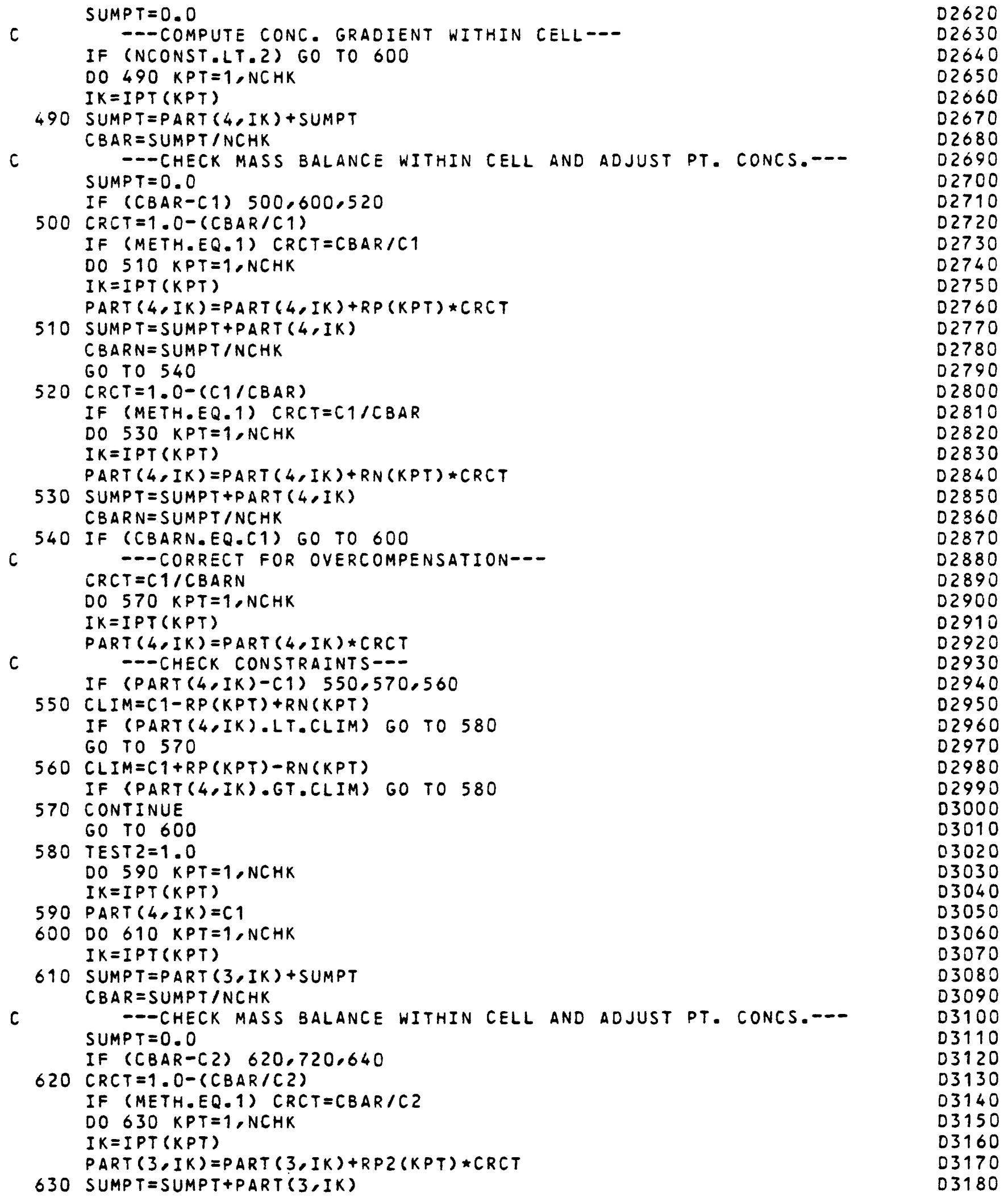




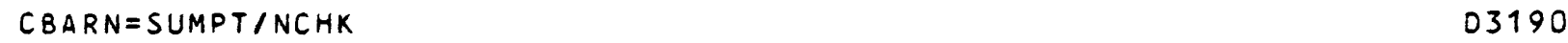

$\begin{array}{ll}\text { GO TO } 660 & 03200\end{array}$

640 CRCT $=1.0-(C 2 / C B A R)$

$\begin{array}{ll}\text { IF (METH.EQ.1) CRCT=C2/CBAR } & \text { D } 2220\end{array}$

$\begin{array}{ll}D O 650 \quad K P T=1, N C H K & 03230\end{array}$

$\begin{array}{ll}I K=I P T(K P T) & 03240\end{array}$

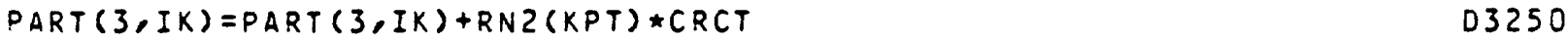

650 SUMPT $=$ SUMPT +PART $(3, I K)$

CBARN $=$ SUMPT/NCHK

c

660 IF (CBARN.EQ.C2) GO TO 720

$C R C T=C 2 / C B A R N$

DO 690 KPT $=1, N C H K$

$I K=I P T(K P T)$

C

PART $(3, I K)=P A R T(3, I K) \star C R C T$

---CHECK CONSTRAINTS---

IF (PART $(3, I K)-C 2) 670,690,680$

$670 C L I M=C 2-R P 2(K P T)+R N 2(K P T)$

IF (PART $(3, I K)$.LT.CLIM) GO TO 700

GO TO 690

$680 C L I M=C 2+R P 2(K P T)-R N 2(K P T)$

IF (PART $(3$, IK). GT.CLIM) GO TO 700

690 CONTINUE

GO TO 720

700 TEST $2=1.0$

DO $710 \quad K P T=1, N C H K$

$I K=I P T(K P T)$

$710 \operatorname{PART}(3, I K)=C 2$

720 CONTINUE

$N P=I N D$

C

IF (INT.EQ.O) CALL CHMOT

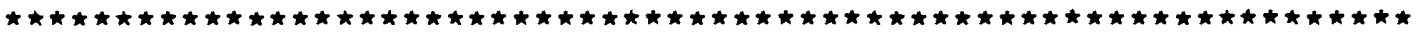

RETURN

C

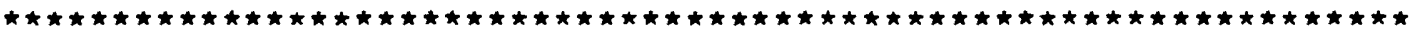

END

SUBROUTINE VELO

IMPLICIT DOUBLE PRECISION $(A-H, O-Z)$

COMMON /PRMJ/ NTIM,NPMP,NPNT,NITP,N,NX,NZ,NP,NREC,INT, NNX,NNZ,NUMO $1 B S, N M O V, I M O V, N P M A X, I T M A X, N Z C R I T, I P R N T, N P T P N D, N P N T M V, N P N T V L, N P N T D, N$ 2PNCHV, NPDELC,ICHK, NCONST

COMMON /PRMCI NODEID $(24,20), N P C E L L(24,20), N P O L O(24,20)$, LIMBO $(500)$, $1 I X O B S(5), I Z O B S(5)$

COMMON /PRESS/ PERM $(24,20), P M R X(24,20,4), P I(24,20), P R(24,20), P C(24$ $1,20), P K(24,20), R E C(24,20)$, DENS $(24,20)$, GTERM $(24,20), V I S C(24,20), V P R$ $2 M(24,20)$, TMWL $(5,50), T M O B S(50), T I M(100), A O P T(20), T I T L E(10), A N F C T R, X$ $3 D E L, Z D E L, W I D T H, S, A R E A, S U M T, R H O, P A R A M, T E S T, T O L, P I N T, H M I N, P Y R, Y O L$

COMMON IOENVIS/ DEN1,DEN2,VIS1,VIS2

COMMON /XINV/ DXINV, DZINV, ARINV,PORINV

COMMON /CHMA/ PART $(4,6400), C O N C(24,20), T D S(24,20), V \times(24,20), V Z(24$, 120), CONINT $(24,20)$, TOSINT $(24,20)$, CNREC $(24,20), T O S R E C(24,20), \operatorname{TMCN}(5$, 250), TMTOS $(5,50)$, POROS, SUMTCH, BETA, TIMV, STORM, STORT, STORMI, STORTI,C 3MSIN, TDSIN, CMSOUT, TDSOUT, FLMIN, FLTIN, FLMOT, FLTOT, SUMIO, TOSIO, CELDI 4S,DLTRAT, CSTORM, CSTORT, DMOLEC

COMMON /CHMC/ SUMC $(24,20), V X B O Y(24,20), V Z B O Y(24,20)$, SUMTOS $(24,20)$,

1 WTFCTR $(24,20)$, SUMWT $(24,20), P T Q(24,20), P T W T(6400)$, ELEV $(24,20)$

COMMON /DIFUS/ DISP $(24,20,4)$
03260

03270

03280

03290

03300

D 3310

03320

03330

03340

03350

03360

03370

D 3380

03390

03400

03410

03420

03430

03440

03450

03460

03470

03480

03490

03500

03510

D 3520

D3530-

E 10

E 20

E 30

E 40

E 50

E 60

E 70

E 80

E 90

E 100

E 110

E 120

$\leq 130$

E 140

E 150

E 160

E 170

E 180

E 190

E 200

E 210

E 220 
$\checkmark M A X=1 . O E-10$

$\checkmark M A Z=1.0 E-10$

$\checkmark M X B D=1.0 E-10$

$\checkmark M Z B D=1.0 E-10$

$T M V=T I M(N) \star 1.0 E 5$

$L I M=0$

$\operatorname{MAXX}=0$

$\operatorname{MAXX} Z=0$

c

$D O 40$ IX $=1, N X$

$D O \quad 40 \quad I Z=1, N Z$

$W T F C T R(I X, I Z)=1.0$

DO 10 IY $Y=1,4$

c

$10 \operatorname{DISP}(I X, I Z, I Y)=0.0$

IF (PERM(IX,IZ).EQ.0.0) GO TO 40

DENSE = DENS $(I X, I Z)$

IF (VPRM(IX,IZ).GT.0.0.AND. (PI $(I X, I Z) . G T . P K(I X, I Z)))$ DENSE = DEN $1 * T D$

1SREC (IX,IZ)+DEN2

$S L E A K=V P R M(I X, I Z) / D E N S(I X, I Z)$

$S L E A K=S L E A K *(P I(I X, I Z)-P K(I X, I Z)+D E N S(I X, I Z) * E L E V(I X, I Z))$

DENSE $=$ DENS $(I X, I Z)$

IF (REC (IX,IZ).LT.0.0) DENSE = DEN $1 * T D S R E C(I X, I Z)+D E N Z$

$c$ DIV $=S L E A K+R E C(I X, I Z) / D E N S E$

c

---VELOCITIES AT NODES--$--X-D I R E C T I O N---$

$D P X=P K(I X-1, I Z)-P K(I X+1, I Z)$

IF (PERM $(I X-1, I Z), E Q .0 .0) \quad D P X=P K(I X, I Z)-P K(I X+1, I Z)$

IF (PERM $(I X+1, I Z), E Q .0 .0) \quad D P X=P K(I X-1, I Z)-P K(I X, I Z)$

IF (PERM(IX-1,IZ).EQ.0.0.AND.PERM $(I X+1, I Z) \cdot E Q \cdot 0.0)$ DPX $=0.0$

$G R D X=D P X \star D X I N V * 0.50$

$V X(I X, I Z)=P E R M(I X, I Z) \star G R D X * P O R I N V / V I S C(I X, I Z)$

$A B V X=A B S(V X(I X, I Z))$

IF $(A B \vee X . G T, V M A X)$ VMAX $=A B \vee X$ $---Z$-DIRECTION---

$D P Z=P K(I X, I Z-1)-P K(I X, I Z+1)$

DENSE $=0.25 * D E N S(I X, I Z-1)+0.25 * D E N S(I X, I Z+1)+0.500 * D E N S(I X, I Z)$ $G R D Z=D P Z \star D Z I N V * 0.500+D E N S E$

IF (PERM (IX,IZ-1) .EQ.0.0.AND.PERM(IX,IZ+1).EQ.0.0) GO TO 20

IF (PERM (IX,IZ-1),$E Q \cdot 0.0) \quad D P Z=(P K(I X, I Z)-P K(I X, I Z+1))$

IF (PERM(IX,IZ-1),EQ.0.0) DENSE $=(D E N S(I X, I Z)+D E N S(I X, I Z+1)) / 2.0$

IF (PERM(IX,IZ-1) .EQ.0.0) GRDZ =(DPZ*DZINV+DENSE) 0.500

IF (PERM $(I X, I Z+1) \cdot E Q \cdot 0.0) \quad D P Z=(P K(I X, I Z-I)-P K(I X, I Z))$

IF $(P E R M(I X, I Z+1), E Q .0 .0)$ DENSE $=(D E N S(I X, I Z)+D E N S(I X, I Z-1)) / 2.0$

IF $(P E R M(I X, I Z+1), E Q .0 .0) \quad G R D Z=(D P Z \star D I I N V+D E N S E) \star 0.500$

GO TO 30

20 GRDZ $=0.0$

$30 \vee Z(I X, I Z)=P E R M(I X, I Z) \star G R D Z \star P O R I N V \star A N F C T R / V I S C(I X, I Z)$ $A B V Z=A B S(V Z(I X, I Z))$

IF ( $A B \vee Z . G T . V M A Z) \quad \vee M A Z=A B \vee Z$ 


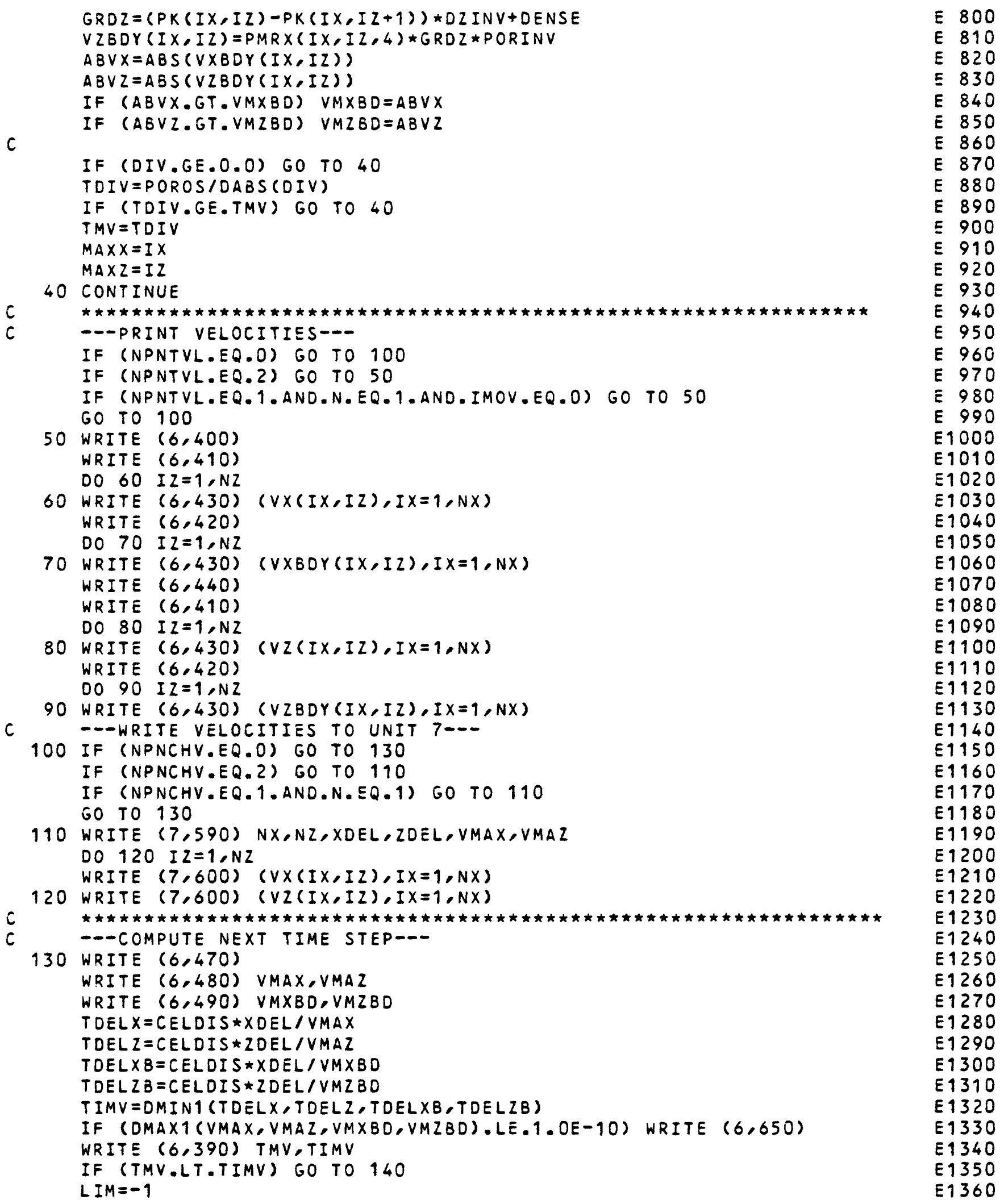


60 TO 150

$E 1370$

140 TIMV $=$ TMV LIM $=1$

150 NTIMV $=$ TIM(N)/TIMV

NMOV $=N T I M V+1$

WRITE $(6,500)$ TIMV, NTIMV, NMOV

TIMV $=$ TIM $(N) / N M O V$

WRITE $(6,450)$ TIM(N)

WRITE $(6,460)$ TIMV

$c$
$c$
$c$

\section{WRITE}

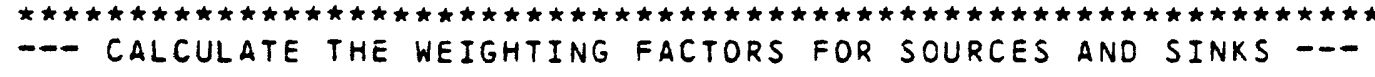

DO 190 IX $X=1, N X$

DO $190 \quad I Z=1, N Z$

IF (PERM $(I X, I Z), E Q .0 .0)$ GO TO 190

IF $(P T Q(I X, I Z) \cdot E Q .0 .0)$ GO TO 190

SUMQ $=0.0$

SUMQIN $=0.0$

$Q S N K=0.0$

$Q S R C=0.0$

$Q=V X B D Y(I X-1, I Z) \star P O R O S \star Z D E L \star W I D T H$

IF $(Q . L T .0 .0)$ SUMQ $=$ SUMQ-Q

IF (Q.GT.0.0) SUMQIN $=$ SUMQIN+Q

$Q=V X B D Y(I X, I Z) \star P O R O S \star Z D E L \star W I D T H$

IF $(Q . G T .0 .0)$ SUMQ $=$ SUMQ+Q

IF $(Q . L T \cdot 0.0)$ SUMQIN $=$ SUMQIN-Q

$Q=V Z B D Y(I X, I Z-1) \star P O R O S \star X O E L \star W I D T H$

IF $(Q . L T \cdot 0.0)$ SUMQ $=$ SUMQ-Q

IF $(Q . G T .0 .0)$ SUMQIN $=$ SUMQIN+Q

$Q=V Z B D Y(I X, I Z) \star P O R O S \star X D E L \star W I D T H$

IF $(Q . G T \cdot 0.0)$ SUMQ $=$ SUMQ+Q

IF $(Q . L T .0 .0)$ SUMQIN $=$ SUMQIN-Q

IF (REC (IX,IZ).GT.0.0) GO TO 180

160 QSRC $=Q S R C-R E C(I X, I Z)$

IF (VPRM(IX,IZ).LE.0.O) GO TO 170

$Q S R C=Q S R C+V P R M(I X, I Z) * V O L \star(P I(I X, I Z)-P K(I X, I Z)+D E N S(I X, I Z) \star E L E V(I X$

$1, I Z)) / D E N S(I X, I Z)$

IF (QSRC.LT.0.0) GO TO 180

170 WTFCTR $(I X, I Z)=Q S R C / S U M O$

IF (WTFCTR(IX,IZ).GT.0.999) WTFCTR $(I X, I Z)=1.0$

GO TO 190

180 QSNK $=$ QSNK+REC $(I X, I Z)$

$Q S N K=Q S N K-V O L \star V P R M(I X, I Z) \star(P I(I X, I Z)-P K(I X, I Z)+D E N S(I X, I Z) \star E L E V(I X$

$1, I Z)) / D E N S(I X, I Z)$

IF $(Q S N K . L T \cdot 0.0)$ GO TO 160

WTFCTR $(I X, I Z)=1.0-(Q S N K / S U M Q I N)$

IF (WTFCTR (IX,IZ).LT.0.001) WTFCTR $(I X, I Z)=0.0$

190 CONTINUE
WRITE $(6,680)$

C DO 136 IZ $=1, N Z$

C 136 WRITE $(6,690)$ (WTFCTR $(I X, I Z), I X=1, N X)$

IF (BETA.EQ.0.0.AND.DMOLEC.EQ.0.0) GO TO 270

c

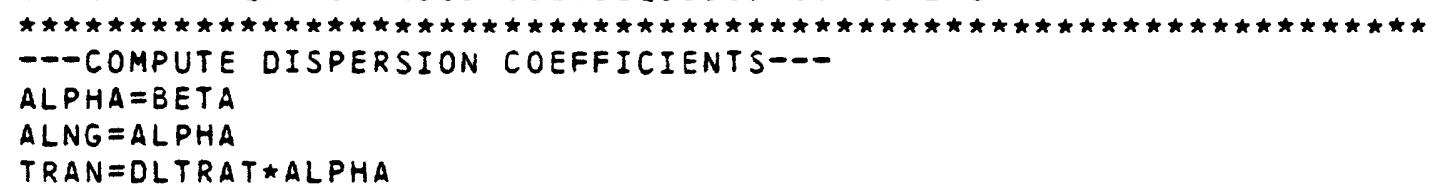

E1380

E1390

$E 1400$

$E 1410$

E1420

$E 1430$

E1440

$\Xi 1450$

E1460

$E 1470$

E1480

51490

E1500

E1510

E1520

E1530

E1540

E1550

E1560

E1570

E1580

E1590

$E 1600$

E1610

E1620

E1630

$E 1640$

E1650

E1660

E1670

E1680

E1690

E1700

E1710

51720

E1730

E1740

$\equiv 1750$

E1760

E1770

E1780

E1790

E1800

E1810

E1820

E1830

E1840

E1850

E1860

E1870

$E 1880$

E1890

$E 1900$

E1910

E1920

$\$ 1930$ 
$X \times 2=\times D E L \star X D E L$

$E 1940$

$Z Z 2=Z D E L \star Z D E L$

E1950

$X Z 2=4.0 * X D E L * Z D E L$

E1960

DO 210 IX $=2, N N X$

E1970

DO 210 IZ $=2, N N Z$

IF (PERM(IX,IZ).EQ.0.0) GO TO 210

E1980

$V X E=V X B D Y(I X, I Z)$

$E 1990$

$V Z S=V Z B D Y(I X, I Z)$

IF (PERM (IX+1,IZ).EQ.0.0) GO TO 200

E2000

E2010

- - FORWARD COEFFICIENTS: $X$-DIRECTION---

$c$

$V Z E=(V Z B D Y(I X, I Z-1)+V Z B D Y(I X+1, I Z-1)+V Z S+V Z B D Y(I X+1, I Z)) / 4.0$

$E 2020$

$\checkmark X E Z=V X E * V X E$

$V Z E Z=V Z E \star V Z E$

VMGE $=S Q R T(V X E Z+V Z E 2)$

IF (VMGE.LT.1.OE-20) GO TO 200

E 2030

E2040

E2050

E2060

E2070

E2080

$D A L N=A L N G \star V M G E$

DTRN $=$ TRAN*VMGE

VMGEZ $=V M G E \star V M G E$

$E 2090$

$E 2100$

$\Xi 2110$

$---X X$ COEFFICIENT---

$D I S P(I X, I Z, 1)=(D A L N * V X E Z+D T R N * V Z E Z) /(V M G E Z \star X X Z)$

$--X Z$ COEFFICIENT---

$D I S P(I X, I Z, 3)=(D A L N-D T R N) \star V X E \star V Z E /(V M G E Z \star X Z 2)$

E2120

E2130

E2140

E2150

E2160

E2170

200 IF (PERM(IX,IZ+1).EQ.0.0) GO TO 210

$V X S=(V X B D Y(I X-1, I Z)+V X E+V X B D Y(I X-1, I Z+1)+V X B D Y(I X, I Z+1)) / 4.0$

$E 2180$

$V Z S Z=V Z S \star V Z S$

$V \times S 2=V \times S \star V \times S$

$E 2190$

E2200

$V M G S=S Q R T(V \times S Z+V Z S 2)$

IF (VMGS.LT.1.OE-20) GO TO 210

$E 2210$

$D A L N=A L N G \star V M G S$

$E 2220$

$D T R N=T R A N \star V M G S$

$E 2230$

E2240

VMGS $2=V M G S * V M G S$

$D I S P(I X, I Z, 2)=(D A L N * V Z S Z+D T R N * V X S Z) /(V M G S 2 * Z Z 2)$

E2250

$E 2260$

E2270

E2280

DISP $(I X, I Z, 4)=(D A L N-D T R N) * V X S * V Z S /(V M G S 2 * X Z 2)$

$E 2290$

210 CONTINUE

c

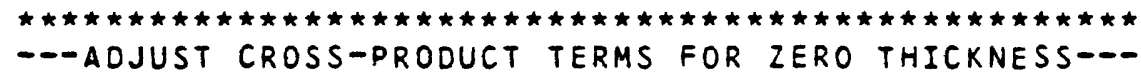

E2300

$E 2310$

DO 240 IX $=2, N N X$

DO $240 \quad I Z=2, N N Z$

IF (PERM (IX,IZ).EQ.0.0) GO TO 230

IF (PERM(IX+1,IZ).EQ.0.0) GO TO 220

DISP $(I X, I Z, 1)=D I S P(I X, I Z, 1)+D M O L E C / X X Z$

52320

E2330

E2340

E 2350

$E 2360$

E2370

E2380

E2390

DISP $(I X, I Z, 2)=D I S P(I X, I Z, 2)+D M O L E C / Z Z 2$

$E 2400$

E 2410

1).EQ.0.0.OR.PERM $(I X+1, I Z-1), E Q .0 .0)$ DISP $(I X, I Z, 3)=0.0$

IF (PERM $(I X+1, I Z), E Q .0 .0 .0 R$. PERM $(I X+1, I Z+1), E Q \cdot 0.0 .0 R$. PERM IIX-1,IZ

1).EQ.0.0.OR.PERM $(I X-1, I Z+1), E Q \cdot 0.0)$ DISP $(I X, I Z, 4)=0.0$

240 CONTINUE

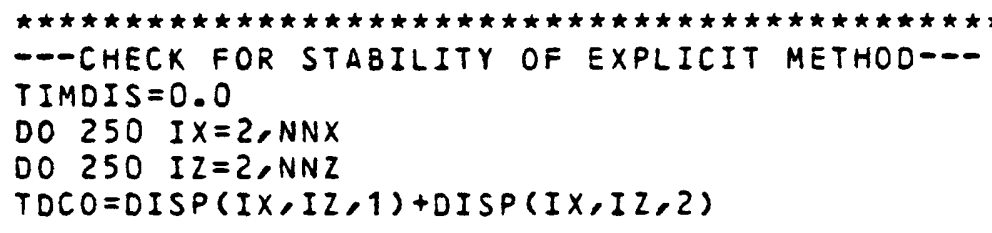




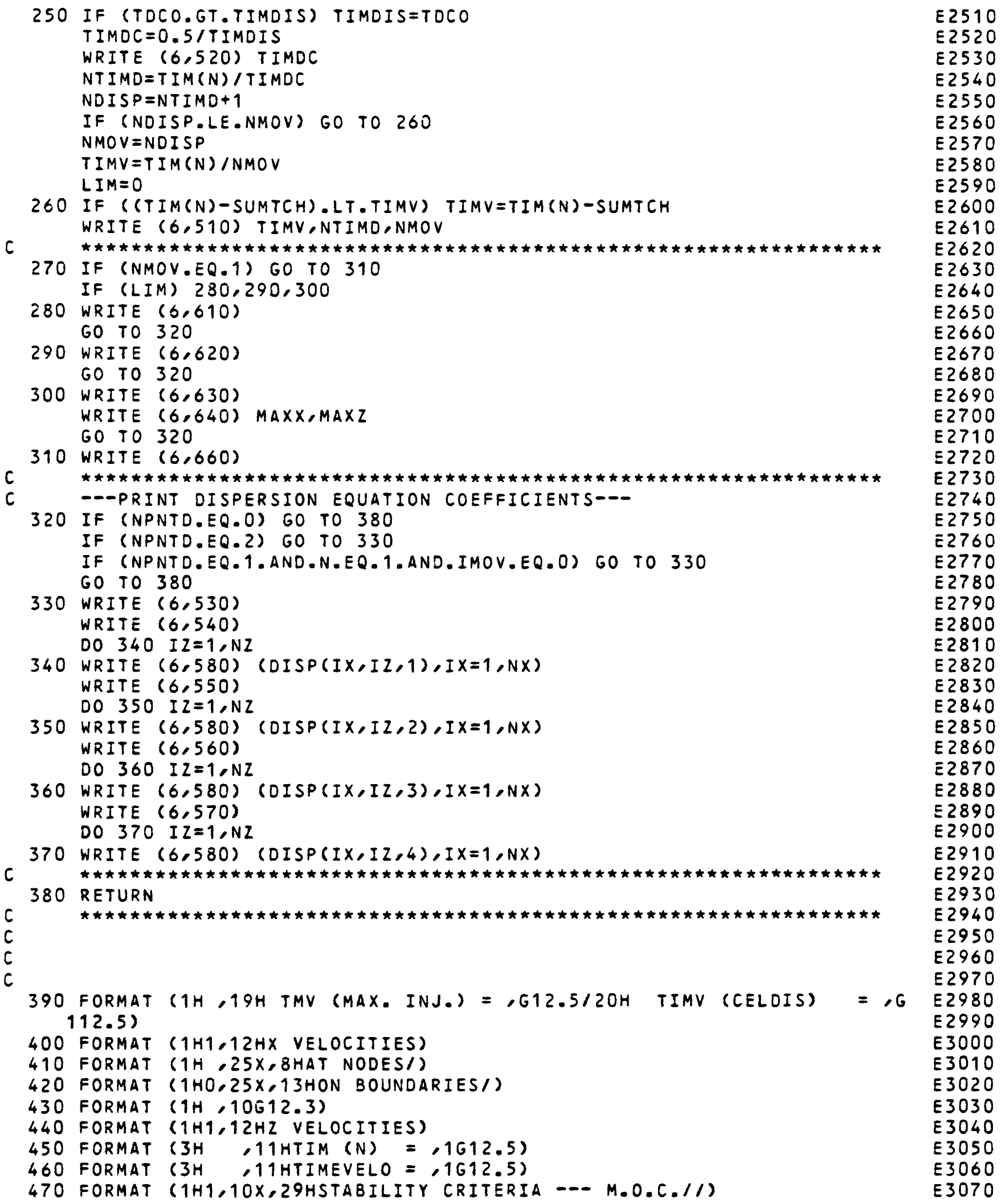




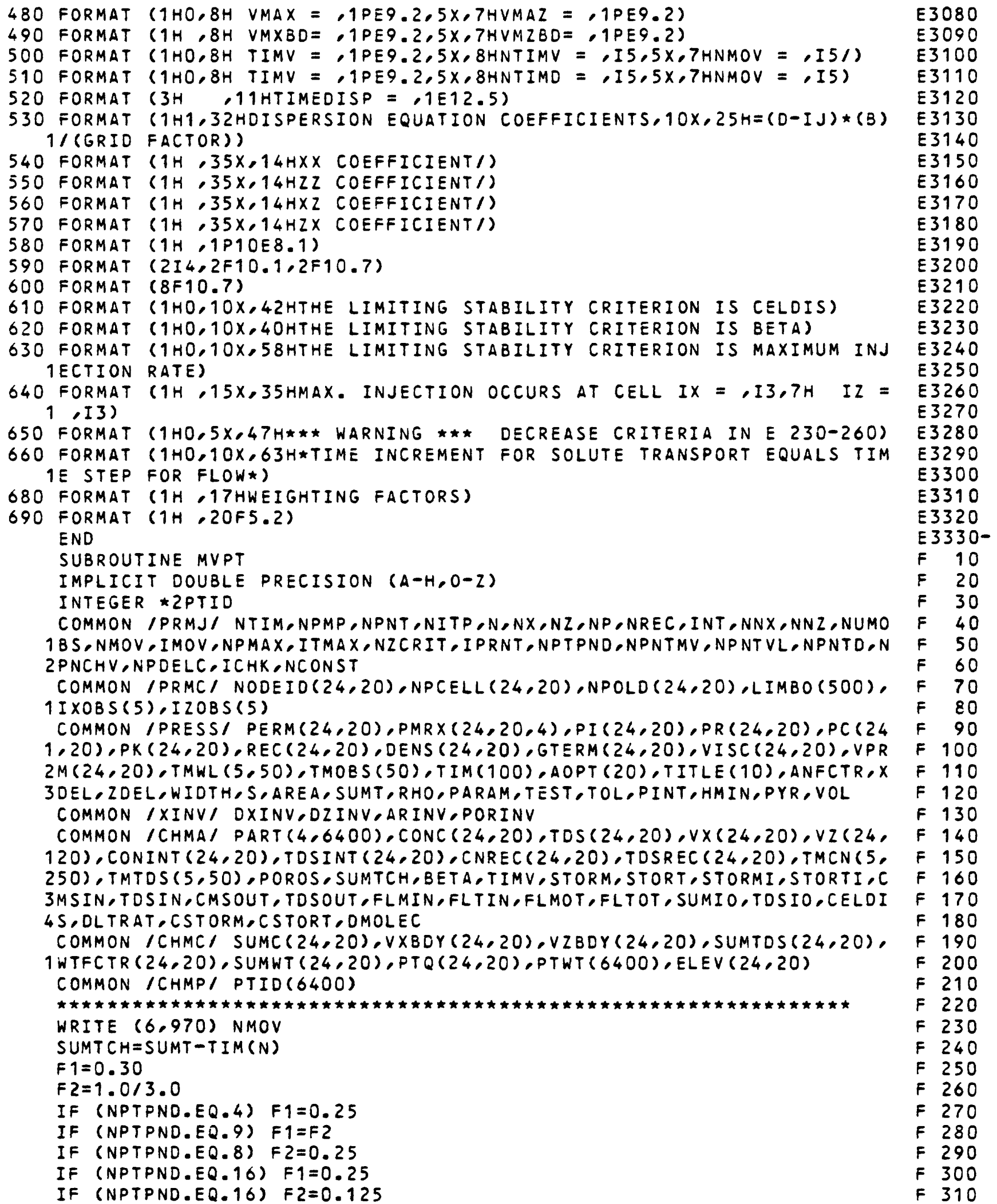


$I M O V=0$

10 IMOV $=I M O V+1$

CONST $1=T I M V \star D X I N V$

CONSTZ $=T I M V \star D Z I N V$

20 NPTM $=$ NP

C

C

C

c

C

c

c

C

C

$$
\text { - - MOVE EACH PARTICLE-- }
$$

DO 880 IN $=1, N P$

IF (PART $(1$, IN).EQ.0.0) GO TO 880

$X O L D=P A R T(1, I N)$

- - COMPUTE OLD LOCATION---

$I X=X O L D+0.5$

I FLAG $=1$

IF (PART $(2, I N), G E .0 .0)$ GO TO 30

IFLAG $=-1$

PART $(2, I N)=-P A R T(2, I N)$

30 ZOLD $=P A R T(2, I N)$

$I Z=Z O L D+0.5$

IF (PERM(IX,IZ).EQ.0.0) GO TO 880

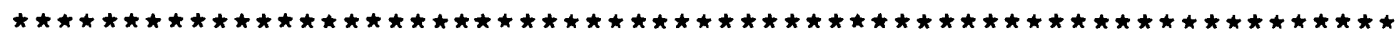

- - COMPUTE NEW LOCATION AND LOCATE CLOSEST NODE---

- - LOCATE NORTHWEST CORNER---

$I V X=X O L D$

IV $Z=Z O L D$

$I X E=I \vee X+1$

$I Z S=I V Z+1$

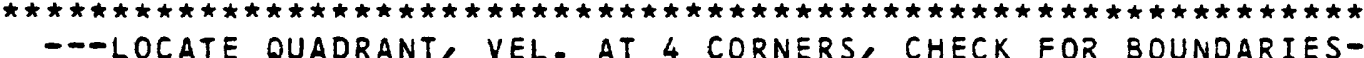

CELDX $=X O L D-I X$

$C E L D Z=Z O L D-I Z$

$I C D=9$

IF (CELDX.EQ.0.0.AND.CELDZ.EQ.0.0) GO TO 450

IF (CELDX.GE.0.0.0R.CELDZ.GE.0.0) GO TO 70

$V X N W=V X B D Y(I V X, I V Z)$

$V X N E=V X(I X E, I V Z)$

$V X S W=V X B D Y(I V X, I Z S)$

$V X S E=V X(I X E, I Z S)$

$V Z N W=V Z B D Y(I V X, I V Z)$

$V Z N E=V Z B D Y(I X E, I V Z)$

$V Z S W=V Z(I V X, I Z S)$

$V Z S E=V Z(I X E, I Z S)$

$I C D=1$

IF (PERM(IVX,IVZ).EQ.0.0) GO TO 50

IF (PTQ(IXE,IVZ).EQ.0.0) GO TO 40

$\checkmark X N E=V X N W$

40 IF (PTQ IVX,IZS).EQ.0.0) GO TO 50 $V Z S W=V Z N W$

50 IF (PTQ IXE,IZS).EQ.0.0) GO TO 270

IF (PERM(IVX,IZS).EQ.0.0) GO TO 60

IF (PERM(IXE+1,IZS).GT.0.0) VXSE=VXSW

60 IF (PERM (IXE,IVZ).EQ.0.0) GO TO 270

IF (PERM(IXE,IZS+1).GT.0.0) VZSE=VZNE

GO TO 270

70 IF (CELDX.LE.0.0.OR.CELDZ.GE.0.0) GO TO 130
F 320

F 330

F 340

F 350

F 360

$F \quad 370$

F 380

F 390

F 400

F 410

F 420

F 430

F 440

F 450

F 460

F 470

F 480

F 490

F 500

F 510

F 520

F 530

F 540

F 550

F 560

$F 570$

F 580

F 590

$F 600$

F 610

F 620

F 630

F 640

F 650

F 660

F 670

F 680

F 690

F 700

F 710

F 720

F 730

F 740

F 750

F 760

F 770

F 780

F 790

F 800

F 810

F 820

F 830

F 840

F 850

F 860

F 870

F 880 
$80 \vee V N W=V X(I V X, I V Z)$

$V X N E=V X B D Y(I V X, I V Z)$

$V X S W=V X(I V X, I Z S)$

$V X S E=V X B D Y(I V X, I Z S)$

$V Z N W=V Z B D Y(I V X, I V Z)$

$V Z N E=V Z B D Y(I X E, I V Z)$

$V Z S W=V Z(I V X, I Z S)$

$V Z S E=V Z(I X E, I Z S)$

$I C D=2$

IF (CELDX.EQ.0.0) GO TO 120

IF (PERM(IXE,IVZ) .EQ.0.0) GO TO 100

IF (PTQ(IXE,IZS),EQ.0.0) GO TO 90 $\checkmark X N W=V X N E$

90 IF (PTQ(IXE,IZS),EQ.0.0) GO TO 100 $V Z S E=V Z N E$

100 IF (PTQ IVX,IZS).EQ.0.0) GO TO 270

IF (PERM(IXE,IZS).EQ.0.0) GO TO 110

IF (PERM(IVX-1,IZS).GT.0.0) VXSW=VXSE

110 IF (PERM(IVX,IVZ).EQ.0.0) GO TO 270

IF (PERM(IVX,IZS+1).GT.0.0) VZSW=VZNW

GO TO 270

120 IF (PTQ(IVX,IZS).EQ.0.0) GO TO 270

IF (PERM(IVX,IVZ).EQ.0.0) GO TO 270

IF (PERM(IVX,IZS+1).GT.0.0) VZSW=VZNW

GO TO 270

c

c

130 IF (CELDZ.LE.0.0.OR.CELDX.GE.0.0) GO TO 190 ---PT. IN SW QUADRANT---

$140 \vee V X N=V X B D Y(I V X, I V Z)$

$\checkmark X N E=V X(I X E, I V Z)$

$V X S W=V X B D Y(I V X, I Z S)$

$V X S E=V X(I X E, I Z S)$

$V Z N W=V Z(I V X, I V Z)$

$V Z N E=V Z(I X E, I V Z)$

$V Z S W=V Z B D Y(I V X, I V Z)$

$V Z S E=V Z B D Y(I X E, I V Z)$

$I C D=3$

IF (CELDZ.EQ.0.0) GO TO 180

IF (PERM(IVX,IZS),EQ.0.0) GO TO 160

IF (PTQ(IVX,IVZ),EQ.0.0) GO TO 150

$V Z N W=V Z S W$

150 IF (PTQ(IXE,IZS) EQ.0.0) GO TO 160

$V X S E=V X S W$

160 IF (PTQ (IXE,IVZ) EEQ.0.0) GO TO 270

IF (PERM(IVX,IVZ).EQ.0.0) GO TO 170

IF (PERM(IXE+1,IVZ).GT.0.0) VXNE=VXNW

170 IF (PERM(IXE,IZS).EQ.0.0) GO TO 270

IF (PERM(IXE, IVZ-1).GT.0.0) VZNE=VZSE

$G O$ TO 270

180 IF (PTQ(IXE,IVZ),EQ.0.0) GO TO 270

IF (PERM(IVX,IVZ).EQ.0.0) GO TO 270

IF (PERM(IXE+1,IVZ).GT.0.0) VXNE=VXNW

c

GO TO 270

c

190 IF (CELDZ.LE.0.0.OR.CELDX.LE.0.0) GO TO 260

$--P T$. IN SE QUADRANT---

F 890

F 900

$F 910$

$F 920$

F 930

$F 940$

$F 950$

$F 960$

F 970

$F 980$

$F 990$

F1000

F1010

F1020

F1030

F1040

F1050

F1060

F1070

F 1080

F1090

F1100

F1110

F1120

F1130

F1140

F1150

F1160

F1170

F1180

F1190

F1200

F 1210

F 1220

F 1230

F1240

F1250

F1260

$F 1270$

F1280

F1290

F1300

F 1310

F1320

F1330

F1340

F1350

F1360

F1370

F1380

F1390

$F 1400$

F1410

F1420

F1430

F1440

F1450 
$200 \vee V X N W=V X(I V X, I V Z)$

$V X N E=V X B O Y(I \vee X, I \vee Z)$

$V X S W=V X(I V X, I Z S)$

$V X S E=V X B D Y(I V X, I Z S)$

$V Z N W=V Z(I V X, I V Z)$

$V Z N E=V Z(I X E, I V Z)$

$V Z S W=V Z B D Y(I V X, I V Z)$

$V Z S E=V Z B D Y(I X E, I V Z)$

ICD $=4$

IF (CELDZ.EQ.0.0) GO TO 240

IF (CELOX.EQ.0.0) GO TO 250

IF (PERM (IXE,IZS) .EQ.0.0) GO TO 220

IF (PTQ(IXE,IVZ).EQ.0.0) GO TO 210 $\checkmark Z N E=V Z S E$

210 IF (PTQ(IVX,IZS).EQ.0.0) GO TO 220 $\checkmark X S W=V X S E$

220 IF (PTQ(IVX,IVZ).EQ.0.0) GO TO 270

IF (PERM(IXE,IVZ).EQ.0.0) GO TO 230

IF (PERM (IVX-1,IVZ).GT.0.0) VXNW=VXNE

230 IF (PERM(IVX,IZS).EQ.0.0) GO TO 270

IF (PERM(IVX,IVZ-1).GT.0.0) VZNW=VZSW

GO TO 270

240 IF (PTQ IVX,IVZ) EEQ.0.0) GO TO 270

IF (PERM(IXE,IVZ).EQ.0.0) GO TO 270

IF (PERM(IVX-1,IVZ).GT.0.0) VXNW=VXNE

GO TO 270

250 IF (PTQ(IVX,IVZ).EQ.0.0) GO TO 270

IF (PERM(IVX,IZS).E0.0.0) GO TO 270

IF (PERM(IVX,IVZ-1).GT.0.0) VZNW=VZSW

c

GO TO 270

260 IF (CELDX.EQ.0.O.AND.CELDZ.LT.0.0) GO TO 80

IF (CELDX.LT.O.O.AND.CELDZ.EQ.0.0) GO TO 140

IF (CELDX.GT.0.0.AND.CELDZ.EQ.0.0) GO TO 200

IF (EELOX.EQ.0.0.AND.CELDZ.GT.0.0) GO TO 200

$F 1460$

F1470

F1480

$F 1490$

F1500

F1510

F1520

F1530

F1540

F1550

F1560

F1570

F1580

F1590

F1600

$F 1610$

F1620

F1630

F1640

F1650

F1660

F1670

F1680

F1690

F1700

F 1710

F 1720

F1730

F1740

F1750

F1760

F 1770

F 1780

$F 1790$ WRITE $(6,980)$ IN,IX,IZ

270 CONTINUE

c

GO CHECK FOR ADJACENT NO-FLOW BOUNDARIES---

$G O$ TO $(280,320,360,400,440)$, ICD

GO TO 440

280 IF (PERM(IXE,IVZ).EQ.0.0) GO TO 290

IF (PERM (IVX,IZS),EQ.0.0) GO TO 300

IF (PERM(IVX,IVZ),EQ.0.0) GO TO 310

GO TO 440

290 VXNE $=V \times S E$

IF (PERM (IVX,IZS).GT.0.0) GO TO 310

$300 \vee Z S W=V Z S E$

$310 \vee \times N W=V X S W$

$V Z N W=V Z N E$

GO TO 440

320 IF (PERM(IVX,IVZ).EQ.0.0) GO TO 330

IF (PERM(IXE,IZS),EQ.0.0) GO TO 340

IF (PERM(IXE.IVZ).EQ.0.0) GO TO 350

GO TO 440

$330 \vee X N W=V X S W$

IF (PERM(IXE,IZS).GT.0.0) GO TO 350

340 VZSE $=V Z S W$

F1800

F1810

F1820

F1830

F1840

F1850

F1860

F1870

F1880

F1890

F 1900

F1910

F1920

F1930

F1940

F1950

F1960

$F 1970$

F1980

F1990

F 2000

F 2010

F 2020 
Program listing -- Continued

$350 \vee \times N E=V \times S E$

$F 2030$

$\checkmark Z N E=V Z N W$

GO TO 440

360 IF (PERM(IXE,IZS).EQ.0.0) GO TO 370

IF (PERM(IVX,IVZ).EQ.0.0) GO TO 330

IF $(P E R M(I V X, I Z S), E Q .0 .0)$ GO TO 390

$F 2040$

$F 2050$

$F 2060$

$F 2070$

F 2080

GO TO 440

$370 \vee \times S E=V \times N E$

IF (PERM (IVX,IVZ).GT.0.0) GO TO 390

$F 2090$

$F 2100$

F 2110

$F 2120$

$380 \vee Z N W=V Z N E$

$F 2130$

$V Z S W=V Z S E$

GO TO 440

$F 2140$

F 2150

F2160

400 IF (PERM(IVX,IZJ).EQ.0.0) GO TO 410

IF (PERM(IXE,IVZ),EQ.0.0) GO TO 420

IF (PERM(IXE,IZS).EQ.0.0) GO TO 430

$F 2170$

GO TO 440

$F 2180$

$F 2190$

$F 2200$

$410 \vee \times S W=V X N W$

IF (PERM(IXE,IVZ).GT.0.0) GO TO 430

$420 \quad V Z N E=V Z N W$

$F 2210$

$430 \quad V Z S E=V Z S W$

$F 2220$

$F 2230$

$\checkmark \times S E=V \times N E$

c

440 CONTINUE

$F 2240$

$F 2250$

$F 2260$

$F 2270$

F2280

CELXD $=X O L D-I \vee X$

$C E L O X H=D M O D(C E L X D, 0.5000)$

$F 2290$

$C E L D X=C E L D X H * 2.0$

$F 2300$

CELDZ $=$ ZOLD-IVZ

$F 2310$

$F 2320$

$F 2330$

$F 2340$

$V X N=V X N W *(1.0-C E L D X)+V X N E \star C E L D X$

$F 2350$

$V X S=V X S W \star(1.0-C E L D X)+V X S E \star C E L D X$

$F 2360$

$F 2370$

$F 2380$

CELOZH $=0 M O D(C E L D Z, 0.5000)$

CELZD $=C E L O Z H * 2.0$

$V Z W=V Z N W *(1 . J-C E L Z D)+V Z S W * C E L Z D$

$F 2390$

$F 2400$

$F 2410$

$V Z E=V Z N E \star(1.0-C E L Z D)+V Z S E \star C E L Z D$

$F 2420$

$Z V E L=V Z W *(1.0-C E L X D)+V Z E * C E L X D$

$F 2430$

$F 2440$

60 TO 460

$450 \times V E L=V X(I X, I Z)$

$Z V E L=V Z(I X, I Z)$

460 DISTX $=X V E L \star C O N S T 1$

DISTZ $=Z$ VEL $\star C O N S T 2$

$F 2450$

$F 2460$

$F 2470$

F2480

$F 2490$

- - BOUNDARY CONDITIONS---

F2500

TEMPX $=X O L D+D I S T X$

F2510

TEMP $Z=Z O L D+D I S T Z$

$F 2520$

IN $X=$ TEMPX +0.5

IN $Z=T E M P Z+0.5$

$F 2530$

$F 2540$

IF (PERM(INX,INZ).GT.0.0) GO TO 500

F 2550

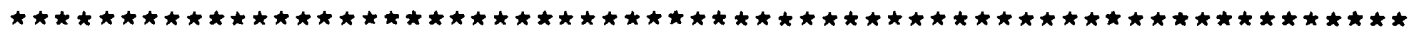

$-\infty X$ BOUNDARY--

IF (PERM(INX,IZ) .EQ.0.0) GO TO 470

$F 2560$

$F 2570$

PART $(1, I N)=T E M P X$

$F 2580$

$F 2590$ 


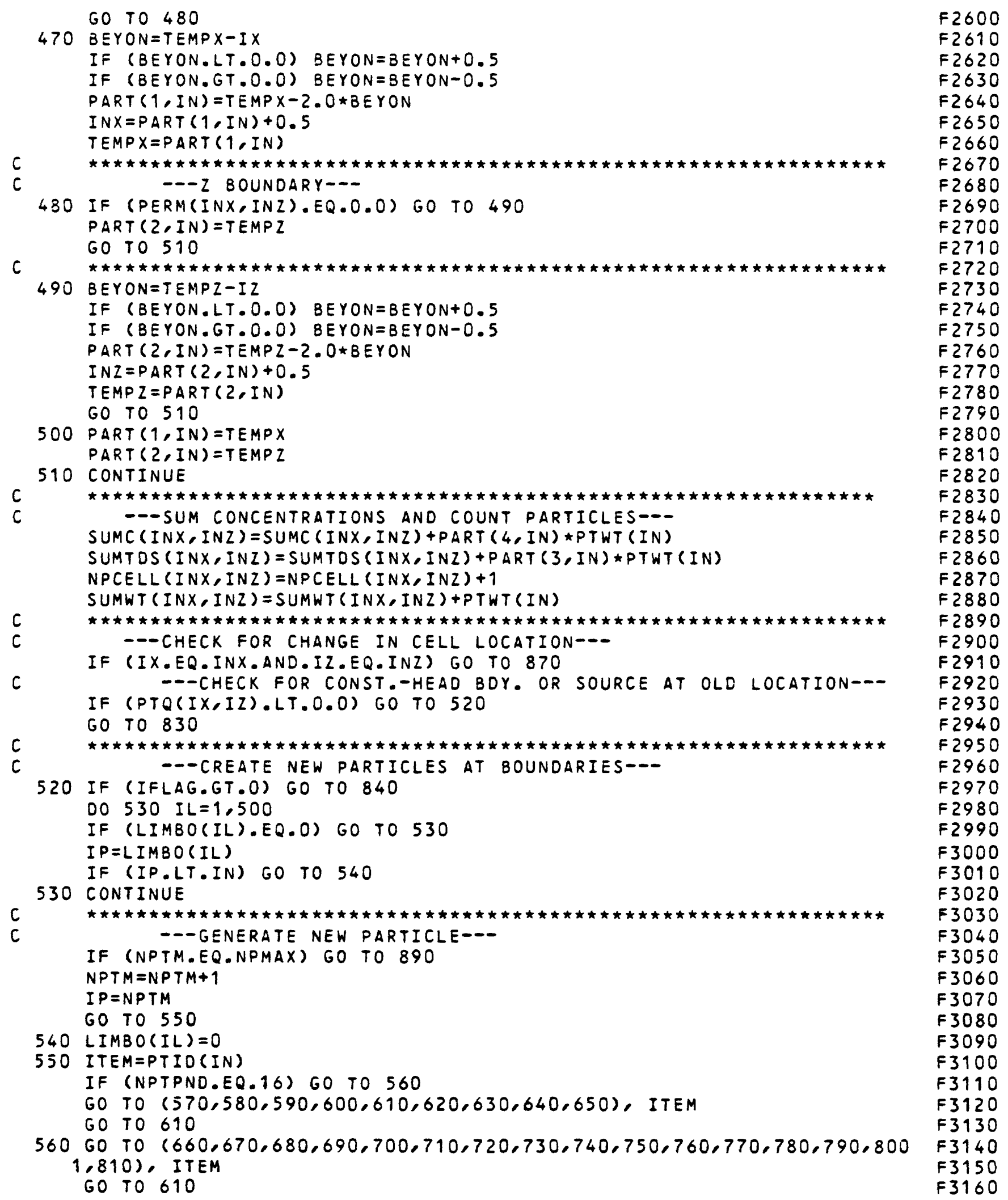


570 PART $(1, I P)=I X-F 1$

$F 3170$

$P A R T(2, I P)=I Z-F I$

F 3180

PTID (IP) $=1$

GO TO 820

580 PART $(1, I P)=I X-F 1$

$P A R T(2, I P)=I Z+F 1$

PTID (IP) $=2$

GO TO 820

$590 \operatorname{PART}(1, I P)=I X+F 1$

$P A R T(2, I P)=I Z-F 1$

$P T I D(I P)=3$

GO TO 820

600 PART $(1, I P)=I X+F 1$

PART $(2, I P)=I Z+F 1$

$P T I O(I P)=4$

GO TO 820

610 PART $(1, I P)=I X$

PART $(2, I P)=I Z$

PTID (IP) $=5$

GO TO 820

F 3190

$F 3200$

F 3210

F 3220

F 3230

F 3240

F 3250

$F 3260$

$F 3270$

F 3280

F 3290

F 3300

F 3310

F 3320

F 3330

F 3340

F 3350

F 3360

F 3370

F 3380

PART $(2, I P)=I Z$

PTIO (IP) $=6$

GO TO 820

$F 3390$

$F 3400$

F 3410

F 3420

F 3430

F 3440

F 3450

F 3460

F 3470

$F 3480$

F3490

F3500

F 3510

F 3520

F 3530

F 3540

F3550

F 3560

F 3570

F3580

F 3590

F 3600

F 3610

$F 3620$

F 3630

F 3640

F3650

F 3660

F 3670

F 3680

F 3690

F 3700

F 3710

F 3720

$$
\text { PTID (IP) }=5
$$

F 3730

710 PART $(1, I P)=I X-F 1-F 2$ 
PART $(2, I P)=I Z+F 1+F 2$

$F 3740$

PTID (IP) $=6$

F 3750

GO TO 820

$720 \operatorname{PART}(1, I P)=I X-F 1+F 2$

$\operatorname{PART}(2, I P)=I Z+F I-F 2$

F 3760

PTID (IP) $=7$

$F 3770$

GO TO 820

F 3780

$F 3790$

F 3800

$730 \operatorname{PART}(1, I P)=I X-F 1+F 2$

PART $(Z, I P)=I Z+F I+F Z$

$F 3810$

$P T I D(I P)=8$

F3820

GO TO 820

$F 3830$

$F 3840$

$740 \operatorname{PART}(1, I P)=I X+F 1-F 2$

$P A R T(2, I P)=I Z-F 1-F 2$

F3850

PTID $(I P)=9$

$F 3860$

GO TO 820

$750 \operatorname{PART}(1, I P)=I X+F 1-F 2$

PART $(2, I P)=I Z-F 1+F 2$

$F 3870$

F 3880

PTID (IP) $=10$

$F 3890$

$F 3900$

$F 3910$

GO TO 820

760 PART $(1, I P)=I X+F 1+F 2$

PART $(2, I P)=I Z-F 1-F 2$

$P T I D(I P)=11$

GO TO 820

770 PART $(1, I P)=I X+F 1+F 2$

PART $(2, I P)=I Z-F 1+F 2$

F3920

$F 3930$

$F 3940$

$F 3950$

$F 3960$

$F 3970$

$F 3980$

PTID (IP) $=12$

60 TO 820

780 PART $(1, I P)=I X+F 1-F 2$

PART $(2, I P)=I Z+F 1-F Z$

PTID (IP) $=13$

GO TO 820

$790 \operatorname{PART}(1, I P)=I X+F 1-F 2$

$P A R T(2, I P)=I Z+F 1+F 2$

PTID (IP) $=14$

GO TO 820

800 PART $(1, I P)=I X+F 1+F 2$

PART $(2, I P)=I Z+F 1-F 2$

$P T I D(I P)=15$

GO TO 820

810 PART $(1, I P)=I X+F 1+F 2$

PART $(2, I P)=I Z+F 1+F 2$

PTID (IP) $=16$

C

GO TO 820

$820 \operatorname{PART}(2, I P)=-P A R T(2, I P)$

PART $(3, I P)=T D S(I X, I Z)$

PART $(4, I P)=\operatorname{CONC}(I X, I Z)$

PTWT (IP) =WTFCTR (IX,IZ)

C

830 IFLAG $=1.0$

---CHECK FOR DISCHARGE BOUNDARY AT NEW LOCATION---

F 3990

$F 4000$

$F 4010$

$F 4020$

$F 4030$

$F 4040$

$F 4050$

$F 4060$

$F 4070$

$F 4080$

F 4090

$F 4100$

F 4110

F 4120

F4130

F 4140

F4150

F4160

F4170

F 4180

F 4190

F4200

$F 4210$

F 4220

F4230

F4240

F4250

F4260

GO TO 880

c

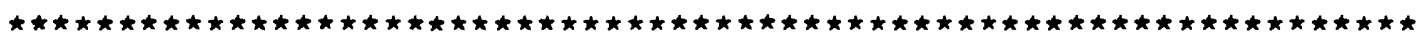

$F 4270$

$F 4280$

$F 4290$

850 PTWT (IN) = PTWT (IN)*WTFCTR (INX,INZ)

$F 4300$ 
$\operatorname{PART}(1, I N)=0.0$

$\operatorname{PART}(2, I N)=0.0$

$F 4320$

$\operatorname{PART}(3, I N)=0.0$

$F 4330$

PART $(4, I N)=0.0$

$F 4340$

DO 860 ID $=1,500$

$F 4350$

IF (LIMBO(ID).GT.O) GO TO 860

$F 4360$

$\operatorname{LIMBO}(I D)=I N$

$F 4370$

GO TO 880

$F 4380$

860 CONTINUE

C

870 IF (IFLAG.LT.O) PART $(2, I N)=-T E M P Z$

$F 4390$

$F 4400$

$F 4410$

$F 4420$

$F 4430$

CONTINUE

C $\quad--E N D$ OF LOOP D-

$F 4440$

GO TO 920

C -- RESTART MOVE IF PT. LIMIT EXCEEDED--

$F 4450$

$F 4460$

$F 4470$

890 WRITE $(6,990)$ IMOV,IN

TEST $=100.0$

WRITE $(6,1000)$

DO $900 \quad I Z=1, N Z$

900 WRITE $(6,1010)$ (NPCELL $(I X, I Z), I X=1, N X)$

CALL GENPT

DO 910 IX $=1, N X$

DO $910 \quad I Z=1, N Z$

$\operatorname{SUMC}(I X, I Z)=0.0$

SUMTOS $(I X, I Z)=0.0$

$F 4480$

$F 4490$

$F 4500$

$F 4510$

$F 4520$

$F 4530$

$F 4540$

$F 4550$

$F 4560$

SUMWT $(I X, I Z)=0.0$

$F 4570$

910 NPCELL $(I X, I Z)=0$

TEST $=0.0$

GO TO 20

C

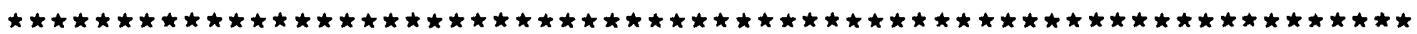

920 SUMTCH $=$ SUMTCH+TIMV

C $N P=N P T M$

---ADJUST NUMBER OF PARTICLES---

WRITE $(6,960)$ NP, IMOV

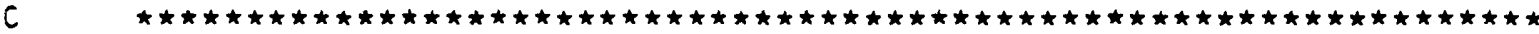

CALL CNCON

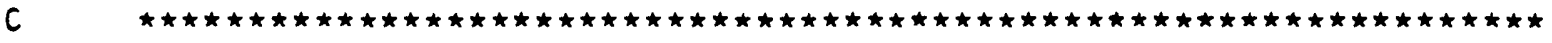

- - STORE OBS. WELL DATA FOR STEADY FLOW PROBLEMS- -

IF (S.GT.0.0) GO TO 940

IF (NUMOBS.LE.O) GO TO 940

$J=M O O(I M O V, 50)$

IF $(J . E Q .0) \mathrm{J}=50$

TMOBS $(J)=S U M T C H$

DO $930 I=1$, NUMOBS

$\operatorname{TMWL}(I, J)=P K(I X O B S(I), I Z O B S(I))$

$\operatorname{TMCN}(I, J)=\operatorname{CONC}(I X O B S(I), I Z O B S(I))$

c

$930 \operatorname{TMTDS}(I, J)=T O S(I X O B S(I), I Z O B S(I))$

-- PRINT CHEMICAL OUTPUT---

IF $(M O D(I M O V, 5 O), E Q .0)$ IPRNT $=1$

940 IF (MOD (IMOV,NPNTMV).EQ.O) IPRNT $=-1$

IF (IPRNT.NE.O) CALL CHMOT

IF (TIMV.LT.0.1) GO TO 950

IF ( $(T I M(N)-S U M T C H) . L T . T I M V) \quad T I M V=T I M(N)-S U M T C H$

GO TO 10

C

$* \star * * * * * * t$

950 RETURN

F4580

$F 4590$

$F 4600$

$F 4610$

F4620

F 4630

F4640

F4650

F4660

F 4670

$F 4680$

F4690

$F 4700$

F 4710

F 4720

F 4730

F 4740

F 4750

F 4760

F4770

F 4780

F 4790

F 4800

F 4810

F 4820

F 4830

F 4840

F4850

F4860

F 4870 
EQFCT2 $=E Q F C T 1 / P O R O S$

6440

$C 1=\operatorname{CONC}(I X, I Z)$

$C Z=T D S(I X, I Z)$

IF $(A B S(C 1) . L T \cdot 1.0 E-20) \quad C 1=0.0$

IF $(A B S(C 2) . L T .1 .0 E-20) \quad C 2=0.0$

$C L K C N 1=0.0$

$C L K C N 2=0.0$

SLEAK $=(P K(I X, I Z)-P I(I X, I Z)+D E N S(I X, I Z) \star E L E V(I X, I Z))$

$S L E A K=S L E A K \star V P R M(I X, I Z) / D E N S(I X, I Z)$

DENSE $=$ DENS $(I X, I Z)$

IF (PI $(I X, I Z) . G T, P K(I X, I Z))$ DENSE = DEN $1 * T D S R E C(I X, I Z)+D E N Z$

IF (SLEAK.GT.0.0) 60 TO 30

CLKCNI = CNREC $(I X, I Z)$

CLKCNZ = TDSREC $(I X, I Z)$

GO TO 40

30 CLKCN1 $=$ C1

$C L K C N 2=C 2$

40 CNREC $1=C 1$

CNREC $2=C 2$

DENSE $=$ DENS $(I X, I Z)$

IF (REC (IX,IZ) . LT.0.O) DENSE=DEN1*TDSREC $(I X, I Z)+D E N Z$

RATE $=R E C(I X, I Z) / D E N S E$

IF (REC (IX,IZ).GT.0.0) GO TO 50

CNREC $1=C N R E C(I X, I Z)$

CNRECZ = TDSREC $(I X, I Z)$

50 DIVI = SLEAK+RATE

DIVZ = SLEAK +RATE

DELC1 $=E Q F C T 2 \star(C 1 \star D I V 1-S L E A K \star C L K C N 1-R A T E \star C N R E C 1)$

$D E L C 2=E Q F C T 2 \star(C 2 \star D I V 2-S L E A K \star C L K C N 2-R A T E \star C N R E C 2)$

$C N C N C(I X, I Z)=C N C N C(I X, I Z)+D E L C 1$

CNTDS $(I X, I Z)=C N T D S(I X, I Z)+D E L C Z$

--CONC. CHANGE DUE TO DISPERSION FOR 0.5*TIMV-----DISPERSION WITH TENSOR COEFFICIENTS---

IF (BETA.EQ.0.0.AND.DMOLEC.EQ.0.0) GO TO 70

IF (NCONST.LT.2) GO TO 60

$X 1=D I S P(I X, I I, 1) *(\operatorname{CONC}(I X+1, I Z)-C 1)$

$X 2=D I S P(I X-1, I Z, 1) *(C O N C(I X-1, I Z)-C 1)$

$Z 1=D I S P(I X, I Z, 2) \star(C O N C(I X, I Z+1)-C 1)$

$22=0 I S P(I X, I Z-1,2) *(\operatorname{CONC}(I X, I Z-1)-C 1)$

$X X 1=D I S P(I X, I Z, 3) *(\operatorname{CONC}(I X, I Z+1)+\operatorname{CONC}(I X+1, I Z+1)-\operatorname{CONC}(I X, I Z-1)-\operatorname{CON}$

$1((I X+1, I Z-1))$

$x \times z=0 I S P(I X-1, I Z, 3) *(\operatorname{CONC}(I X, I Z+1)+\operatorname{CONC}(I X-1, I Z+1)-\operatorname{CONC}(I X, I Z-1)-C$

$10 N C(I X-1, I z-1))=$

$Z Z 1=D I S P(I X, I Z, 4) *(\operatorname{CONC}(I X+1, I Z)+\operatorname{CONC}(I X+1, I Z+1)-\operatorname{CONC}(I X-1, I Z)-\operatorname{CON}$

$1((I X-1, I Z+1))$

$Z Z Z=D I S P(I X, I Z-1,4) \star(\operatorname{CONC}(I X+1, I Z)+\operatorname{CONC}(I X+1, I Z-1)-\operatorname{CONC}(I X-1, I Z)-C$ $10 N C(I X-1, I Z-1))$

CNCNC $(I X, I Z)=C N C N C(I X, I Z)+E Q F C T 1 *(X 1+X 2+Z 1+Z 2+X X 1-X X 2+Z Z 1-Z Z 2)$

$60 \times 1=D I S P(I X, I Z, 1) *(T D S(I X+1, I Z)-C 2)$

$X 2=D I S P(I X-1, I Z, 1) *(\operatorname{TDS}(I X-1, I Z)-C 2)$

$Z 1=D I S P(I X, I Z, 2) *(T D S(I X, I Z+1)-(2)$

$Z 2=D I S P(I X, I Z-1,2) *(T D S(I X, I Z-1)-C 2)$

$X X 1=D I S P(I X, I Z, 3) *(\operatorname{TOS}(I X, I Z+1)+\operatorname{TDS}(I X+1, I Z+1)-\operatorname{TDS}(I X, I Z-1)-\operatorname{TDS}(I X$

$1+1, I Z-1))$

$X X 2=D I S P(I X-1, I Z, 3) *(T D S(I X, I Z+1)+\operatorname{TDS}(I X-1, I Z+1)-T D S(I X, I Z-1)-T D S($ $1 I X-1, I z-1))$

$Z Z 1=D I S P(I X, I Z, 4) \star \operatorname{TTDS}(I X+1, I Z)+\operatorname{TDS}(I X+1, I Z+1)-\operatorname{TDS}(I X-1, I Z)-\operatorname{TDS}(I X$

6450

6460

6470

6480

6490

G 500

G 510

G 520

G 530

$G 540$

$G 550$

G 560

G 570

G 580

$G 590$

$G 600$

G 610

G 620

G 630

G 640

G 650

$G 660$

G 670

G 680

$G 690$

$G 700$

G 710

G 720

$G 730$

$G 740$

G 750

$G 760$

$G 770$

G 780

G 790

$G 800$

$G 810$

G 820

G 830

G 840

$G 850$

G 860

G 870

G 880

$G 890$

$G 900$

$G 910$

G 920

$G \quad 930$

$G 940$

$G 950$

$G 960$

G 970

$G 980$

G 990

61000 


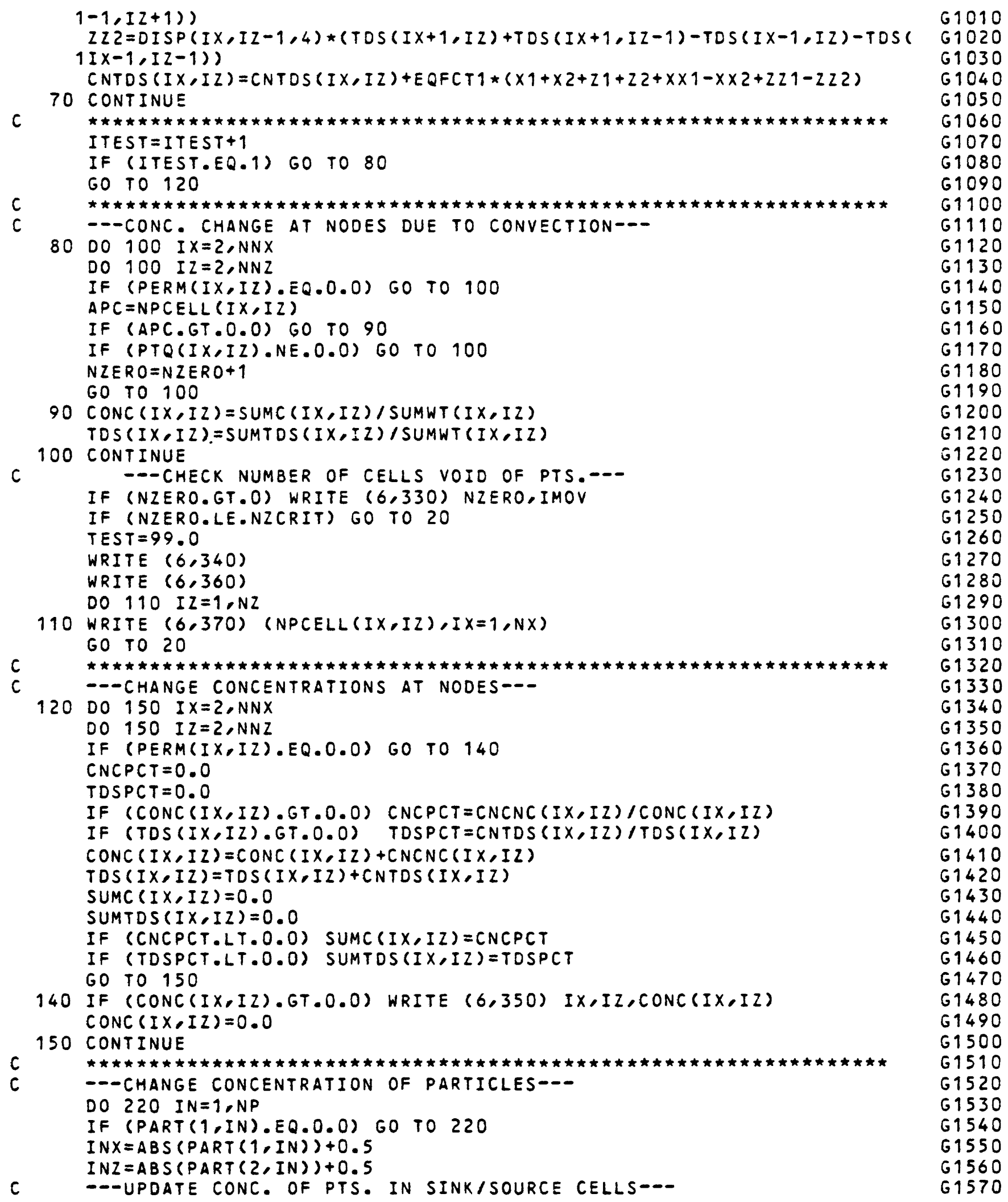


IF (PTQ INX,INZ).EQ.0.0) GO TO 160

PART $(4, I N)=\operatorname{CONC}(I N X, I N Z)$

61580

PART $(3, I N)=T D S(I N X, I N Z)$

61590

GO TO 220

160 IF (CNCNC(INX,INZ).LT.0.0) GO TO 180

$170 \operatorname{PART}(4, I N)=$ PART $(4, I N)+C N C N C(I N X, I N Z)$

GO TO 190

180 IF (CONC(INX,INZ).LE.0.0) GO TO 170

IF (SUMC (INX,INZ).LT.-1.0) GO TO 170

PART $(4, I N)=$ PART $(4, I N)+P A R T(4, I N)$ *SUMC (INX,INZ)

190 IF (CNTDS(INX,INZ).LT.0.0) GO TO 210

200 PART $(3, I N)=P A R T(3, I N)+C N T D S(I N X, I N Z)$

GO TO 220

210 IF (TOS (INX,INZ).LE.0.0) GO TO 200

IF (SUMTDS(INX,INZ).LT.-1.0) GO TO 200

PART $(3, I N)=P A R T(3, I N)+P A R T(3, I N) \star S U M T O S(I N X, I N Z)$

220 CONTINUE

WRITE $(6,320)$ TIM(N), TIMV,SUMTCH

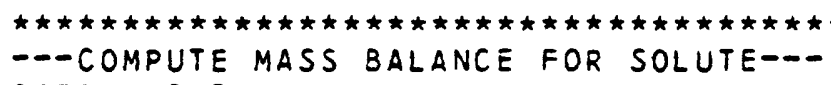

CSTORM $=0.0$

$S T O R M=0.0$

CSTORT $=0.0$

$S T O R T=0.0$

DO 290 IX $=2, N N X$

DO 290 IZ $=2, N N Z$

IF (PERM(IX,IZ).EQ.0.0) GO TO 290

$\operatorname{SUMC}(I X, I Z)=0.0$

SUMWT $(I X, I Z)=0.0$

$\operatorname{SUMTDS}(I X, I Z)=0.0$

c

$W T F C T=0.0$

C ---COMPUTE MASS OF SOLUTE IN STORAGE---

$S T O R M=S T O R M+C O N C(I X, I Z) \star W I D T H \star A R P O R$

C - - ACCOUNT FOR MASS PUMPED IN, OUT, RECHARGED, \& DISCHARGED--$S T O R T=S T O R T+T D S(I X, I Z) \star W I D T H \star A R P O R$ IF $(R E C(I X, I Z)) \quad 240,250,230$

230 RATE $=R E C(I X, I Z) \star V O L / D E N S(I X, I Z)$

TDSOUT $=$ TDSOUT + (RATE TIMV*0.5* (TDSOLD $(I X, I Z)+T O S(I X, I Z)))$

CMSOUT $=$ CMSOUT $+(R A T E \star T I M V * 0.5 *(C N O L D(I X, I Z)+C O N C(I X, I Z)))$ GO TO 250

240 DENSE $=$ DEN $1 * T O S R E C(I X, I Z)+D E N 2$

RATE $=R E C(I X, I Z) * V O L / D E N S E$

TOSIN $=$ TDSIN+RATE TOSREC $(I X, I Z) \star T I M V$

CMSIN $=$ CMSIN $+R A T E * C N R E C(I X, I Z) * T I M V$

$c$

c

250 IF (VPRM(IX.IZ) ER BOUNDARY FLOW-

$F L W=V P R M(I X, I Z) *(P I(I X, I Z)-P K(I X, I Z)+D E N S(I X, I Z) \star E L E V(I X, I Z))$

$F L W=F L W / D E N S(I X, I Z)$

IF (FLW.GT.0.0) GO TO 260

IF (FLW.LT.O.O) GO TO 270

GO TO 280

C -- MASS IN BOUNOARY DURING TIME STEP---

260 FLMIN $=F L M I N+F L W * C N R E C(I X, I Z) \star T V A \star W I D T H$

$F L T I N=F L T I N+F L W * T D S R E C(I X, I Z) * T V A * W I O T H$

c GO TO 280

61600

61610

61620

61630

61640

61650

61660

61670

61680

61690

61700

61710

61720

61730

61740

61750

61760

61770

61780

61790

61800

G1810

61820

61830

61840

61850

G1860

61870

61880

61890

61900

61910

61920

G1930

61940

61950

61960

61970

61980

61990

G2000

G2010

62020

62030

62040

62050

62060

62070

62080

62090

G2100

62110

62120

62130

62140 


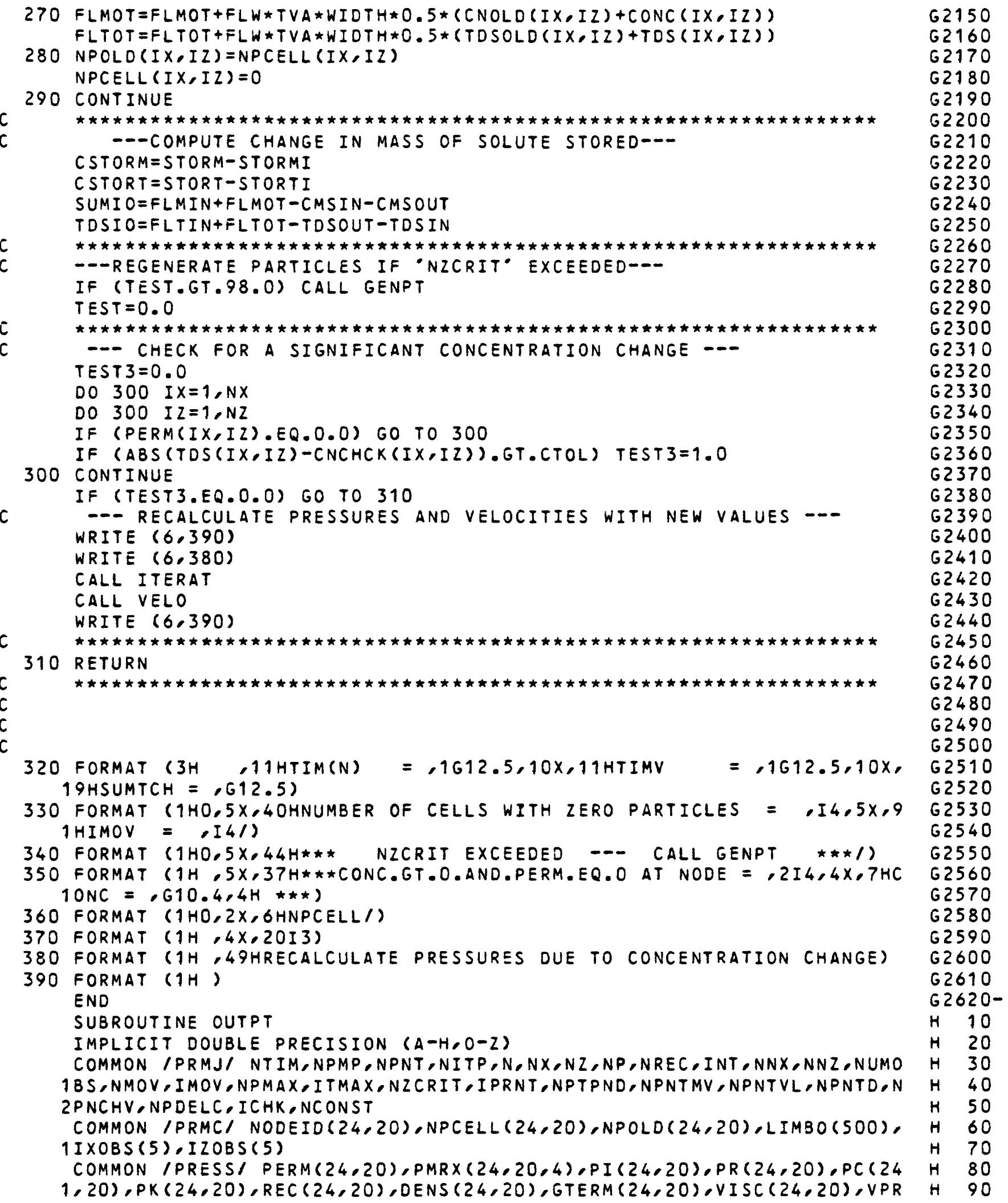


$2 M(24,20), T M W L(5,50), T M O B S(50), T I M(100), A O P T(20), T I T L E(10), A N F C T R, X$ 3DEL, ZDEL, WIDTH, S, AREA, SUMT, RHO, PARAM, TEST, TOL, PINT, HMIN, PYR, VOL COMMON /CHMA/ PART $(4,6400), C O N C(24,20), T D S(24,20), V \times(24,20), V Z(24$, 120), CONINT $(24,20)$, TDSINT $(24,20)$, CNREC $(24,20), T D S R E C(24,20)$, TMCN $(5$, 250), TMTOS $(5,50)$, POROS, SUMTCH, BETA,TIMV, STORM, STORT, STORMI, STORTI, C 3MSIN, TDSIN, CMSOUT, TDSOUT, FLMIN, FLTIN, FLMOT, FLTOT, SUMIO, TOSIO, CELDI 4S,DLTRAT,CSTORM, CSTORT, DMOLEC

COMMON /CHMCI SUMC $(24,20), V X B D Y(24,20), V Z B D Y(24,20), \operatorname{SUMTOS}(24,20)$, 1WTFCTR $(24,20)$, SUMWT $(24,20), P T Q(24,20), P T W T(6400), E L E V(24,20)$

COMMON IDENVIS/ DEN1, DEN2,VIS1,VIS2

COMMON /BALM/ TOTLQ,TOTLQI,TPIN, TPOUT

H 100 


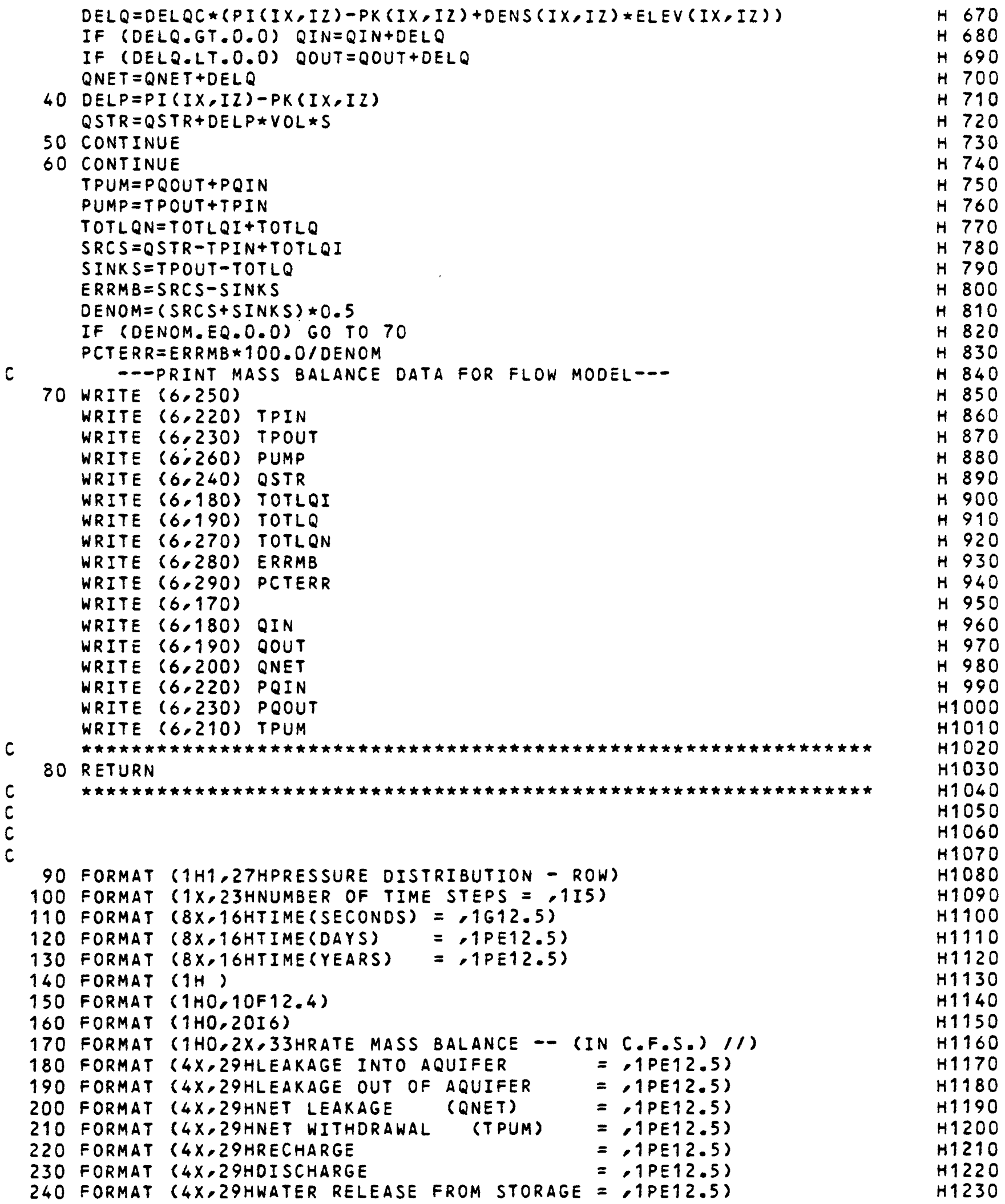




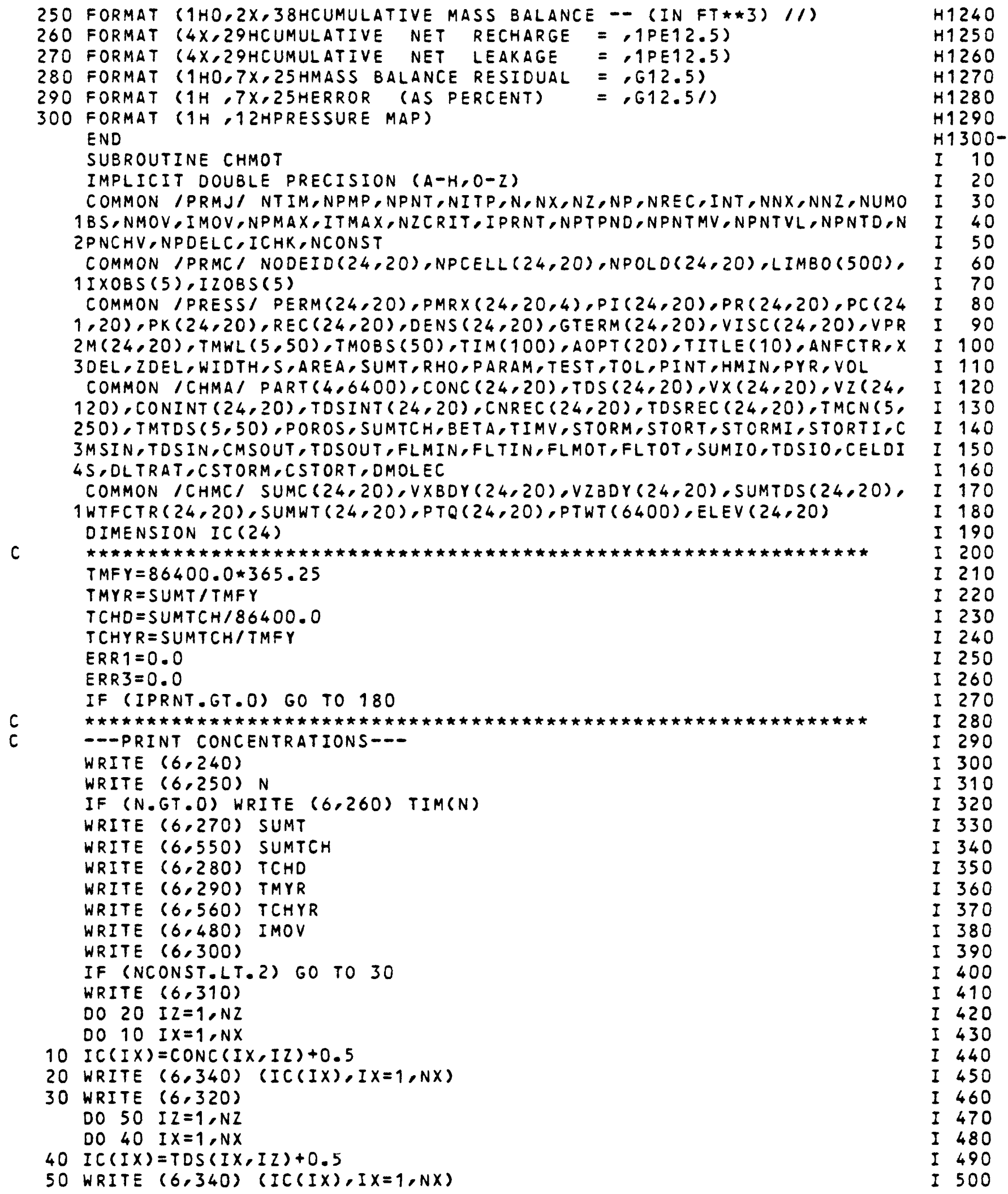


Program listing -- Continued

$c$

IF $(N . E Q . O)$ GO TO 230

IF (NPDELC.EQ.0) GO TO 110

I 510

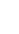

c

---PRINT CHANGES IN CONCENTRATION---

WRITE $(6,330)$

WRITE $(6,250) \mathrm{N}$

WRITE $(6,260)$ TIM(N)

WRITE $(6,270)$ SUMT

WRITE $(6,550)$ SUMTCH

WRITE $(6,280)$ TCHD

WRITE $(6,290)$ TMYR

WRITE $(6,560)$ TCHYR

WRITE $(6,480)$ IMOV

WRITE $(6,300)$

IF (NCONST.LT.2) GO TO 80

WRITE $(6,310)$

DO 70 I $Z=1, N Z$

$D O \quad 60$ IX $=1, N X$

CNG $=\operatorname{CONC}(I X, I Z)-\operatorname{CONINT}(I X, I Z)$

$60 I C(I X)=C N G$

70 WRITE $(6,340) \quad(I C(I X), I X=1, N X)$

80 WRITE $(6,320)$

DO $100 \quad I Z=1, N Z$

DO 90 IX $=1, N X$

CNG $=\operatorname{TDS}(I X, I Z)-T D S I N T(I X, I Z)$

$90 I C(I X)=C N G$

$c$

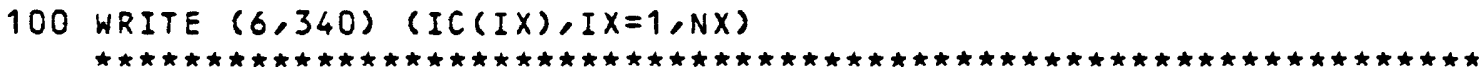

c

-- PRINT MASS BALANCE DATA FOR SOLUTE---

110 IF (NCONST.LT.2) GO TO 140

RESID $=$ SUMIO-CSTORM

SUMIN = FLMIN-CMSIN

IF (SUMIN.EQ.0.0) GO TO 120

ERRI = RESID*100.0/ SUMIN

120 IF (STORMI.EQ.0.0) GO TO 130

ERR $3=-100.0 * R E S I D /(S T O R M I-S U M I O)$

130 WRITE $(6,300)$

WRITE $(6,350)$

WRITE $(6,310)$

WRITE $(6,300)$

WRITE $(6,360)$ FLMIN

WRITE $(6,370)$ FLMOT

RECIN $=-$ CMSIN

RECOUT $=-$ CMSOUT

WRITE $(6,390)$ RECIN

WRITE $(6,380)$ RECOUT

WRITE $(6,400)$ SUMIO

WRITE $(6,410)$ STORMI

WRITE $(6,420)$ STORM

WRITE $(6,430)$ CSTORM

WRITE $(6,440)$

WRITE $(6,450)$ RESID

WRITE $(6,460)$ ERR1

IF (STORMI.EQ.0.0) GO TO 140

WRITE $(6,470)$

WRITE $(6,460)$ ERR3 


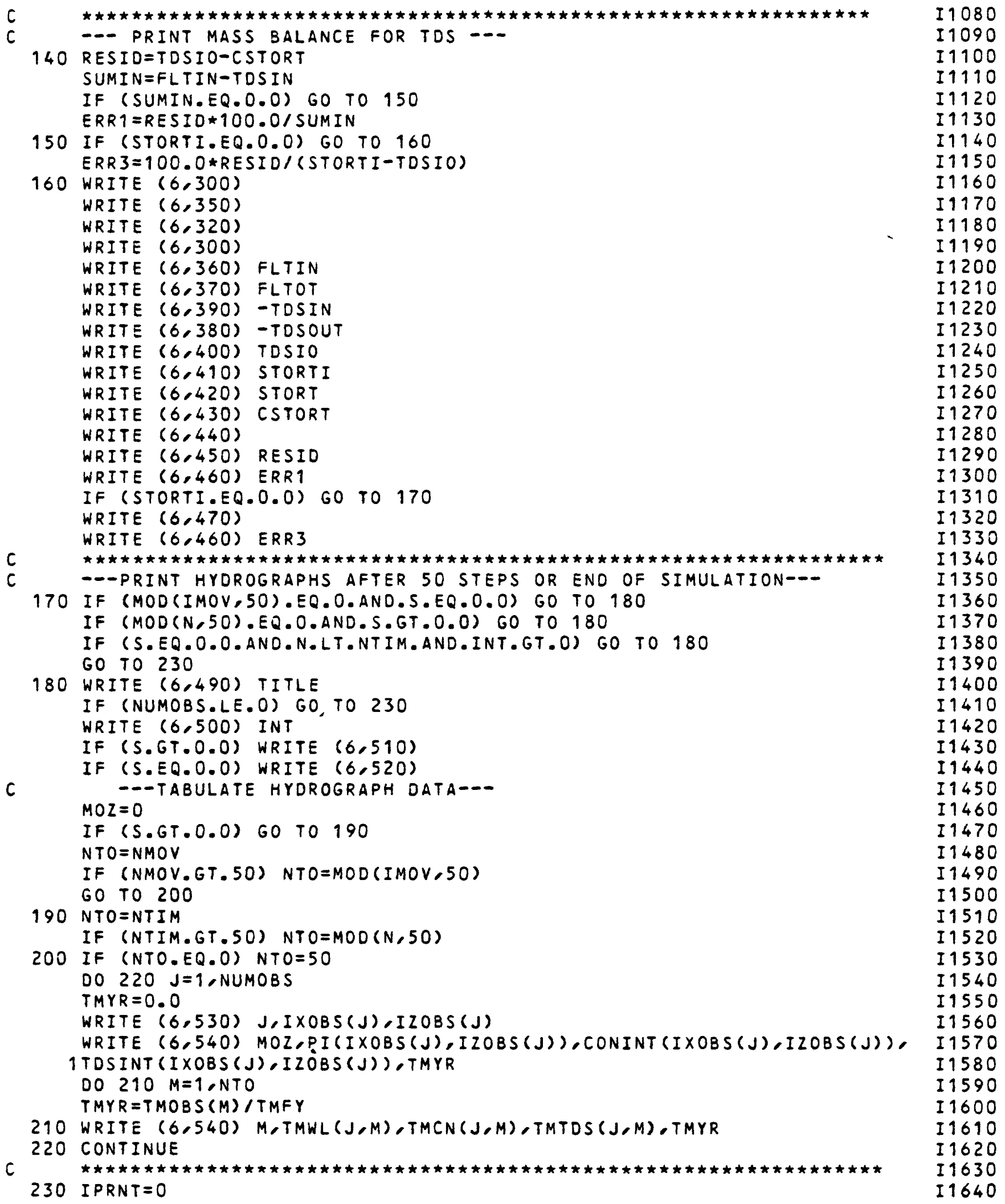




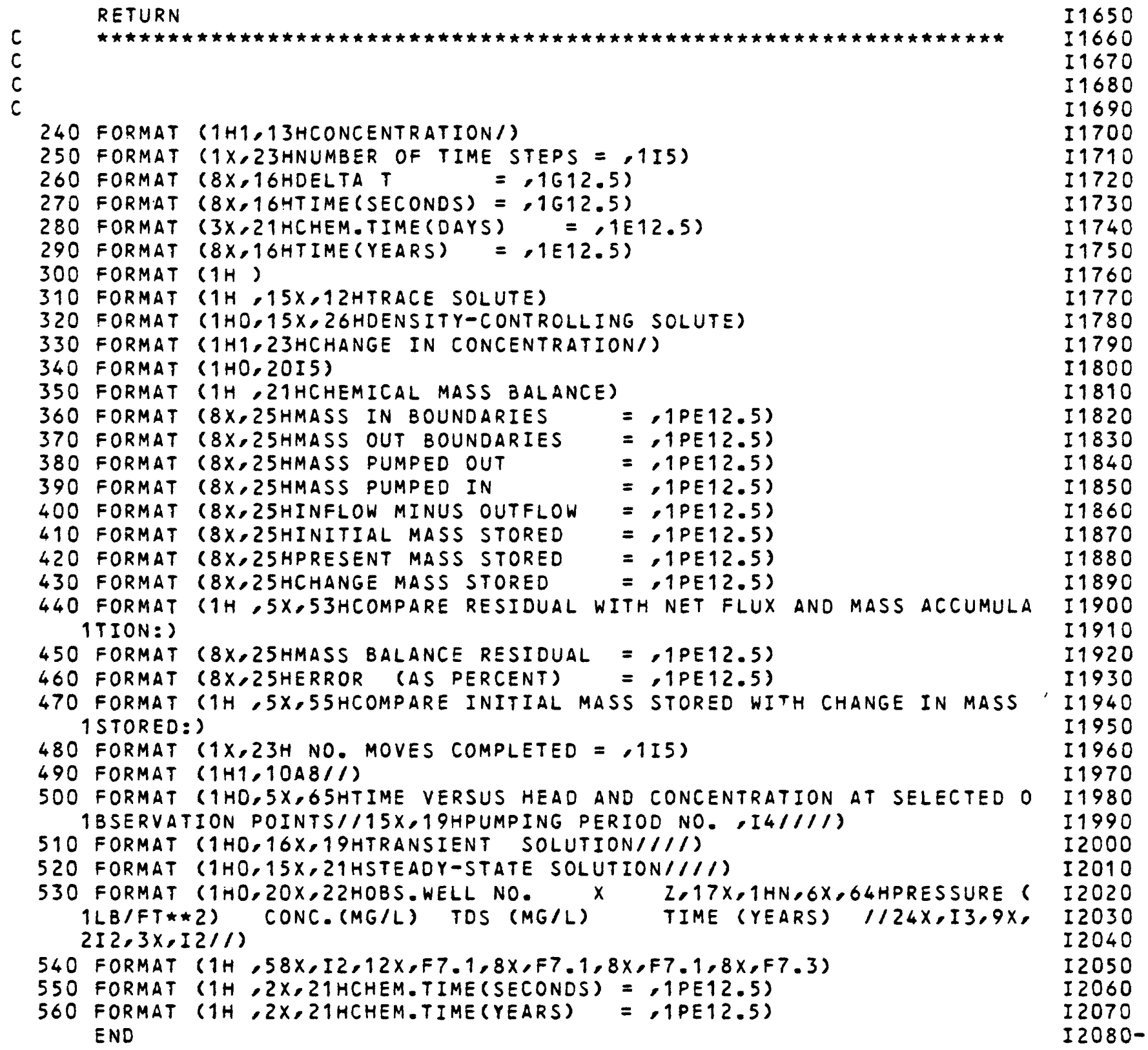

